\title{
morios:
}

BNWL-1964

UC-70

has boon reproduced from the best avIBIS. It

copy to permit the from the best available

ab111ty. ....

\section{The Resuspension of Material \\ Dispersed by Atmospheric \\ Diffusion from a Point Source}

December 1975

Prepared for the U.S. Energy

Research and Development Administration

under Contract E(45-1):1830 


\section{DISCLAIMER}

This report was prepared as an account of work sponsored by an agency of the United States Government. Neither the United States Government nor any agency Thereof, nor any of their employees, makes any warranty, express or implied, or assumes any legal liability or responsibility for the accuracy, completeness, or usefulness of any information, apparatus, product, or process disclosed, or represents that its use would not infringe privately owned rights. Reference herein to any specific commercial product, process, or service by trade name, trademark, manufacturer, or otherwise does not necessarily constitute or imply its endorsement, recommendation, or favoring by the United States Government or any agency thereof. The views and opinions of authors expressed herein do not necessarily state or reflect those of the United States Government or any agency thereof. 


\section{DISCLAIMER}

Portions of this document may be illegible in electronic image products. Images are produced from the best available original document. 


\section{NOTICE}

This report was prepared as an account of work sponsored by the United States Government. Neither the United States nor the United States Energy Research and Development Administration, nor any of their employees, nor any of their contractors, subcontractors, or their employees, makes any warranty, express or implied, or assumes any legal liability or responsibility for the accuracy, completeness or usefulness of any information, apparatus, product or process disclosed, or represents that its use would not infringe privately owned rights.

\section{PACIFIC NORTHWEST LABORATORY}

operated by

BATTELLE

for the

\section{U.S. ENERGY RESEARCH AND DEVELOPMENT ADMINISTRATION}

Under Contract $E(45-1)-1830$

National Technical Information Service

U.S. Department of Commerce

5285 Port Roval Road

Springfield, Virginia 22151

Price: Printed Copy \$5.50; Microfiche $\$ 2.25$ 


\section{ABSTRACT}

A mathematical analysis was made of the resuspension of material initially deposited on the ground consequent to atmospheric diffusion from a surface point source. It is concluded that the air concentration of the initial plume without depletion due to deposition is in general greater than the sum of the air concentrations of the depleted initial plume and the resuspended plume. The major qualification to this result is that redeposition from the resuspended plume and subsequent additional resuspension was negleated in the calculations. 
List of Figures ...................... . iv

List of Tables...................... iv

Introduction . . . . . . . . . . . . . . . . 1

Summary and Conclusions ................ 3

Discussion ................... 5

The Surface Flux Model... . . . . . . . . . 5

The Initlal Plume . . . . . . . . . . 8

The Resuspended Plume . . . . . . . . . . . . 9

Comparison of the Climatologically-Averaged Initial and

Resuspended Plumes . . . . . . . . . . . . 12

Acknowledgements . . . . . . . . . . . . . . 24

References .................. . 25

Appendices . . . . . . . . . . . . . . . 26

A. Hanford Climatology Used for Computations . . . . 26

B. The Climatologically-Averaged Initial Plume . . . 28

C. A Climatologically-Averaged Comparison of the Source Depletion and Surface Depletion Models . . . . . 38

D. The Climatologically-Averaged Resuspended Plume . . 41

E. The Net Effect of Redeposition... . . . . . 50 
1. Polar-Averaged, Normalized Air Concentrations vs.

Radial Distance for $\mathrm{v}_{\mathrm{d}} / \mathrm{u}=10^{-3}$............. 13

2. Polar-Averaged, Normalized Air Concentrations vs.

Radial Distance for $\mathrm{v}_{\mathrm{d}} / \mathrm{u}=10^{-2}$. . . . . . . . . . 14

3. Normalized Air Concentrations vs. Azimuth at a Radial

Distance of $400 \mathrm{~m}$. . . . . . . . . . . . 20

4. Normalized Air Concentrations vs. Radial Distance for the

ESE and WSW Directions .............. 21

5. Polar-Averaged, Normal1zed Resuspended Air Concentrations vs,

Radial Distance for $\Lambda \equiv A_{u}^{N}$. . . . . . . . . . . 22

6. Normalized Resuspended Air Concentrations vs. Azimuth al a Radial Dietance of $2 \mathrm{~km}$ for $\Lambda=A u^{\mathrm{N}}$.......... 23

C-1. Climatologically-Averaged Comparison Between Source Depletion and Surface Depletion Models ... . . . . 40 


\section{LIST OF TABLES}

1. Formulas for the Determination of $\sigma_{z}$ and $\sigma_{y} \cdot \cdots \cdot \ldots \cdot \ldots$

A-1. Joint Probability Distribution of Wind Speed and Wind

Direction at $50 \mathrm{ft}$ Level vs. Atmospherlc Stability . . . . 27

B-1. Initial Plume Air Concentration. No Deposition . . . . . 29

B-2. Inftial Plume Air Concentration. Surface Depletion Model, $\mathrm{v}_{\mathrm{d}} / \mathrm{u}=10^{-2} \cdot$. . . . . . . . . . . . . . . 30

B-3. Deposition Flux. Surface Depletion Mode1, $v_{d} / u=10^{-2}$. . . 31

B-4. Initial Plume Air Concentration. Surface Depletion Model, $\mathrm{v}_{\mathrm{d}} / \mathrm{u}=10^{-3} \cdot$. . . . . . . . . . . . . . . . . . 32

B-5. Deposition Flux. Surface Depletion Model, $v_{d} / u=10^{-3}$. . . 33

B-6. Initial Plume Air Concentration. Source Depletion Model, $v_{\mathrm{d}} / \mathrm{u}=10^{-2}$...................... 34

B-7. Deposition Flux. Source Depletion Model, $\mathrm{v}_{\mathrm{d}} / \mathrm{u}=10^{-2} \cdot \cdots 35$

B-8. Initial Plume Air Concentration. Source Depletion Model,

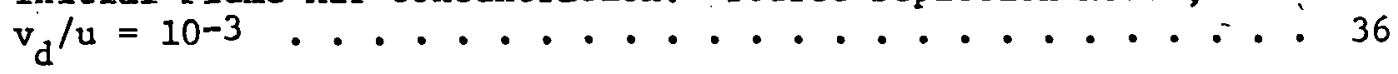

B-9. Deposition Flux. Source Depletion Model, $v_{d} / u=10^{-3}$... 37

D-1. Climatologically-Averaged Resuspended Air Concentration Distribution for $\mathrm{v}_{\mathrm{d}} / \mathrm{u}=10^{-2}$. . . . . . . . . . . . 42

D-2. Climatologically-Averaged Resuspended Air Concentration . Distribution for $\mathrm{v}_{\mathrm{d}} / \mathrm{u}=10^{-3}$................ 46 


$$
-\ldots+\cdots
$$

BNWL-1964

UC-70

\section{$\underline{\text { Errata }}$}

\section{The Resuspension of Material Dispersed by} Atmospheric Diffusion from a Point Source

Page 10 In equations (11) and (12) $v_{d} C, v_{d} C_{d}$ and $v_{d}^{\prime} C_{r}$ should read:

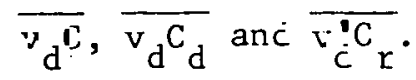

PEge 18 The last line sholid read: " $\mathrm{v}_{\mathrm{d}} / \mathrm{u}=10^{-3} \ldots$ " ,

Page 20 The dimensions of the ordinate should read: $\left(5 \mathrm{sec} / \mathrm{m}^{3}\right)$.

Page 22 The right-hand label on the abscissa should read: $10^{4}$.

Page 23 The dimensions of tie ordinate should read: (sec'm ${ }^{3}$ ).

Page 38 Tre line preceling equation (C-3) should reac: "..times ecuation (9) ..." 
THE RESUSPENSION OF MATERIAL DISPERSED BY ATMOSPHERIC

DIFFUSION FROM A POINT SOURCE

Thomas W. Horst

\section{INTRODUCTION}

In the Systems Safety Task of the Waste Fixation Program, risk assessment is being used to identify dominant sequences for the accidental release of radionuclides during the management of commercial high level waste. This assessment, sponsored by the Division, of Nuclear Fue1. Cycle and Production, U. S. Energy Research and Development Administration, is based on a conceptual system that includes liquid storage, solidification, basin storage, rail transport, and retrievable surface storage facilities.

The handling of nuclear waste may involve both chronic and accidental releases of these materials into the environment, and it has been tentatively established (Winegardner (1975)) that release to the atmosphere is associated with the dominant failure sequences. Thus atmospheric transport is a primary pathway for exposure of man to these materials, and estimates of atmospheric transport and diffusion are an important ingredient of quantitative evaluations of the long term radiological consequences of waste management.

These estimates need to primarily consider two distinct routes between source and receptor. One is the direct atmospheric route, which can be quantitatively evaluated by accounting for atmospheric dilution of the material and depletion processes, such as deposition on the underlying terrain, which directly remove material from the airborne plume. A second route is a consequence of the deposition of material from the initial plume. This deposited material forms a secondary source of material which may subsequently be resuspended by the wind and contribute to the air concentration at downwind receptors. Proper evaluation of the atmospheric concentration of contaminant must account for both of these routes.

Much research has been applied to underslanding the dilution or diffusion of material released into the atmosphere, and the results have 
been distilled into routine methodologies for estimating the airborne concentrations of materials directly transported from source to receptor. A great deal less has been done to understand the process of resuspension and to apply existing knowledge of atmospheric diffusion to the determination of the alrborne contamination downwind of this secondary source of pollutant. Consequently, quantitative evaluation of the hazards associated with resuspension presently must be made with much less confidence than for direct transport. It is the intent of this study to provide a basis for simplifying the procedures for accounting for the additional air concentration caused by resuspension and to investigate the relative magnitude of the resuspended material compared with that of the initial plume. The techniques developed are sufficiently general for application to chronic as well as other accidental releases to the atmosphere. 
One year of hourly data from the Hanford Meteorological Tower has been selccted to iepresent a rypical climatological distribution of the meteorological variables which control atmospheric diffusion, deposition and resuspension. This data has been used in the surface flux model of Horst (1974a) to predict the probable value of both the initial air concentration $C_{d}$, accounting for the depletion due to deposition, and the consequent air concentration of resuspended material $C_{r}$ whose source is the material deposited on the ground by the initial plume. The computations of $C_{d}$ and the resulting deposition flux and surface contamination were made for two values of the ratio of deposition velocity to wind speed, $v_{d} / u=10^{-2}$ and $10^{-3}$, corresponding for the Hanford data to particles with a specific gravity of 3 and diameters of $10 \mu \mathrm{m}$ and $1 \mu \mathrm{m}$ respectively. The resuspended air concentration was calculated using as its source only the material deposited from the initial plume. Redeposition from the resuspended plume and the consequent formation of a secondary resuspension. source was neglected. The deposition from the resuspended plume decreases $C_{r}$ and the secondary resuspension increases $C_{r}$, and thus it is likely that the net effect of redeposition is small. Also neglected was the effect of weathering or fixation of a portion of the surface contamination, making it unavailable for resuspension. Since this process is assumed to result In an Irreversible loss of material from the atmosphere, its neglect is conservative in the sense that the atmospheric concentration of resuspended material is maximized.

Due to the ground acting as both a source and a sink for atmospheric contamination, the air and surface concentrations are strongly dependent upon one another. If it were not for the small value of the resuspension rate $\Lambda$, this would require an hour-by-hour computation of the air and ground concentrations using the sequential history of the appropriate meteorological variables. However the surface contamination changes with a time constant of years, while the diffusion, deposition and resuspension processes respond to the hour-by-hour changes of the weather. It is shown that this makes it possible to compute the climatologically-averaged values 
of the air and ground concentrations using only the foint probability distributions of the relevant meteorological variables. This conclusion greatly simplifies the computational effort required for the evaluation of resuspension.

The most important result of this study, however, follows from a comparison of $\mathrm{C}_{d}$ and $\mathrm{C}_{r}$ with the initial air concentration undepleted by deposition, $\mathrm{C}_{0}$. The computations show that

$$
C_{0} \geq C_{d}+C_{r}
$$

or that

$$
E_{0} \geq I_{d}+E_{r}
$$

where $E$ is the exposure or time integral of the corresponding air concentration. In words, the air concentration (and exposure) due to both the depleted Initial plume and the resuspended plume is less than or equal to that due to the initial plume without allowing for depletion by deposition. A conservative estimate of the air concentration or exposure may therefore be made in the simplest manner possible, by neglecting both deposition and resuspension.

The ondy qual.ficatiun to this regult to the neglect of redepasition. It is 11kely, however, that the nel effect of redepouition is small and in a sense to reduce $C_{r}$. Moreover, this result also includes the conservative neglect of losses due to weathering. In addition, $C_{r}$ in the preceding equation is the maximum, steady-state value even though this value may be atrained only after a release for a continuous period of many years. Correspondingly, the exposure to the resuspended air concentration has been calculated over the entire perlod required tu resuspend all of the deposited contamination. Since a single receptor may not be exposed for . this extended period, this assumption is also conservative. 


\section{DISCUSSION}

The Surface Flux Model

As indicated in the Introduction, the atmospheric dilution of material released from a point source can be calculated by well-established methods. The most common of these is the Gaussian plume model,

$$
C_{0}=\frac{\dot{Q}}{u} D=\frac{\dot{Q}}{\pi u \sigma_{y} \sigma z} e^{-y^{2} / 2 \sigma_{y}^{2}} e^{-z^{2} / 2 \sigma_{z}^{2}}
$$

which describes the air concentration $c_{0}$ (quantity of contaminant per $\mathrm{m}^{3}$ ) of non-depositing material released at a rate $\dot{Q}$ (quantity per sec) from a surface point source. $C_{0}$ is evaluated at $a$ height $z$ and at horizontal distances $x$ downwind and $y$ crosswind of the source. Additionally, $u$ is the mean wind speed (blowing toward positive $x$ ) and $\sigma_{y}$ and $\sigma_{z}$ are standard deviations of the plume cross-section. This equation is also used to define the diffusion function $D$ which describes the dilution of the airborne material due to crosswind spread of the plume.

The diffusion parameters $\sigma_{z}$ and $\sigma_{y}$ may be calculated with the interpolation formulas of Briggs (1973) which are based on several series of atmospheric diffusion experiments and are shown in Table 1 . These are a function of downwind distance $x$ (in meters) and the turbulent state of the atmosphere or atmospheric stability. The stability in turn is a function of wind speed and the input of heat from the ground to the air. This may be determined by a simple scheme due to Briggs, also listed in Table 1 .

The deposition flux (quantity per $\mathrm{m}^{2}$ per $\mathrm{sec}$ ) is calculated by multiplying the air concentration at the reference height $z_{d}$ by a deposition velocity $v_{d}$,

$$
F_{d}=-v_{d} c\left(x, y, z_{d}\right)
$$


Table 1.

Formulas for the Determination of $\sigma_{z}$ and $\sigma_{y}\left(x, \sigma_{z}, \sigma_{y}\right.$ in meters $)$

$\begin{array}{clc}\text { Stability Class } & \frac{\sigma_{z}}{.20 \mathrm{x}} & \frac{\sigma_{\mathrm{y}}}{.22 \times\left(1+10^{-4} \mathrm{x}\right)^{-1 / 2}} \\ \mathrm{~A} & .12 \mathrm{x} & .16 \times\left(1+10^{-4} \mathrm{x}\right)^{-1 / 2} \\ \mathrm{~B} & .08 \times\left(1+2 * 10^{-4} \mathrm{x}\right)^{-1 / 2} & .11 \times\left(1+10^{-4} \mathrm{x}\right)^{-1 / 2} \\ \mathrm{D} & .06 \times\left(1+1.5 * 10^{-3} \mathrm{x}\right)^{-1 / 2} & .08 \times\left(1+10^{-4} \mathrm{x}\right)^{-1 / 2} \\ \mathrm{E} & .03 \times\left(1+3 * 10^{-4} \mathrm{x}\right)^{-1} & .06 \times\left(1+10^{-4} \mathrm{x}\right)^{-1 / 2} \\ \mathrm{~F} & .02 \times\left(1+3 * 10^{-4} \mathrm{x}\right)^{-1} & .04 \times\left(1+10^{-4} \mathrm{x}\right)^{-1 / 2}\end{array}$

\section{Stab1l1ty Liass}

\begin{tabular}{|c|c|c|c|c|}
\hline Wind Speed, mph: & $\underline{0-3}$ & $4-7$ & $8-12$ & $13 \&$ greater \\
\hline Day & A & B & C & $\mathrm{D}$ \\
\hline Night & $\mathrm{E}$ & $E$ & D & D \\
\hline
\end{tabular}

For this study deposition velocities were determined for particles of specific gravity 3 and diameters of $1 \mu \mathrm{m}$ and $10 \mu \mathrm{m}$ by applying the correlations of Sehmel and Hodgson (1974). It was found that a good approximation for the surface roughness at Hanford was

$$
\mathrm{v}_{\mathrm{d}}=\mathrm{Au}_{50}
$$

where $A=10^{-3}$ for the $1 \mu \mathrm{m}$ particles and $10^{-2}$ for the $10 \mu \mathrm{m}$ particles and $u_{50}$ is the mean wind speed at a helght of $50 \mathrm{ft}$.

The resuspension flux is calculated by multiplying the surface. contamination $G$ (quantity per $\mathrm{m}^{2}$ ) by a resuspension rate $\Lambda$ (fraction per sec),

$$
F_{\mathbf{I}}=\Lambda \mathrm{G}
$$


The surface contamination, in turn, depends on the competing processes of deposition and resuspension and perhaps also on a fixation or weathering process which makes surface contamination unavailable for resuspension,

$$
\frac{\partial G}{\partial t}=v_{d} C-\Lambda G-\alpha G
$$

where $\alpha$ is a rate of fixation. A very limited number of measurements (Sehmel and Lloyd (1975)) indicate that the resuspension rate is typically on the order of $10^{-10}$ to $10^{-8} \mathrm{sec}^{-1}$, corresponding to half lives of the surface contamination on the order of years. The weathering process will be henceforth neglected in this analysis, both due to great uncertainty about the value of $\alpha$ and in order to maximize the predicted atr concentration due to resuspension.

Deposition and resuspension are combined with the Gaussian plume model in the surface flux model of Horst (1974a),

$$
C(x, y, z)=\frac{\dot{Q}}{u} D(x, y, z)+\int_{0}^{x} \int_{-\infty}^{\infty} F(\xi, n) \frac{D}{u}(x-\xi, y-n, z) d \eta d \xi
$$

Here $F$ is the net flux from the ground to the air and for the general case would be equal to the sum of (2) and (4),

$$
C=\frac{\dot{Q} D}{u}+\int_{0}^{x} \int_{-\infty}^{\infty}\left[\Lambda G(\xi, n)-v_{d} C\left(\xi, n, z_{d}\right)\right] \frac{D}{u}(x-\xi, y-n, z) d n d \xi
$$

For the purpose of this study, the air concentration will be divided into two components,

$$
c=c_{d}+c_{r}
$$

The initial air. concentration $C_{d}$ is that due to direct transport from the release point, accounting for losses due to deposition, and is calculated 
by setting $\Lambda$ equal to zero in (7). The air concentration of resuspended material $C_{r}$ is similarly calculated from (7) by setting $\dot{Q}$ equal to zero.

The Intial Plume

Since the equations presented thus far apply only for a given micrometeorological situation, and we are interested here chiefly in long-term air concentrations, they must be averaged over the appropriate distribution of wind speed, wind direction and atmospheric stability. Wind direction is commonly recorded to the nearest of the 16 points of the compass, e.g., N, $\mathrm{NNE}, \mathrm{NE}$ and hence (1) must be averaged over each of the 16 sectors. If it is assumed that the wind has an equal probability of blowing in any of the directions enclosed by a single sector, an approximate average is

$$
D(x, \theta, z)=\frac{16}{\pi x \sqrt{2 \pi} \sigma_{z}} e^{-z^{2} / 2 \sigma^{2}}
$$

within the sector designated by $\theta$ and zero outside of it. This assumes that the portions of the plume which actually overlap into adjacent sectors are balanced by an equal overlap from those adjacent sectors.

The initial air concentrations were calculated for a receptor at a height of $1 \mathrm{~m}$, the deposition reference height $z_{\mathrm{d}}$. Substituting (9) into (7) with $\Lambda=0$ and with $z=z_{d}$,

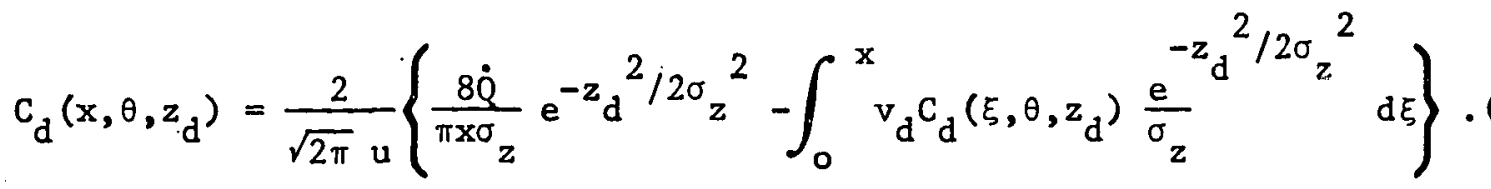

Calculations of $C_{d}$ and the deposition flux $v_{d} C_{d}$ were made with this equation for all possible combinations of wind speed, wind direction and atmospheric stability. Each was then multiplied by its probability of occurrence and they were summed to give the climatologically-averaged values $\vec{C}_{d}$ and $\overline{v_{d} C_{d}}$. Results were obtalned for no deposition $\left(\bar{c}_{o}\right), v_{d} / u=10^{-2}$ and $v_{\mathrm{d}} / \mathrm{u}=10^{-3}$. at downwind distances from $15 \mathrm{~m}$ to $100 \mathrm{~km}$ and for all 16 wind directions. Although the Gaussian model is a poor representation of the 
plume at downwind distances as great as $100 \mathrm{~km}$, it is used here to match current practice in environmental evaluations.

Since the intent of this study is generic rather than particular, one year (1970) of Hanford Meteorological Tower data was selected as representing a typical distribution of the micrometeorological variables. It is also for this reason that the Gaussian plume model and the coarse stability classification of the latter part of Table 1 are entirely adequate. Due to the lag in response of the ground to changes in insolation, day was considered to start one hour after sunrise and night to start one hour after sunset. The wind speed and direction data from the $50 \mathrm{ft}$ level of the tower were selected as most appropriate for the long transport distances considered here. This diffusion climatology is summarized in Appendix A.

The calculated initial air concentrations and deposition fluxes, normalized by $\dot{Q}$, are 1 isted in Appendix $B$ as a function of azimuthal direction and of radial distance from the release point. The distributions calculated as above with the surface flux or surface depletion model are used exclusively in the work reported in the main body of this report. Also included in Appendix $B$ are the results of similar calculations using the less accurate source depletion model. This model is described in Appendix $C$ and its predictions are compared with those of the surface depletion model.

The Resuspended Plume

A particular investigation of the resuspension problem would require the simultaneous solution of (5) and (7) for each hour of meteorology over the period of interest, probably years considering the small value of the resuspension rate. This is not practical since (7) in most cases requires a numerical computation of the integral, a procedure which is especially tedious due to the appearance in the integrand of the upper limit of the integral. However, the large difference between the time scale of variation of the relevant meteorological processes (hours and days) and the time scale for decay of the surface contamination (years) permits an alternate method of analysis for the climatologically-averaged problem. 
Due to the small value of the resuspension rate, the current value of the surface contamination is the cumulative result of the preceding months and years of meteorology, the only exception possibly occurring Immediately after a windstorm which significantly depletes $G$ in a short period. Thus the current value of $G$ will be uncorrelated with the current meteorology, and the climatologically-averaged value $\bar{G}$ may be used in (7) for evaluating the climatologically-averaged value of the resuspended air concentration. If now we further assume that the time scale for the decay of $G$ is greater than the time required to obtain stationary averages of $v_{d} C$ and $\Lambda, \bar{G}$ is found by climatologically-averaging the solution of (5)

$$
\bar{G}(t)=v_{d} c\left(1-e^{-\bar{\Lambda} t}\right) / \bar{\Lambda}
$$

Thus, rather than using the sequential time history of meteorology to solve (5) and (7), the joint probability distribution of wind speed, wind direction and stability may be used to find the climatologically-averaged resuspension rate $\bar{\Lambda}$, the surface contamination $\bar{G}$ due to the deposition flux $\overline{v_{d} C}$, and finally the resuspended alr concentration $\bar{C}_{\mathbf{r}}$. $\bar{G}$ may be divided into two components by substituting (8) into (11),

$$
\bar{G}=\bar{G}_{d}+\bar{G}_{r}=\left(v_{d} C_{d}+v_{d}^{\prime} C_{r}\right)\left(1-e^{-\bar{\Lambda} \tau}\right) / \bar{\Lambda}
$$

Here we have allowed for the possibility of a different deposition velocity $v_{d}^{\prime}$ for the resuspended material. Substitution of (12) into (7) with $\dot{Q}=0$ would then give an equation for $C_{r}$ or $v_{d}^{\prime} C_{r}$, but solution of the integral would require prior knowledge of $\overline{v_{d} C_{r}}$ and at this point we know only $\overline{v_{d} C_{d}}$. Thus an estimate of $C_{r}$ will first be calculated by neglecting deposition from the resuspended plume or redeposition. Setting $v_{d}^{\prime}=0$,

$$
C_{r}^{\prime}\left(x, y, z_{d}\right)=\frac{\left(1-e^{-\bar{\Lambda} t}\right)}{\bar{\Lambda}} \int_{0}^{x} \int_{-\infty}^{m} \Lambda \overline{v_{d} C_{d}}(\xi, n) \frac{D}{u}\left(x-\xi, y-n, z_{d}\right) d \xi d n \text {. }
$$


This equation may then be evaluated for each set of micrometeorological conditions and subsequently the climatologically-averaged value $\bar{C}_{r}^{\prime}$ may be calculated.

Neglecting redeposition maximizes the resuspended air concentration whose source $\bar{G}_{\mathrm{d}}$ is material deposited from the direct plume. However, the redeposition flux generates a secondary surface contamination $\bar{G}_{r}$ which will increase the resuspended air concentration as it in turn is resuspended. The resulting net error in $C_{r}$, whose source is both $\bar{G}_{d}$ and $\bar{G}_{r}$, due to neglecting redeposition is discussed in Appendix $E$.

The climatologically-averaged values of $C_{d}, v_{d} C_{d}, G_{d}, \Lambda$ and $C_{r}^{\prime}$ have been presented thus far as the time-averaged mean values for a long term continuous or chronic release of material. For the case of a short term accidental release, $\overline{\mathrm{C}}_{\mathrm{d}}$ and $\overline{\mathrm{v}}_{\mathrm{d}} \mathrm{C}_{\mathrm{d}}$ may be considered to be the mean or probable values in a statistical sense. Substituting the quantity of material released $Q$ for the rate of release $\dot{Q}, \overline{v_{d} C_{d}}$ is the probable deposition per unit area and the solution of (5) is

$$
\bar{G}_{d}=\overline{v_{d} C_{d}} e^{-\bar{\Lambda} t}
$$

$\overline{\mathrm{C}}_{\mathrm{r}}^{\prime}$ is calculated as before and is the climatologically-averaged value of the resuspended air concentration due to the statistically averaged consequences of an accidental release.

Since (13) is most easily calculated in a cartesian coordinate system, the polar distribution of the deposition flux $\overline{v_{d} C_{d}}$ was first mapped onto a cartesian system with $x$ increasing in the downwind direction. The expense of numerically calculating (13) limits the number of grid points used, and a $40 \times 40 \mathrm{grid}$ was selected as a reasonable compromise between resolution and expense. Calculations were made for several values of the grid interval to cover the horizontal range of interest, $15 \mathrm{~m} \mathrm{to} 100 \mathrm{~km}$. The calculated values were then mapped back into a 16 direction polar coordinate system to facilitate computation of the climatological average and to match the resolution of $\bar{C}_{r}^{\prime}$ with that of $\bar{C}_{d}$ and of the original climatological data upon which it is based. Appendix $D$ lists the values of $\bar{C}_{r}^{\prime}$ 
calculated for a constant resuspension rate. The factor $\left(1-e^{-\bar{\Lambda} t}\right)$ was set equal to its maximum value of unity $(t \rightarrow \infty)$, corresponding to a steadystate value of $\dot{C}_{r}^{\prime}$ and making the results independent of $\Lambda$.

One problem arises from the need to increase the grid interval to calculate $C_{r}^{\prime}$ for large downwind distances. The surface contamination distribution is sharply peaked near the center of the polar coordinate system, the source point for the original release of the material. As the grid interval is increased this peak is not adequately resolved. A correction has therefore been made at the cartesian grid points closest to the source point. The value of $\overline{v_{d} C_{d}}$ at these points has been increased to compensace for the amount of surface contamination in the vicinity of the source which has not been accounted for in the coordinate transformation. However, even though this produces a surface contamination distribution which has the proper amount of material, the peak of the cartesian distribution is unavoldably broader and lower than the actual peak. It will be seen later that the errors generated by this problem do not seriously affect the results of this study.

Comparison of the Climatologically-Averaged Initial and Resuspended Plumes.

Figures 1 and 2 show the calculated afr concentrations, normalized by the release rate $Q$, for the $1 \mu \mathrm{m} \cdot\left(v_{d} / u=10^{-3}\right)$ and $10 \mu \mathrm{m}\left(v_{d} / u=10^{-2}\right)$ particles respectively. Recall that these deposition velocities are also dependent on the spectfic gravity of the particle (3) and the roughness of the deposition surface (Hanford $z_{0}=3 \mathrm{~cm}$ ). These air concentrations have been polar-averaged over all wind directions and are plotted as a function of distance from the original source. Four different curves are found in each figure: the undepleted air concentration $\overline{\mathrm{C}}_{0}$, the depleted air concentration $\bar{C}_{d}$, their difference $\bar{C}_{o}-\bar{C}_{d}$, and the resuspended air concentration $\bar{C}_{r}^{\prime}$.

As mentioned previousiy, $\bar{C}_{r}^{\prime}$ has been calculated in several overlapping ranges of downwind distance, grid intervals of $25 \mathrm{~m}, 200 \mathrm{~m}, 1 \mathrm{~km}$ and $5 \mathrm{~km}$ for $v_{d} / \mathrm{u}=10^{-3}$ and $25 \mathrm{~m}, 100 \mathrm{~m}, 500 \mathrm{~m}$ and $5 \mathrm{~km}$ for $\mathrm{v}_{\mathrm{d}} / \mathrm{u}=10^{-2}$, and this is evident in the results. For each grid interval value $\bar{c}_{r}^{\prime}$ appears to 


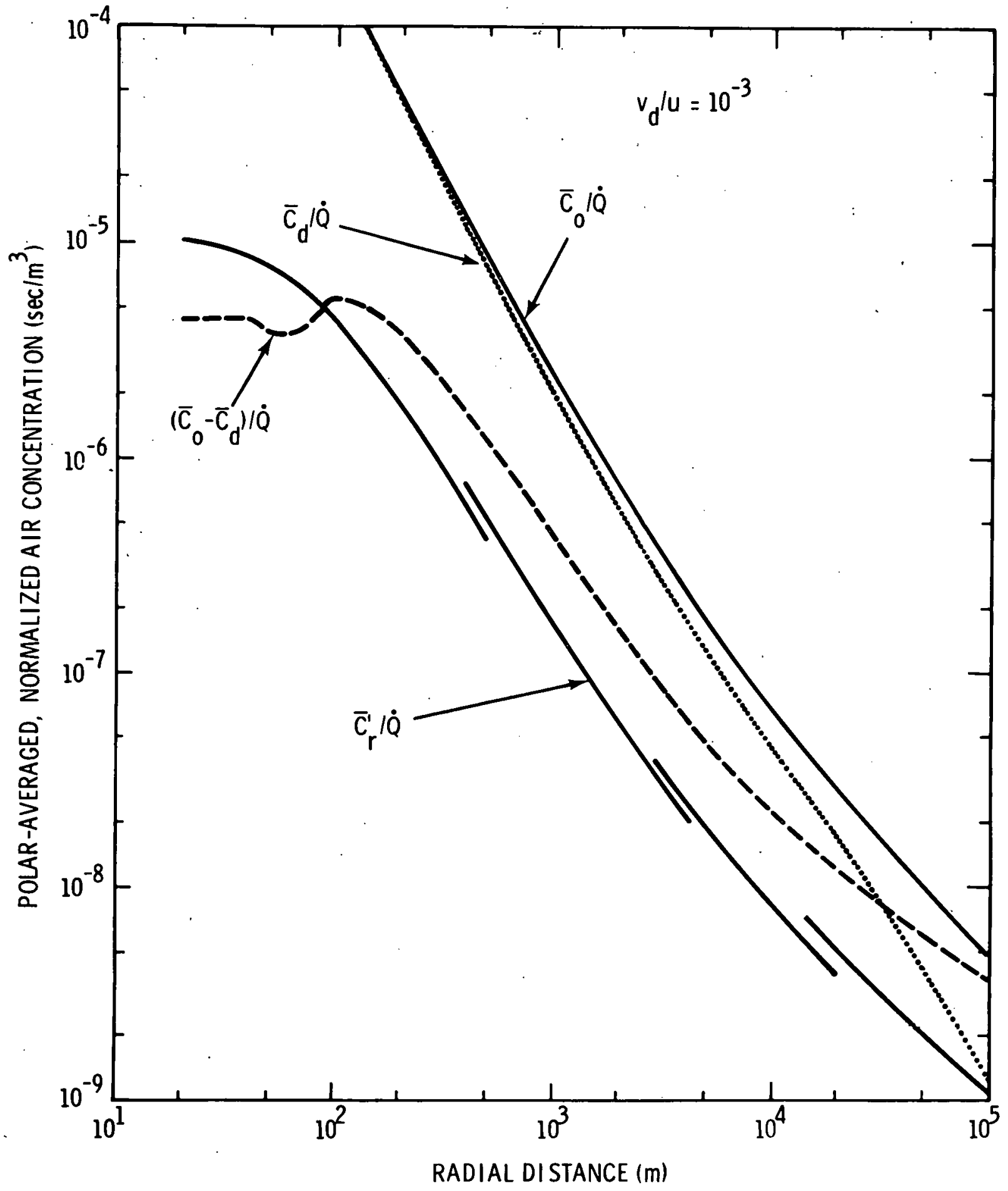

Figure 1. Pnlar-Averaged, Normalized Air Concentrations vs. Radial Distance for $v_{d} / u=10^{-3}$. 


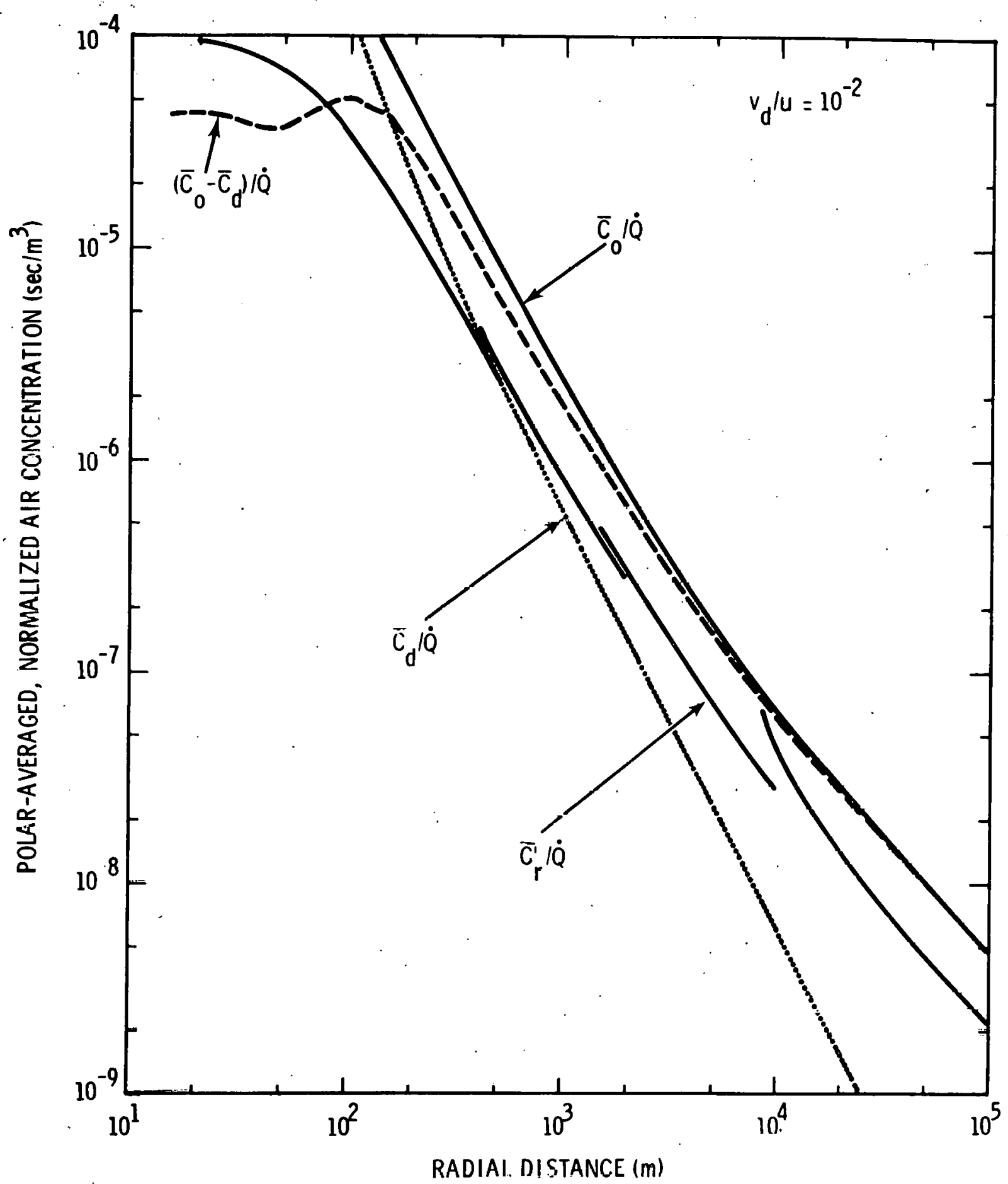

Figure 2. Polar-Averaged, Normalized Afr Concentrations vs. Radial Distance for $v_{d} / u=10^{-2}$. 
be overestimated at those points closest to the original source point. This is apparently due to the previously-mentioned manner in which the surface contamination in the vicinity of the source has been accounted for. Some has been located at an artificially large distance from the source, and hence $\bar{C}_{r}^{\prime}$ at larger distances has been overestimated because the materlal resuspended from those central points has less travel distance in which to diffuse in the atmosphere. Since this effect will become less important for each grid interval as the travel distance from the source is increased, the $\overline{\mathrm{C}}_{r}^{\prime}$ at the largest distances should have the least error and the best estimate of $\bar{C}_{r}^{\prime}$ from these calculations should be a curve connecting the $\bar{C}_{r}^{\prime}$ at $x=20$ grid intervals.

The risk associated with these alr concentrations is most commonly related to the exposure to the airborne contamination. This is either the average air concentration multiplied by the time during which an individual is exposed to the contamination or the time integrated air concentration

$$
E \equiv \int_{0}^{T} C d t
$$

If the quantity of material released $Q$ is substituted for the rate of release $\dot{Q}$, the normalized curves for $\bar{C}_{0}$ and $\bar{C}_{d}$ may be interpreted as the respective exposures per unit of material released. The exposure to the resuspended material is found by replacing (11) in equation (13) by (14) and integrating over the time of exposure since deposition, giving

$$
\overline{\mathrm{E}}_{\mathbf{r}}^{\prime} / Q=\overline{\mathrm{C}}_{\mathrm{r}}^{\prime} / \dot{Q}
$$

The maximum exposure to the resuspended material is received by increasing the exposure time until all of the material is resuspended, and this corresponds to $\left(1-e^{-\bar{\Lambda} t}\right)=1$. Thus the normalized curve for $\bar{c}_{r}^{\prime}$ in . Figs. 1 and 2 may be interpreted as this maximum exposure. We may now proceed to a very useful comparison of the initial plume with the resuspension plume. Horst (1974c) has shown that for the special 
case of a single wind speed, wind direction and stability

$$
\mathrm{C}_{\mathbf{r}}+\mathrm{C}_{\mathrm{d}}=\mathrm{C}_{\mathrm{o}}
$$

when the system reaches. a steady state. What occurs is that the surface contamination $G$ increases until the resuspension $f 1 u x \Lambda G$ exactly balances the deposition flux $v_{d} C$. Thus there is no longer any net transfer from the air to the ground and $G$ is equal to its steady state value $v_{d} c / \Lambda$. Further, the sum of the depleted, initial alr concentration and the resuspended air concentration is for the same reason then equal to the air concentration as it would have been without the occurrence of either depositiun ur resuspension. It is evident from the rirves for $\bar{C}_{r}^{\prime}$ and $\bar{C}_{0}-\bar{C}_{d}$ in Figs. 1 and 2 that

$$
\overline{\mathrm{C}}_{\mathrm{r}}^{\prime}+\overline{\mathrm{C}}_{\mathrm{d}}<\overline{\mathrm{C}}_{\mathrm{o}}
$$

rather than (17). (Recall that $\overline{\mathrm{C}}_{\mathbf{r}}^{\prime}$ as plotted is the steady state value.) Equally important

$$
\overline{\mathrm{E}}_{\mathrm{r}}^{\prime}+\overline{\mathrm{E}}_{\mathrm{d}}<\overline{\mathrm{E}}_{\mathrm{o}}
$$

where $\bar{E}_{r}^{\prime}$ is the maximum value of the exposure, calculatcd by allowiug a11 of the material to resuspend. Thus a conservative estimate of the exposure could have been made by ignoring both deposition and resuspension!*

There are two important qualifications to the preccding stateütnt. One is the already-mentioned neglent of redepooition and substuutent additional resuspension. It cannot be conclusively stated at this time whether this results in a net loss or a net gain to $\bar{C}_{r}$, but it is likely that it is a small effect. The second qualification occurs in the immedlate vicinity of the original source.

Actually (18) and (19) should also include the possibility of equality in the limit as $v_{d}$ goes to zero. 
It can be seen in Figs. 1 and 2 that (18) and (19) are not valid for distances less then about $100 \mathrm{~m}$. This may be explained by examining

$$
C_{0}\left(z_{d}\right)-C_{d}\left(z_{d}\right)=\frac{v_{d}}{u} \int_{0}^{x} C_{d}\left(\xi, \theta, z_{d}\right) D\left(x-\xi, \theta, z_{d}\right) d \xi .
$$

Independent of the values of $C_{d}$ and $D, C_{o}-C_{d}$ goes to zero at $x=0$ since for very small downwind travel distances the deposition has had insufficient opportunity to decrease $C_{d}$ below its undepleted value $C_{0}$. Further, in the immediate vicinity of the original source $C_{0}\left(z_{d}\right)$ and $C_{d}\left(z_{d}\right)$ (or equivalently $D\left(x, \theta, z_{d}\right)$ ) are themselves quite small since the diffusion process as represented by the Gaussian plume model requires a travel distance of several meters to generate a substantial air concentration at a height of $z_{d}=1 \mathrm{~m}$ from a surface source. Thus $D, C_{0}$ and $C_{d}$ initially increase with travel distance to a peak in the vicinity of $x \sim 15 \mathrm{~m}$. The difference $C_{o}-C_{d}$ is proportional to the convolution of $C_{d}$ and $D$ and hence increases more slowly, peaking in the vicinity of $\mathrm{x} \sim 100 \mathrm{~m}$.

The resuspended air concentration, on the other hand, has as its source the material deposited from $C_{d}$. For any given wind direction this material has also been deposited upwind of the origin due to previous winds which blew in the opposite direction. Thus $C_{r}^{\prime}$ does not go to zero at the origin. Further the peak in the ground contamination corresponds

- to the peak in $\mathrm{C}_{\mathrm{d}}$, 1.e., it lies at a radius of about $15 \mathrm{~m}$ from the origin, and thus the peak of $C_{r}^{\prime}$ also occurs in this same region. This explains the fact that $\bar{C}_{r}^{\prime}$ exceeds $\bar{C}_{0}-\bar{C}_{d}$ for distances less than about $100 \mathrm{~m}$. $\bar{C}_{0}$ can nevertheless be seen to still be a conservative approximation to $\bar{c}_{r}^{\prime}+\bar{C}_{d}$ except perhaps within several meters of the original source where $\overline{\mathrm{C}}_{0}$ and $\overline{\mathrm{C}}_{\mathrm{d}}$ both become very small. Although this may be an unrealistic prediction of the Gaussian plume model for $z=1 \mathrm{~m}$ and a surface release, it would be very reasonable to expect $\bar{C}_{r}$ to exceed $\bar{C}_{0}$ and $\bar{C}_{d}$ at ground level immediately below an elevated source such as the chronic release from a process stack. 
Figures 1 and 2 display the polar-averaged air concentrations or exposures. Figure 3 shows the polar distributions of $\overline{\mathrm{C}}_{0}-\overline{\mathrm{C}}_{\mathrm{d}}$ and $\overline{\mathrm{C}}_{\mathrm{r}}^{\prime}$ for both $v_{d} / u=10^{-3}$ and $10^{-2}$ at a radial distance of $400 \mathrm{~m}$ from the primary source. The qualitative relationships (18) and (19) are valid for all $\theta$. The peak corresponds to the direction toward which the wind blows most frequently, ESE. Note that the ratio of $\bar{C}_{r}^{\prime}$ to $\bar{C}_{0}-\bar{C}_{d}$ is smallest in this direction. This may also be inferred from Figure 4 which shows $\bar{C}_{0}-\bar{C}_{d}$ and $\bar{C}_{r}^{\prime}$ as a function of radial distance for two individual azimuths, ESE and WSW: Recalling the results of Horst (1974c) for a single wilnd speed, wind direction and stability, it may be hypothesized that (17) is the limiting case of (18) when the wind direction is constant. Additional investigation is necessary to substantiate this.

The results reported thus far have been calculated with a constant rcouspension rate. Although little ts presently known about the resuspension rate, it should realistically be a function of both the current value of such variables as wind speed, atmospherfc turbulence and soil moisture and of thelr past history. The wind speed is probably the most important of the atmospheric parameters. Bagnold (1941) has shown that the horizontal flux of resuspended material is proportional to the third power of the amount by which the wind speed exceeds a threshhold value. If the vertical resuspension flux is directly proportional to the horizontal flux, this would Imply a dependence of the resuspension rate on the cube of the wind speed. Sehmel and Lloyd (1975), on the other hand, have measured the resuspension rate to be proportional to a power of the wind speed as great as 6.5 .

In order to Investigate the dependence of $\bar{C}_{r}^{\prime}$ on the functional relationship between resuspension rate and wind speed, calculations were made assuming that

$$
\Lambda=A u^{\mathrm{N}}
$$

for several values of the exponent N. Fig. 5 shows the resulting polaraveraged values of $\bar{C}_{r}^{\prime}$ over a limited range of downwind distance and for $v_{d} / u=10^{-2}$. Increasing the dependence of $\Lambda$ on wind speed decreases $\bar{C}_{r}^{\prime}$ 
below that previously calculated for a constant $\Lambda(N=0)$. Fig. 6 , the polar distribution of $\bar{C}_{r}^{\prime}$ at a radial distance of $2 \mathrm{~km}$, shows that this is still true despite the enhancement of the peak in the ESE direction with increasing $\mathrm{N}$. Thus (18) and (19) are only strengthened by allowing $\Lambda$ to increase with the wind speed.

The decrease of $\bar{C}_{r}^{\prime}$ with increasing $N$ is directly due to the fact that the atmospheric diffusion is inversely proportional to the wind speed. Thus the numerator of (13) does not increase as rapidly with increasing $\mathrm{N}$ as does the denominator. A simple analysis shows that the decrease of $\bar{C}_{r}^{\prime}$ with increasing $N$ appears to reach an asymptotic limit at about $0.2 \bar{C}_{r}^{\prime}(N=0)$, and this is also suggested by Figs. 5 and 6 . 


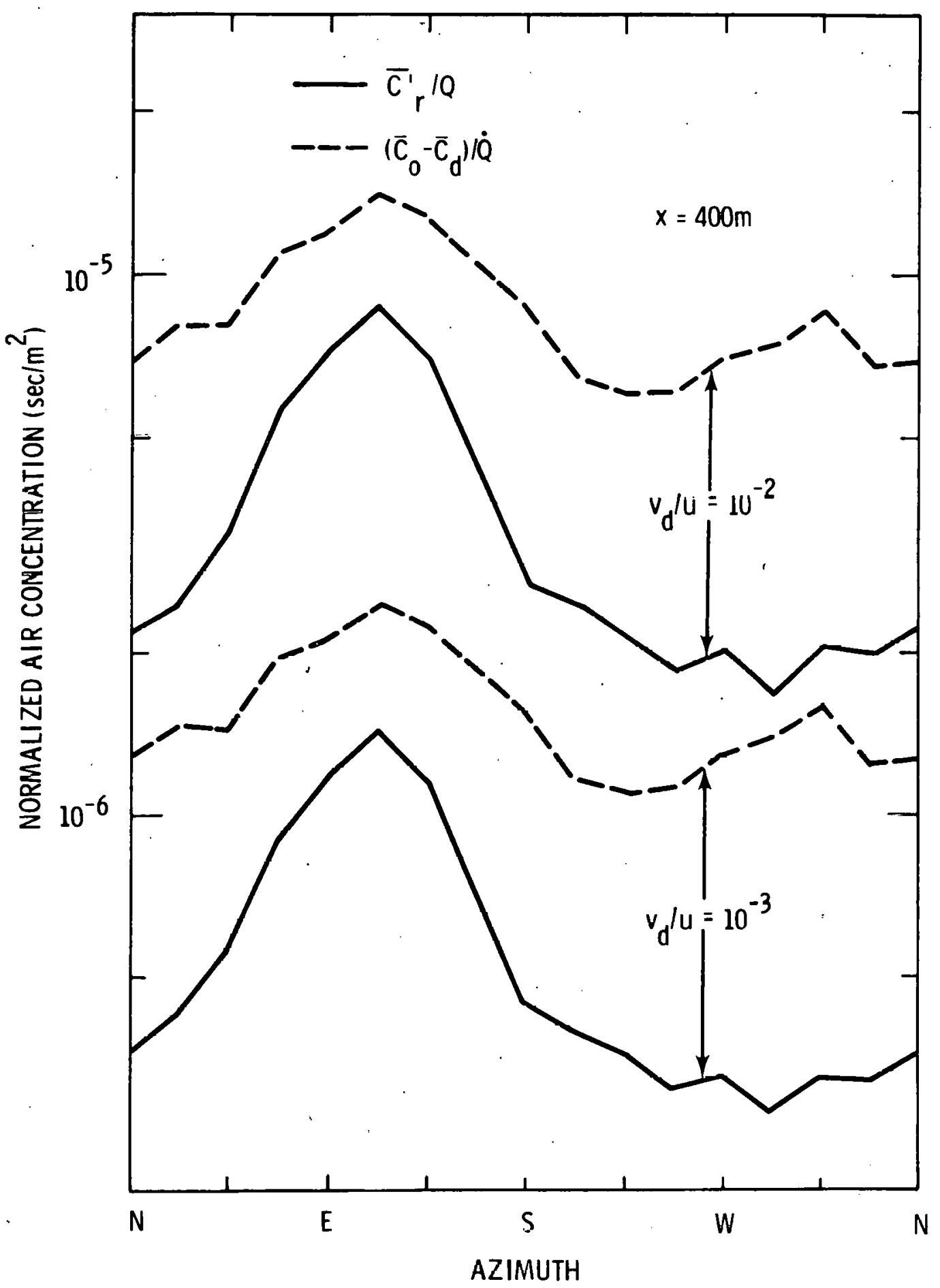

Figure 3. Normalized Air Concentrations vs. Azimuth at a Radial Distance of $400 \mathrm{~m}$. 


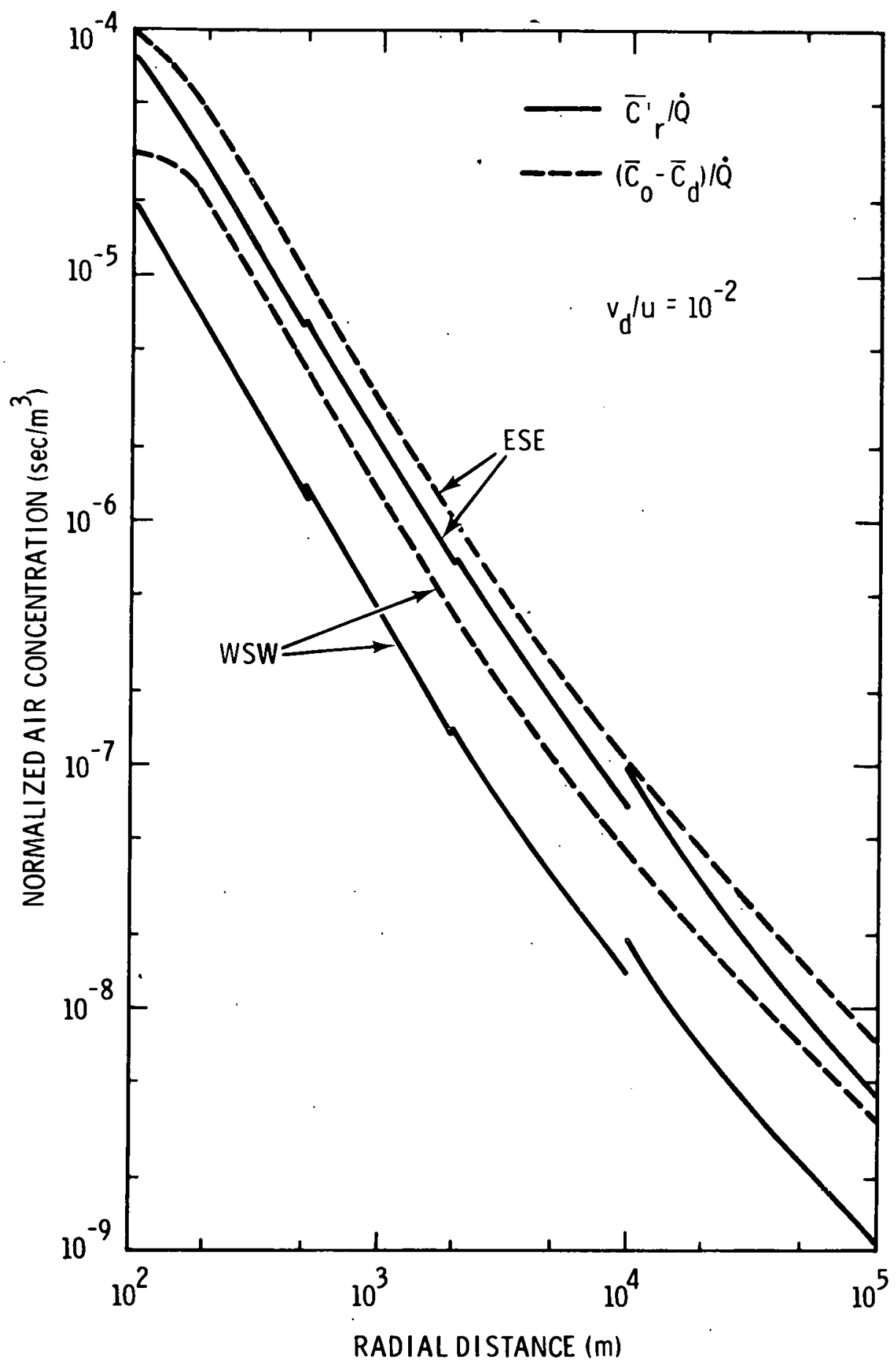

Figure 4. Normalized Air Concentrations vs. Radial Distance for the ESE and WSW Directione. 


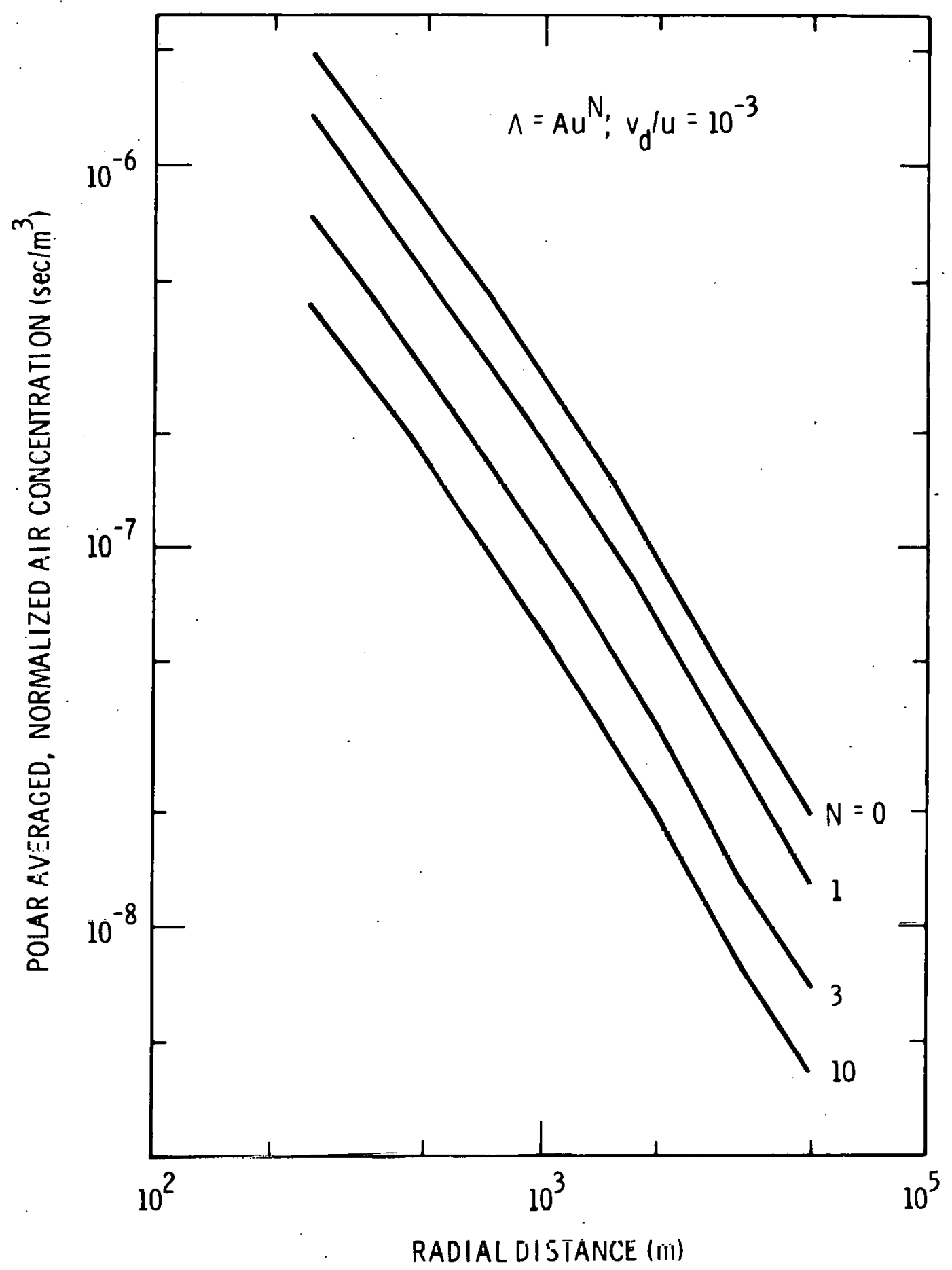

Figure 5. Polar-Averaged, Normalized Resuspended Air Concentrations vs. Radial Distance for $\Lambda=A u^{N}$. 


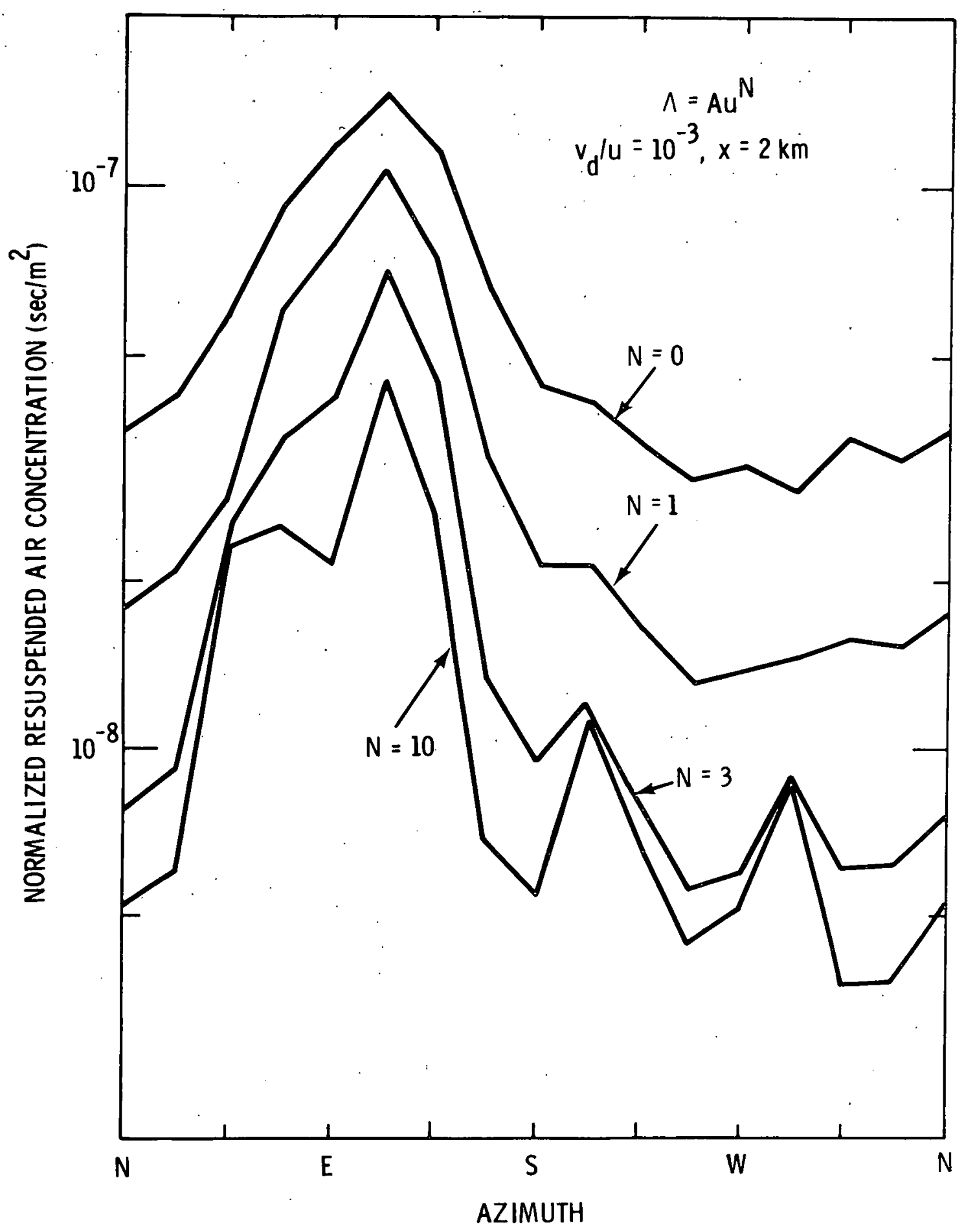

Figure 6. Normalized Resuspended Air Concentrations vs. Azimuth at a Radial Distance of $2 \mathrm{~km}$ for $\Lambda=\mathrm{Au}^{\mathrm{N}}$. 
Portions of this study were accomplished with the capable assistance of T. J. Bander and W. E. Davis, and discussions with W. G. N. Slinn and E. C. Watson provided additional insight into the problem of resuspension. The help of these individuals is greatly appreciated. 


\section{REFERENCES}

Bagnold, R. A., 1941: The Physics of Blown Sands and Desert Dunes, Methuen and Co., Ltd., London.

Briggs, G. A., 1973: Diffusion Estimation for Small Emissions, ATDL Contribution 79, Air Resources Atmospheric Turbulence and Diffusion Laboratory, Oak Ridge, TN.

Horst, T. W., 1974a: "A Surface Flux Model for Diffusion, Deposition and Resuspension," Pacific Northwest Laboratory Annual Report for 1973 to USAEC Division of Biomedical and Environmental Research, Vol. II, Part 3 , Atmospheric Sciences, BNWL-1850 PT3, Battelle, Pacific Northwest Laboratories, Richland, WA, 1974.

, 1974b: "A Surface Depletion Model for Deposition from a

Gaussian.Plume," Proceedings of Atmosphere-Surface Exchange of Particulate and Gaseous Pollutants - 1974 Symposium, Richland, WA, September 4-6, 1974, CONF-740921, AEC Symposium Series (In Press).

, 1974c: "Coment" following "Theoretical Resuspension Ratios," by A. J. Amato, Proceedings of Atmosphere-Surface Exchange of Particulate and Gaseous Pollutants - 1974 Symposium, Richland, WA, September 4-6, 1974, CONF-740921, AEC Symposium Series (In Press).

Sehmel, G. A. and W. H. Hodgson, 1974: "Predicted Dry Deposition Velocities," Proceedings of Atmosphere-Surface Exchange of Particulate and Gaseous Pollutants - 1974 Symposium, Richland, WA; September 4-6, 1974, CONF-740921, AEC Symposium Series (In Press).

Sehmel, G. A. and F. D. Lloyd, 1975: "Initial Particle Resuspension Rates - A Field Experiment Using Tracer Particles," Pacific Northwest Laboratory Annual Report for 1974 to the USAEC Division of Biomedical and Environmental Research, Part 3, Atmospheric Sciences, BNWL-1950, Pt. 3, Battelle, Pacific Northwest Laboratories, Richland, WA.

Van der Hoven, I., 1968: "Deposition of Particles and Gases," Meteorology and Atomic Energy, D. Slade (Ed.), USAEC TID-21490.

Winegardner, W. K., 1975: Personal communication'. 


\section{APPENDIX A: Hańford Climatology Used for Computations}

The following table summarizes the 8760 hours of Hanford Meteorological Tower data for 1970 which were used for the computations of this report. The numbers shown are the foint probability density of wind direction (from which the wind is blowing), wind speed class and stability class. The stabllity was classifled according to the wind speed vs. day or night scheme of Table 1. Below each probability entry is the corresponding average wind speed in $\mathrm{mph}$.

These data include 253 hours during which the wind direction was classified as variable and 262 hours during which the wind speed was classified as calm. The hours of varlable direction were placed in the approprlate speed class according to the measured wind speed and they, along with the calms, were distributed equally over the 16 wind directions. The calms were arbitrarily assigned a wind speed of $0.5 \mathrm{mph}$ and thus, for computing the initial plumes, were classified as stability A (95 hours) or F ( 167 hours) according to whether they occurred during the day or night. No resuspension was attributed to the calms, even for the case of resuspension rate independent of wind speed. 
TABLE A-1

JOINT PROBABILITY DISTRIBUTION OF WIND SPEED AND WIND DIRECTION AT 50-FOOT-LEVEL

\section{VS. ATMOSPHERIC STABILITY}

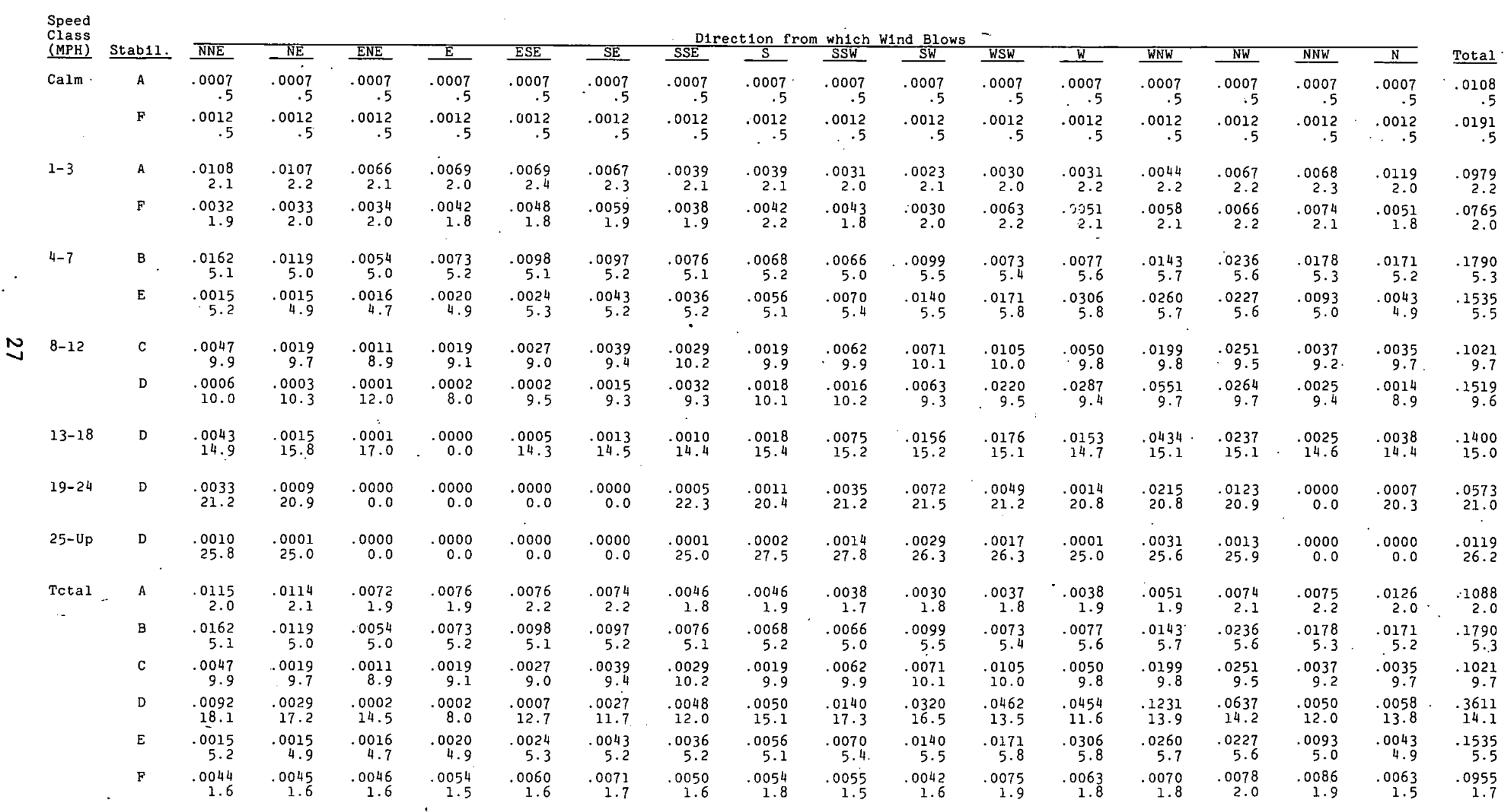




\section{APPENDIX B: The C1Imatologically-Averaged Initial Plume}

The following tables show the climatologically-averaged values of the initial plume air concentration $\bar{C}_{d}$ and deposition flux $\overline{v_{d} c_{d}}$ for no deposition $\left(\bar{c}_{o}\right), v_{d} / u=10^{-2}$, and $\cdot v_{d} / u=10^{-3} \cdot \bar{c}_{d}$ and $\overline{v_{d} c_{d}}$ have both been normalized by the source strength $\dot{Q}$ and hence have dimensions of $\mathrm{sec} / \mathrm{m}^{3}$ and $\mathrm{m}^{-3}$, respectively. The results are tabulated as a function of azimuthal direction and of radial distance from the original source. Those labeled "Surface Depletion Model" are the result of computations made with equation (10) and were utilized in the body of this report. The tables labeled "Source Depletion Model" are discussed in Appendix C. 
table b-1. INItIAL plume air concentration.

NO OEPLSITION

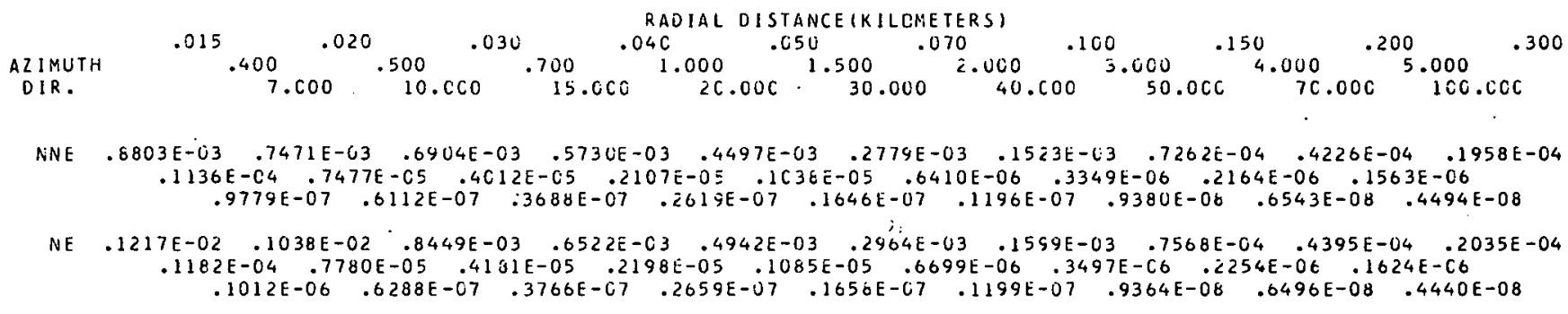

ENE .1583E-02 .1366E-02 .1122E-02 .8713E-03 . .6624E-C3 .3935E-03 .2154E-C3 .1C21E-03 .5538E-04 .2754E-04 $.1601 \mathrm{E}-04 \quad .1056 \mathrm{E}-04 \quad .5624 \mathrm{E}-05 \quad .2996 \mathrm{E}-05 \quad .1486 \mathrm{E}-05 \quad .9166 \mathrm{E}-06 \quad .4755 \mathrm{E}-06 \quad .3093 \mathrm{E}-06 \quad .2230 \mathrm{E}-06$

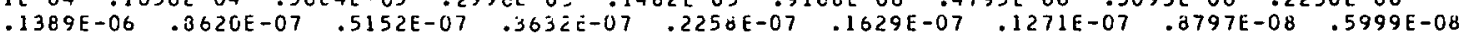

E $\quad .1691 E-02 \quad .1567 E-02 \quad .130 C E-02 \quad .9919 E-03 \quad .7453 E-03 \quad .4432 E-03 \quad .2320 E-03 \quad .1124 E-03 \quad .6529 E-04 \quad .3 C 26 E-C 4$

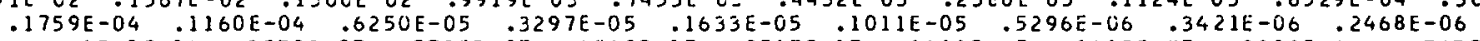

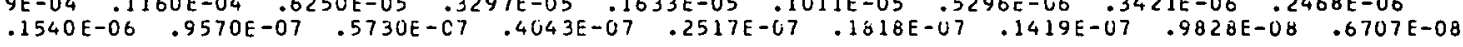

ESE .3178E-02 .2581E-02 $.1822 E-02 \quad .1306 E-02 \quad .9545 E-03 \quad .5548 E-03 \quad .2947 E-03 \quad .1386 E-03 \quad .8042 E-04 \quad .3731 E-04$ $.2173 \mathrm{E}-04 \quad .1435 \mathrm{E}-04.7747 \mathrm{E}-05$. $4094 \mathrm{E}-05$. $2030 \mathrm{E}-05$. .1255E-05 .6544E-06 .4203E-06.3014E-06

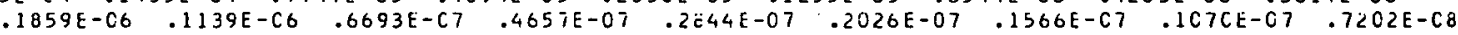

SE $.2758 E-02 \quad .2182 E-02 \quad .1571 E-02 \quad .1148 E-02 \quad .8481 E-03 \quad .4976 E-03 \quad .2654 E-03 \quad .1249 E-03 \quad .7238 E-04 \quad .3346 E-04$

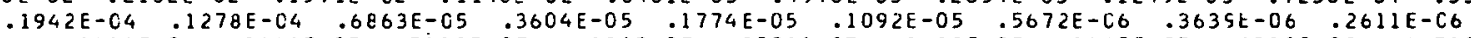
$\begin{array}{lllllllll}.1614 \mathrm{E}-06 & .9942 \mathrm{E}-07 & .5893 \mathrm{E}-07 & 07131 \mathrm{E}-07 & .07551 \mathrm{E}-\mathrm{C} 7 & .1632 \mathrm{E}-07 & .07425 \mathrm{E}-07 & .07820 \mathrm{E}-08 & .0671 \mathrm{E}-08\end{array}$

SSE .125EE-02 .1022E-02 .9110E-03 .7477E-03 .5841E-03 .3596E-03 .1966E-C3 .936CE-04 .5441E-04 .2516E-04

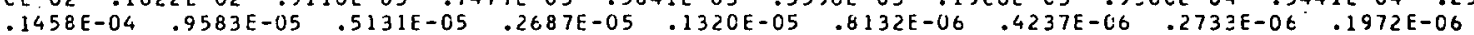
$\begin{array}{lllllllll}.1233 \mathrm{E}-06 & .7709 \mathrm{E}-07 & .4657 \mathrm{E}-07 & 03311 \mathrm{E}-\mathrm{J} 7 & .2085 \mathrm{E}-07 & .1517 \mathrm{E}-07 & .1191 \mathrm{E}-07 & .0323 \mathrm{E}-08 & .5727 \mathrm{E}-08\end{array}$

$S \quad .1514 E-02 \quad .1089 E-02 \quad .8483 E-03 \quad .6707 E-03 \quad .5171 E-03 \quad .3153 E-03 \quad .1716 E-C 3 \quad .8146 E-04 \quad .4729 E-04 \quad .2183 E-04$ $.1263 E-04 \quad .8288 E-05 \quad .4426 E-05$.2310E-U5 .1129E-05 .6926E-06 .3585E-06 .2301E-06 .1654E-06

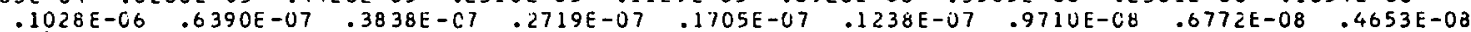

SSW .1401E-02 .9599E-03 .6867E-03 .5286E-03 .4027E-03 .2434E-03 .1319E-03 .6245E-04 .3621E-04 .1670E-04

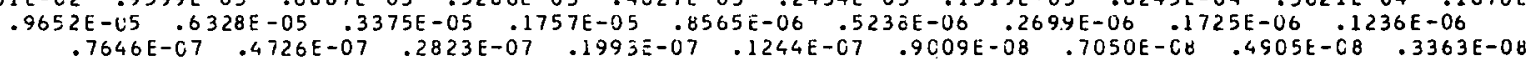

$S h \quad .1146 E-02 \quad .7938 E-03 \quad .6028 E-03 \quad .4759 E-03 \quad .3672 E-C 3 \quad .2242 E-03 \quad .1221 E-03 \quad .5797 E-04 \quad .3364 E-04 \quad .1552 E-04$ $.8974 \mathrm{E}-05 \quad .5885 \mathrm{E}-05 \quad .3139 \mathrm{E}-05 \quad .1636 \mathrm{E}-05 \quad .7981 \mathrm{E}-06 \quad .4887 \mathrm{E}-06 \quad .2524 \mathrm{E}-\mathrm{C6} \quad .1617 \mathrm{E}-0 \mathrm{6} \quad .1161 \mathrm{E}-\mathrm{C6}$

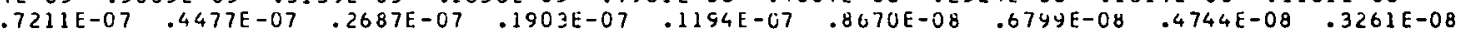

$W 5 \mathrm{WH} .7295 E-03 \quad .5503 E-03 \quad .5020 E-C 3 \quad .4252 E-03 \quad .3377 E-03 \quad .2109 E-03 \quad .1162 E-03 \quad .5551 E-04 \quad .323 U E-04 \cdot .1494 E-04$

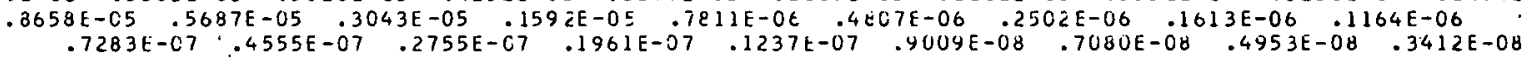

h. .8235E-03 .6259E-03 .5764E-03 .4897E-C2 .3893E-03 .2433E-03 .1341E-03 .6408E- $044 \quad .3729 E-04 \quad .1726 E-04$ $.9999 \mathrm{E}-05 \quad .6569 \mathrm{E}-05 \quad .3515 \mathrm{E}-05$.1839E-05 .9028E-06 .5556E-06 .2894E-06 .1366E-06. $1347 \mathrm{E}-06$

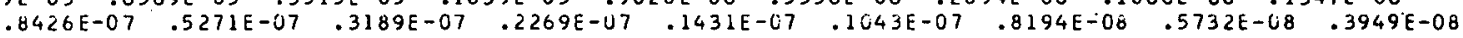

WNW .8432E-03 $.6507 E-03 \quad .6041 E-03 \quad .5135 E-03 \quad .4082 E-03 \quad .2551 E-03 \quad .14 C 5 E-03 \quad .6718 E-04 \quad .3910 E-04 \quad .1809 E-04$

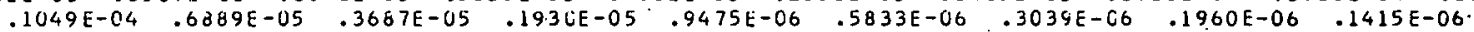
$\begin{array}{lllllllll}.6854 E-07 & .5539 E-C 7 & .3351 E-C 7 & .2385 E-07 & .1504 E-07 & .1096 E-07 & .8609 E-066 & .6 C 21 E-C 8 & .4148 E-C 8\end{array}$

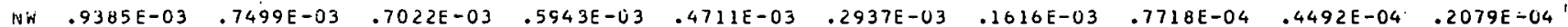

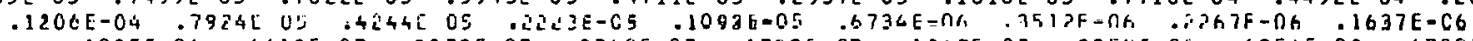

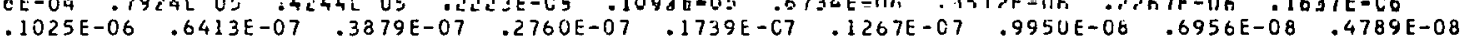

NNW .7765E-C3 .6223E-C3 $.5724 E-03 \quad .4803 E-03 \quad .3794 E-03 \quad .23 .58 E-03 \quad .1256 E-C 3 \quad .6186 E-04 \quad .360 C E-04 \quad .1667 E-04$ $.9668 E-05 . .6357 E-05 \quad .3407 E-05 \quad .1786 E-05 \quad .8785 E-06 \quad .5415 E-06 \quad .2825 E-06 \quad .1823 E-06 \quad .1316 E-06$ $.8233 \mathrm{E}-07.5146 \mathrm{E}-07 \quad .3108 \mathrm{E}-07 \quad .2204 \mathrm{E}-07 \quad .1390 \mathrm{E}-\mathrm{C7} \quad .1011 \mathrm{E}-07.7939 \mathrm{E}-\mathrm{CB} \quad .5544 \mathrm{E}-08 \quad .3813 \mathrm{E}-08$

$N \quad .7312 E-03 \quad .6143 E-03 \quad .5799 E-03 \quad .4864 E-03 \quad .3835 E-03 \cdot .2379 E-03 \quad .1306 E-03 \quad .6230 E-04 \quad .3625 E-04 \quad .1679 E-04$

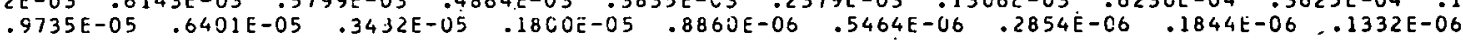
$.8344 \mathrm{E}-07.5723 \mathrm{E}-\mathrm{C} 7$. $.3159 \mathrm{E}-\mathrm{C} 7$.2248E-07 .1416E-07 .1031E-07 .8098E-08 .5659E-08 .3895E-08

TRIA1 .P147F-01 .1716E-01 .1394E-01 .1095E-01 .8394E-02 .5008E-CE .27EOE-C2 .1310E-02 .7611E-03 .3523E-03

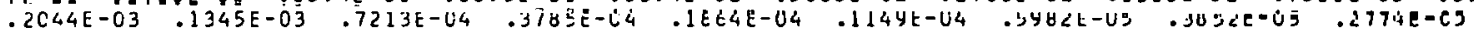

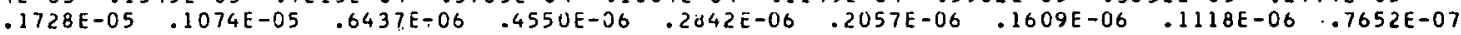


table B-2. INITIAL PLUHE AIR CONCENTRATION.

SURFACE DEPLETION MODEL, VO/U $=.01 C$

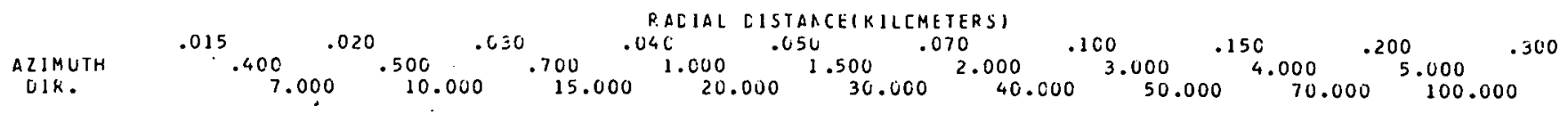

NNE $\quad .8521 E-03 \quad .7181 E-03 \quad .6642 E-03 \quad .5492 E-03 \quad .4245 E-03 \quad .2426 E-03 \quad .1080 E-03 \quad .3601 E-04 \quad .1676 E-04 \quad .6389 E-05$

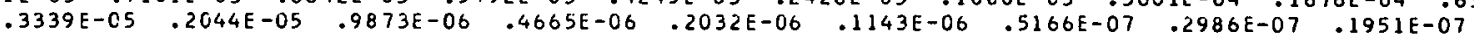

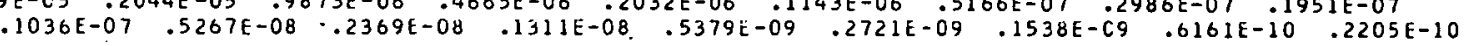

NE .1189E-02 .1006E-02 .8102E-03 .6168E-03 .4561E-03 ..2504E-C3 .1167E-03 .3815E-04 .1829E-04 .7116E-05 $.3753 E-05$.2311E-05 .1127E-05 .5368E-06 .236CE-06 .1335E-06 .6C76E-07 .3519E-07 .2304E-07

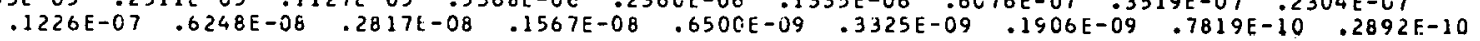

ENE .1554E-02 $.1330 E-02 \quad .1078 E-02 \quad .8237 E-03 \quad .6109 E-03 \quad .3368 E-03 \quad .1491 E-03 \quad .5127 E-04 \quad .2452 E-04 \quad .9537 E-05 \quad$ $.5034 \mathrm{E}-05$.3103E-05 .1516E-C5 .7241E-00 .3194E-C6 .1811E-06 .8268E-07.4796E-07 .3142E-07

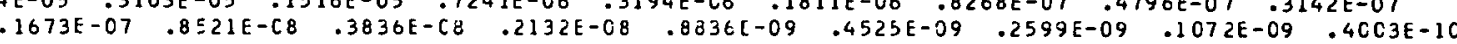

E .1663E-02 .1533E-02 .1256E-02 .9407E-03 .6854E-03 .3690E-03 .1617E-03 .5620E-04 .2718E-04 .1062E-04

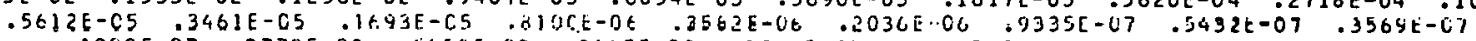

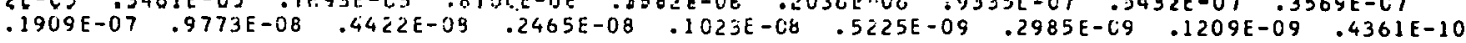

FSE .3136E-02 .2520E-C2 .1731E-0Z .1206E-CZ . .522F-02 .45 $16 E-03 \quad .2061 E-63 \quad .7200 E-04 \quad .3566 E=04 \quad .1425 E-04$

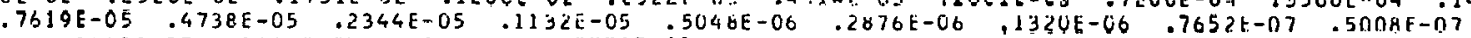

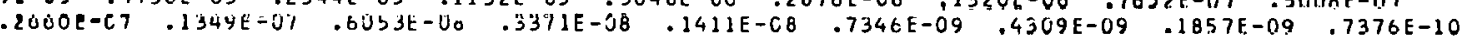

SE .2700E-02 .211CE-0Z .1499E-C2 .1067E-02 $.7664 E-03 \quad .412 C E-03 \quad .1828 E-C 3 \quad .6485 E-04 \quad .3176 E-04 \quad .1256 E-04$

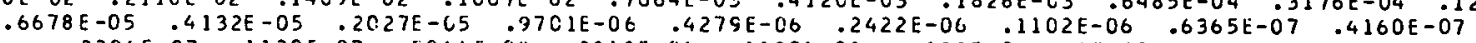

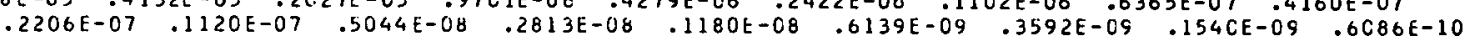

SSE. .1208E-U2 .9737E-03 .8723E-03 .7152E-03.5509E-03 .3140E-03 .1359E-03 .4682E-04.2187E-04.8353E-05 $-4367 \mathrm{E}-05$.2672E-UE .1239E-05 .6072E-06 .2634E-06 .1477E-06 .6641E-07 .3825E-07 .2494E-07

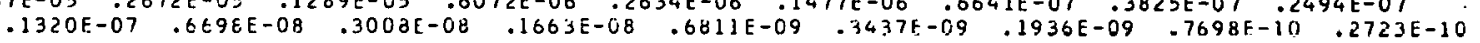

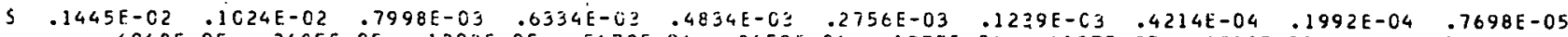

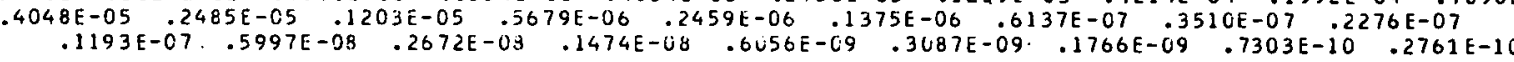

SSW .1339E-02 .9000E-03 .6428E-03 .4936E-03 .3729E-03 .2119E-03 .9575E-C4 .3300E-04 .1574E-04 .6136E-05

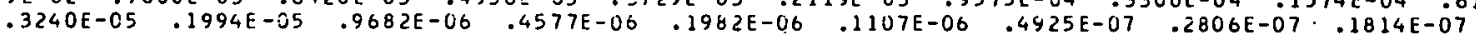

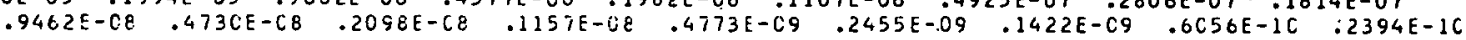

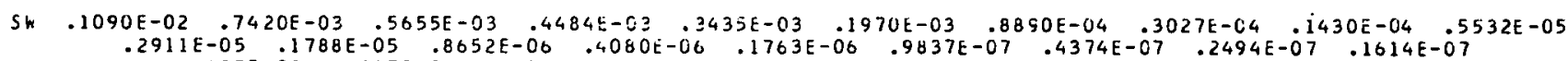

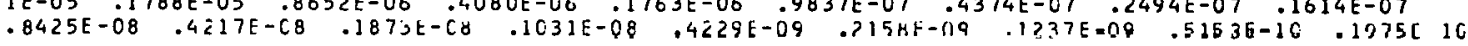

WSW .6920E-03 .5168E-03 .4789E-03 .4083E-03 .3218E-03 $.1878 E-03 \quad .8434 F-04 \quad .2791 E-04 \quad .1290 E-04 \quad .4897 E-05 \quad$

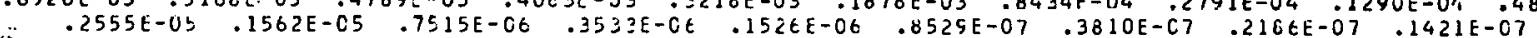

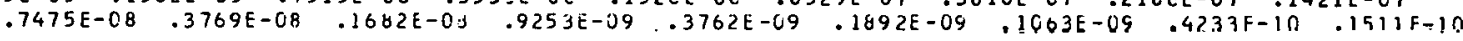

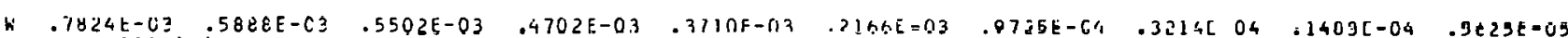

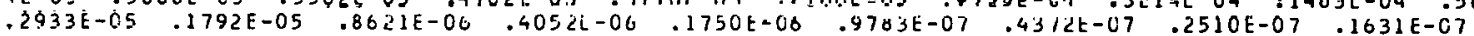

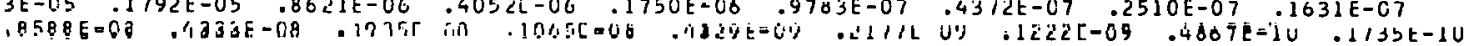

WNW .BU44E-03 .6141E-03 .5770E-03 .4929E-03 .3380E-03 .2267E-03 .1017E-C3 .3357E-04 .1548E-04 .5866E-05

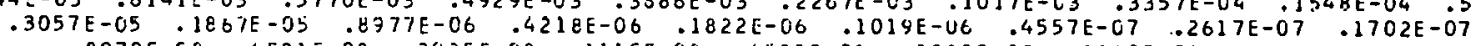

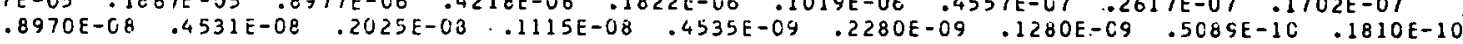

$\mathrm{Nh} .8983 \mathrm{E}-\mathrm{C3} \quad .7116 \mathrm{E}-03 \quad .6729 \mathrm{E}-0 \mathrm{C} \quad .5700 \mathrm{E}-03 \quad .4478 \mathrm{E}-03 \quad .2597 \mathrm{E}-03 \quad .1162 \mathrm{E}-03 \quad .3643 \mathrm{E}-04 \quad .1776 \mathrm{E}-04 \quad .6735 \mathrm{E}-05$ $.3512 \mathrm{E}-05$.2145E-0E .1033E-05 .4858E-06 .2103t-U6.1178E-06 .5285E-07.3042E-07.1982E-07

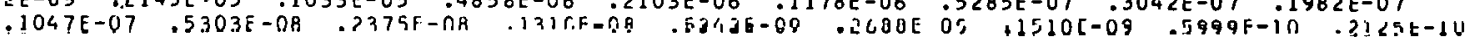

NNW $.7455 E-03 \quad .5920 E-03 \quad .5484 E-03 \quad .4605 E-03 \quad .3596 E-03 \quad .2078 E-03 \quad .9295 E-04 \quad .3 C 85 E-04 \quad .1430 E-04 \quad .5437 E-05$

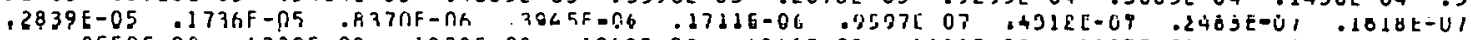

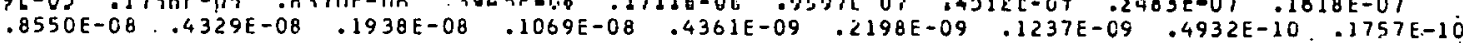

$N \quad .7017 E-03 \quad .5863 E-03 \quad .5580 E-03 \quad .4679 E-03 \quad .3639 E-03 \quad .2090 E-03 \quad .9369 E-C 4 \quad .3091 F-04 \quad .1634 E=04 \quad .5452 E-05$

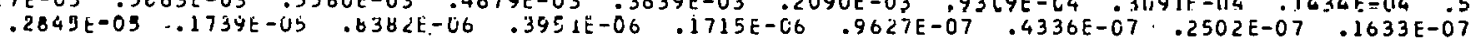

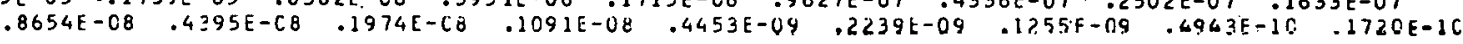

TOTAL .2080E-01 .1647E-01 .1329E-01 .1036E-01 .7794E-02 .4368E-02 $\quad .1946 E-02 \quad .6645 E-03 \quad .3156 E-03 \quad .1222 E-03$

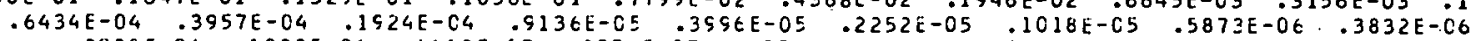

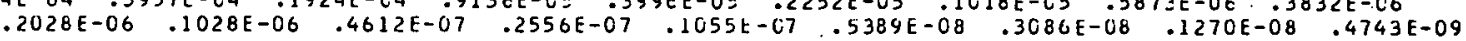


TABLE B-3. TEEPASITILIN FLUX.

SURFACE EEPLÉIJUN HLLEL, VIIU $=.018$

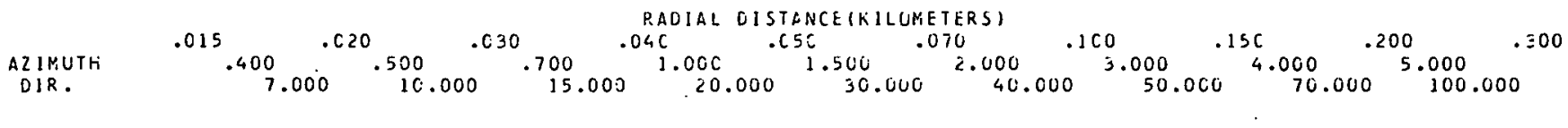

NNE .2371E-04 .1819E-04 .1147E-U4 .7597E-0S .5214E-C5 .2ES3E-05 .1155E-05 .4427E-06 .2232E-06 .9064E-07

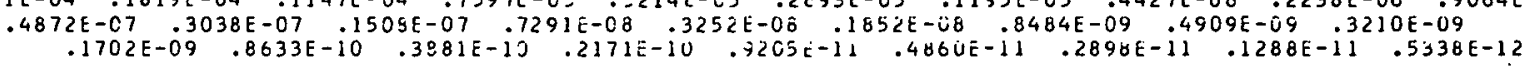

NE .4239E-04 .3306E-04 .2001E-04 .1266E-C4 .0400E-05 .41Y2E-05 .1852E-05 .7091E-06 .3670E-06 .1511E-06

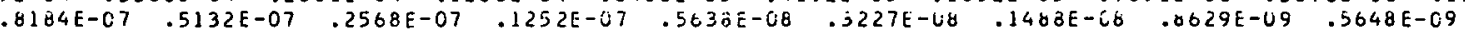
$.2997 E-09.1519 E-C 3$.6910E-10 .3807E-1C .1614E-10 .8527E-11 .5095E-11.2270E-11 .9414E-12

ENE .5610E-04 .441CE-04 .2696E-C4 .1720E-04 .115CE-04 .57b1E-05 .2558E-05 .9723E-06 .5007E-06 .2056E-06

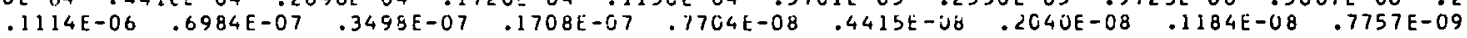

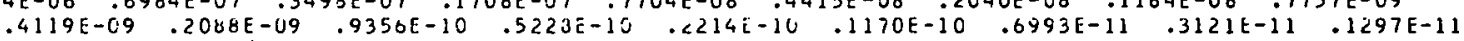

E .5484E-04 .4660E-04 .3070E-04 .2006E-04 .1343E-04 .6725E-C5 .2931E-05 .1103E-05 .5658E-06 .2307E-06

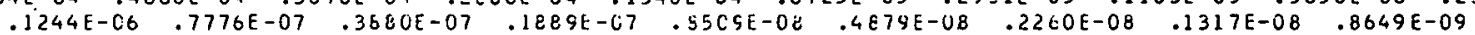

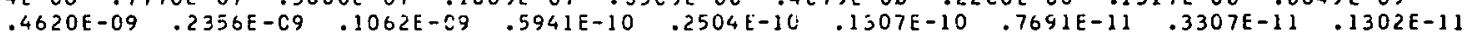

ESE .1327E-03 .10C9E-03 .5719E-04 .346EE-C4 .2247E-C4 .1103E-04 .4961E-US .1938E-C5 .1020E-05 .4266E-06

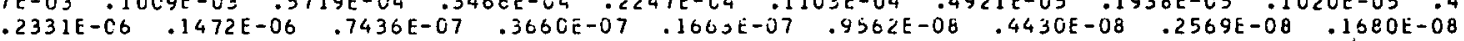
$.8889 \mathrm{E}-09$.44BCE-C9 .1995E-C; .111CE-0S .4717E-1C .2b12E-1C .1517E-10 .6921E-11 .2959E-11

SE .9479E-04 .7688E-04 .4093E-04 .2536E-04 .107UE-04 .8ं3U5E-05 .3694E-U5 .1431E-05 .7453E-06 .3083E-06

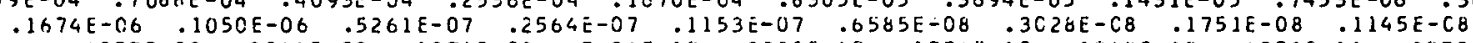

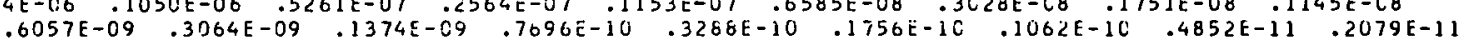

SSE $.2347 E-04 \quad .1772 E-04 \quad .1204 E-04 \quad .8454 E-05 \quad .6000 E-C 5 \quad .3183 E-05 \quad .14 C 9 E-05 \quad .5061 E-66 \quad .2503 E-06 \quad .9941 E-07 \quad$ $5283 \mathrm{E}-07 \quad .3265 \mathrm{E}-07 \quad .1597 \mathrm{E}-07 \quad .7604 \mathrm{E}-08 \quad .3330 \mathrm{E}-0 \mathrm{E} \quad .1875 \mathrm{E}-0 \mathrm{EE} \quad .8464 \mathrm{E}-09 . .4867 \mathrm{E}-0.09 .3172 \mathrm{E}-0.09$

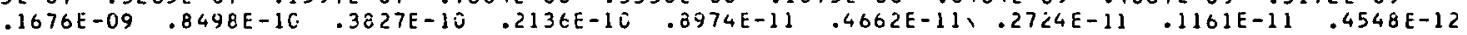

S.2436E-04 .1669E-04 .9992E-05 .6667E-05 .4E42E-C5 .2451E-05 .11C1E-05 .4069E-06 .2047E-06 .8265E-07

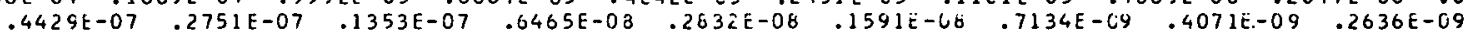

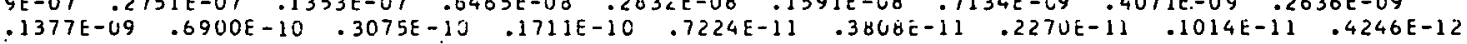

S5h .2629E-04 .1736E-04 .9399E-05 .5895E-05 .3979E-C5 .2CE4E-05 .93E9E-C6 .3591E-06 .1847E-06 .7549E-07

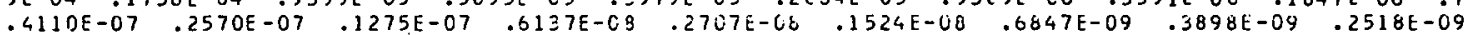

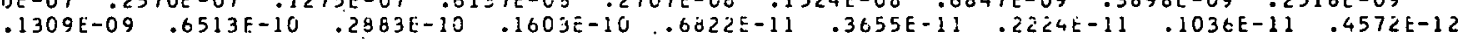

Sh .1622E-04 .1061E-04 .615BE-05 .411CE-L5 .2030E-05 .1540E-CE $.6975 E-C 6 \quad .2576 E-06 \quad .1294 E-06 \quad .5226 E-07$

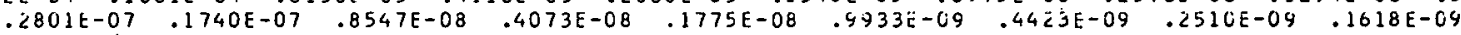

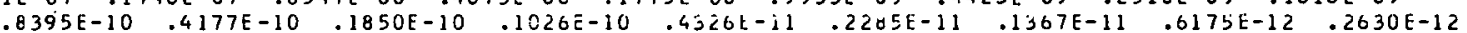

WSW .7804E-05 .5450E-05 .3826E-05 $.2845 E-05 \quad 02102 E-05 \quad .1165 E-05 \quad .5223 E-06 \quad .1225 E-06 \quad .8613 E-07 \quad .3453 E-07$

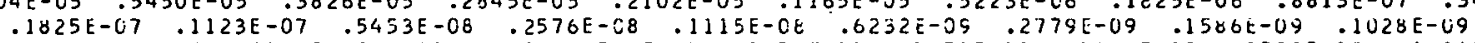

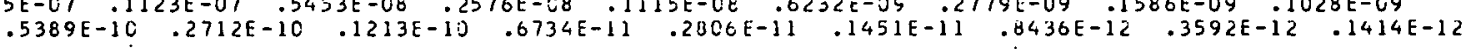

N.9878E-05 .6857E-05 .471CE-05 .346ZE-CE .2E44E-CE .14C5E-0b .6257E-06 .2210E-06 .1071E-06 .46C3E-07

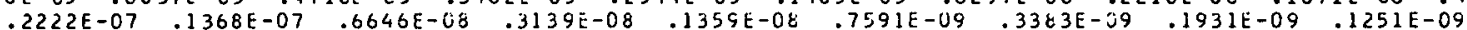
$.6556 \mathrm{E}-10$.3301E-10 .1479E-iJ .3220E-i1 .3441E-11. .1767E-11. .1645E-11.4498E-12.1798E-12

WNH .1256E-04 .8687E-05 .5772E-05 $.4156 \mathrm{E}-05 \quad .3021 \mathrm{E}-05 \quad .1654 \mathrm{E}-05 \quad .7415 \mathrm{E}-60 \quad .2626 \mathrm{E}-0 \mathrm{E} \quad .1281 \mathrm{E}-06.06054 \mathrm{E}-07$

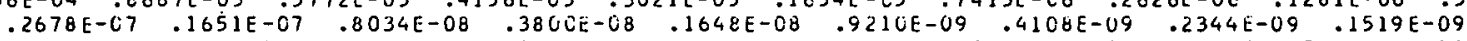

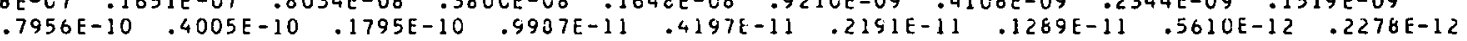

NW .1544E-04 .1127E-04 .7675E-05 $.5492 E-05 \quad .3901 E-05 \quad .2144 E-05 \quad .95501-C 0 \quad .3293 E-0 E \quad .1661 E-06 \quad .6561 E-07$

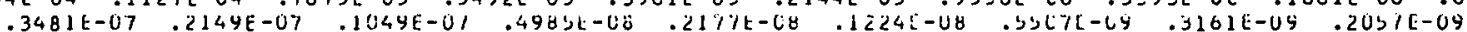

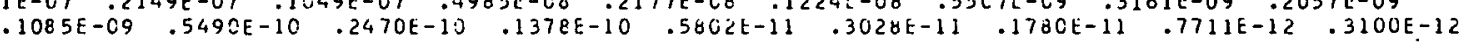

NNW .1371E-04 .1010E-04. .6593E-05 .4563E-05 .322aE-05 .1719E-05 .76EJE-G6 .2767E-06 .1372E-06 .5478E-07

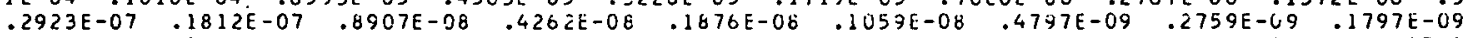
$.9478 \mathrm{E}-10 \quad .4791 \mathrm{E}-10 \quad .2149 \mathrm{E}-10 \quad .1198 \mathrm{E}-10 \quad .5049 \mathrm{E}-11 \quad .2644 \mathrm{E}-11 \quad .1562 \mathrm{E}-11 \quad .6834 \mathrm{E}-12 \quad .2781 \mathrm{E}-12$

N!. $.1320 E-C 4 \quad .1040 E-04 \quad .7281 E-05 \quad .5151 E-05 \quad .3665 E-05 \quad .1447 E-05 \quad .0599 E-06 \quad .3076 E-66 \quad .1517 E-06 \quad .6 C 21 E-67$

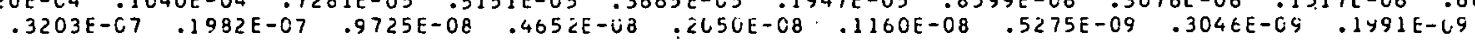

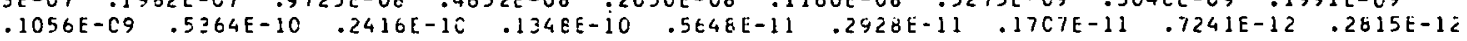

TOTAL .5675E-03 .4288E-03 .2607E-03 .1683E-03 .1138E-C3 .5600E-04 .2577E-04 .9715E-C5 .497UE-U5 .2031E-05

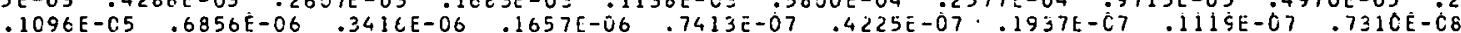

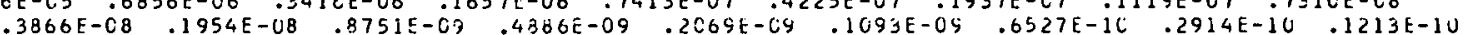


table B-4. INITIAL PLUME Air CEnCENTRATION.

SURFACE DEPLETION MOUEL, VU/L =.001

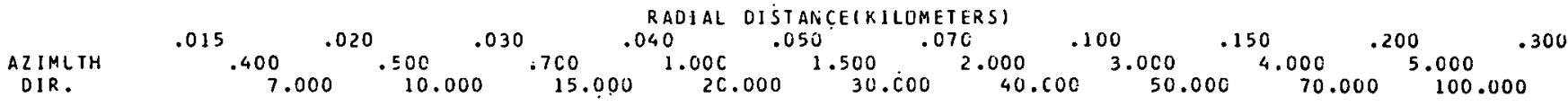

NNE .8775E-03 .7443E-03 .68777E-03 .5705E-03 .447UE-03 .2743E-03 .1476E-03 .6831E-04 .3882E-04 .1742E-04

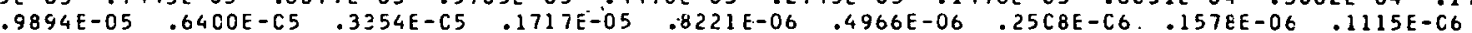
$.6705 \mathrm{E}-07.3984 \mathrm{E}-07 \quad .2235 \mathrm{E}-07 \quad .1488 \mathrm{E}-07.0291 \mathrm{E}-\mathrm{C} 8$.5396E-08 .3811E-08 .2177E-08 .1121E-08

NE .1214E-02 .1035E-02 .8414E-03 .6485E-03 .4902E-03 .2915E-03 .1546E-03 .7118E-04 .4047E-04 .1821E-04 $.1037 \mathrm{E}-04.6724 \mathrm{E}-0 \mathrm{~S} \quad .3537 \mathrm{E}-05$. $1818 \mathrm{E}-\mathrm{CS} .874 \mathrm{CE}-06$.5291E-06 .2678E-06 .1685E-06 .1189E-06

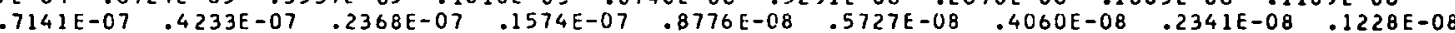

ENE .158CE-02 .1362E-02 .1118E-02 .8664E-03 .6570E-CE .3520E-03 .2083E-03 .9605E-04. .5465E-04 .2462E-04

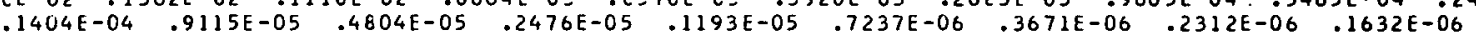

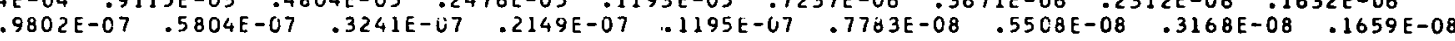

E $\quad .1688 \mathrm{E}-02 \quad .1564 \mathrm{E}-02 \quad .1296 \mathrm{E}-02 \quad .9866 \mathrm{E}-03 \quad .7390 \mathrm{E}-03 \quad .4354 \mathrm{E}-03 \quad .2257 \mathrm{E}-03 \quad .1 \mathrm{C56E-03} \quad .6008 \mathrm{E}-04 \quad .2709 \mathrm{E}-04$ $: 1546[-04 \quad 1004[-04 \quad .5300[-05$.27]GE-C5 .1322[-05 .00]1[-06 .4085[-06 .2579[-06.1824E-06

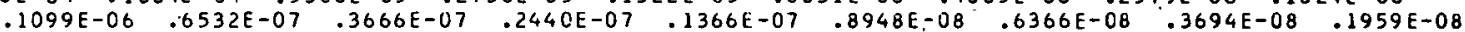

ESE $.3174 \mathrm{E}-02 \quad .2575 \mathrm{E}-02 \quad .1813 \mathrm{E}-02 \quad .1296 \mathrm{E}-02 \quad .9436 \mathrm{E}-03 \quad .5436 \mathrm{E}-03 \quad .2843 \mathrm{E}-03 \quad .1305 \mathrm{E}-03 \quad .7434 \mathrm{E}-04 \quad .3365 \mathrm{E}^{\circ}-04$

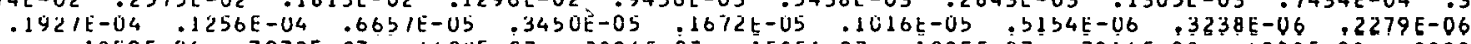

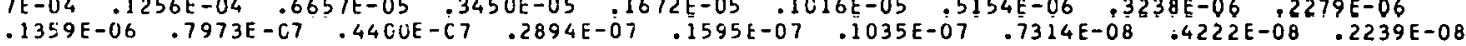

SE .2752E-02 .2175E-02 .1563E-02 .1140E-02 .8394E-03 .4dd5E-03 .2564E-03 .1177E-03 .6688E-04.3012E-04

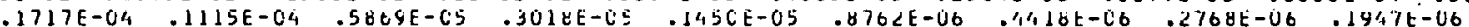
$\begin{array}{lllllllll}.1162 \mathrm{E}-06 & .6836 \mathrm{E}-07 & .3793 \mathrm{E}-07 & .2506 \mathrm{E}-07 & .1389 \mathrm{E}-07 & .9040 \mathrm{E}-08 & .6401 \mathrm{E}-08 & .0862 \mathrm{E}-08 & .0847 \mathrm{E}-08\end{array}$

SSE .1251E-C2 .1C17E-02 .9CESE-03 .7442E-02 .5805E-03 .3549E-03 .19C6E-03 .8809E-04 .5002E-04 .2241E-04 $.1271 \mathrm{E}-04$ :8215E-05 .4295E-05 .2194.E-05 .1046E-05 .6305E-06 .3174E-06 .1993E-06 .1406E-06

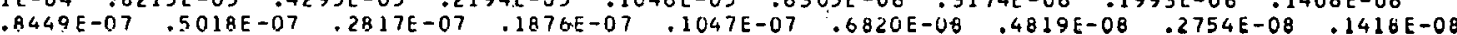

S.1508E-02 .1083E-02 .8432E-03 .6667E-03 .5134E-03 .3112E-03 .1666E-03 .7686E-04 .4362E-04 .1953E-04

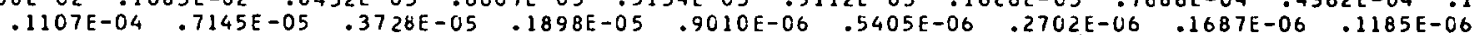

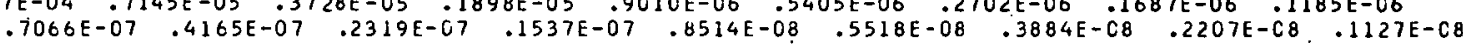

SSh .1395E-02 .9539E-03 .6839E-03 .5249E-02 .3995E-03 .2401E-03 .1280E-03 .590IE-04 .3348E-04. .1499E-04 $.8493 \mathrm{E}-05$.5480E-05 .2857E-05 .1453E-05 .6877E-06 .4115E-06 .2047E-06 .1273E-06 .8907E-07 $.5283 \mathrm{E}-07 \quad .3095 \mathrm{E}-07 \quad .1712 \mathrm{E}-07 \quad .1129 \mathrm{E}-07 \quad .6216 \mathrm{E}-08 \quad .4012 \mathrm{E}-08 \quad .2815 \mathrm{E}-00 \quad .1592 \mathrm{E}-08 \quad .8098 \mathrm{E}-09$

$5 h^{*} .1141 E-02 \quad .7886 E-03 \quad .5988 E-03 \quad .473 C E-03 \quad .1646 E-C 3 \quad .2214 E-03 \quad .1186 E-03 \quad .5474 E-04 \quad .3106 E-04.1390 E-04$ $.7870 \mathrm{E}-05$.5076E-05 .2645E-05 .1344E-0.5 .6366E-06 .3811E-06 .1900E-06 .1183E-06 .06297E-07

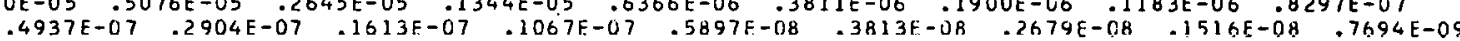

WSW .7262E-03 $\quad .5469 E-03 \quad .4995 E-03 \quad .4234 E-03 \quad .3360 E-03 \quad .2036 E-03 \quad .1129 E-03 \quad .5229 E-04 \quad .2970 E-04 \quad .1329 E-64$

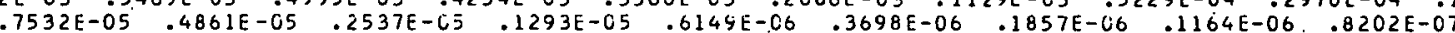

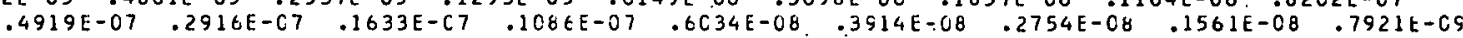

$k: \begin{array}{llllllllll}0195 \mathrm{E}-03 & .6222 \mathrm{E}-03 & .5736 \mathrm{E}-03 & .4876 \mathrm{E}-03 & .3873 \mathrm{E}-03 & .2406 \mathrm{E}-03 & .1302 \mathrm{E}-03 & .6036 \mathrm{E}-04 & .3428 \mathrm{E}-04 & .1535 \mathrm{E}-04\end{array}$

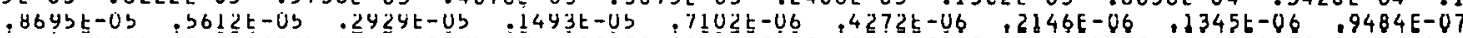

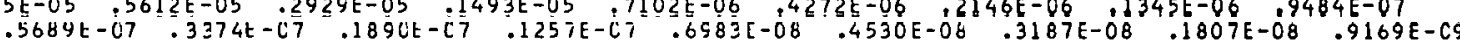

WNW .8394E-03 $.6470 E-03 \quad .6012 E-03 \quad .5113 E-03 \quad .4061 E-03 \quad .2522 E-03 \quad .1365 E-03 \quad .6326 E-04 \quad .3593 E-04 \quad .1609 E-04$ $.9115 E-05$.5883E-C5 .3071E-C5 .156EE-CE .7452E-06 .4484E-06 .2254E-C6. $1413 E-06$

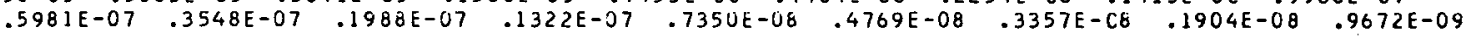

$\therefore N h \quad .9345 E-03 \quad .746 C E-C 3 \quad .6991 E-03 \quad .5918 E-03 \quad .4656 E-03 \quad .2902 E-03 \quad .1568 E-C 3 \quad: 7265 E-04 \quad .4127 E-04.04849 E-04$ $.1048 E-04 \quad .6770 E-05 \quad .3537 E-05 \quad .1806 E-05 \quad .8609 E-06 \quad .5187 E-06 \quad .2611 \mathrm{E}-06 \quad .1639 \mathrm{E}-06 \quad .1157 \mathrm{E}-06$ $.6950 \mathrm{E}-07 \quad .4127 \mathrm{E}-07 \quad .2315 \mathrm{E}-07 \quad .1541 \mathrm{E}-070.8576 \mathrm{E}-08 \quad .5572 \mathrm{E}-08 \quad .3927 \mathrm{E}-08 \quad .2233 \mathrm{E}-08 \quad .1140 \mathrm{E}-08$

$N N W \quad .7738 E-03 \quad .6193 E-03 \quad .5699 E-03 \quad .4783 E-03 \quad .3773 E-03 \quad .2329 E-03 \quad .1257 E-03 \quad .5823 E-04.03308 E-04 \quad .1483 E-04$

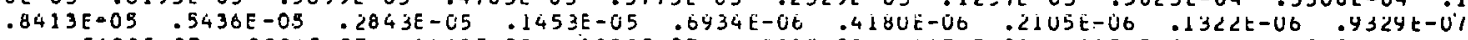

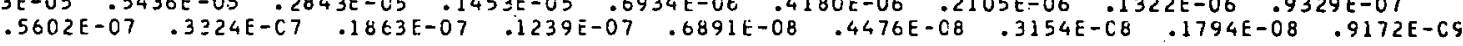

$N \quad .7283 E-03 \quad .6115 E-03 \quad .5776 E-03 \quad .4845 E-03 \quad .3015 E-03 \quad .2356 E-03 \quad 01266 E-03 \quad .5861 E-04 \quad .3330 E-04 \quad 01493 E-04$ $.8470 \mathrm{E}-05 \quad .5474 \mathrm{E}-05 \quad .2864 \mathrm{E}-05 \quad .1464 \mathrm{E}-05 \quad .6996 \mathrm{E}-06 \quad .4221 \mathrm{E}-06 \quad .2130 \mathrm{E}-06 \quad .1339 \mathrm{E}-06 \quad .9460 \mathrm{E}-0 \mathrm{0}$

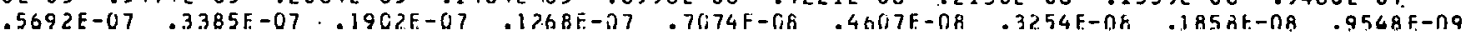

TOTAL .214CE-01 $.1709 E-01 \quad .1387 E-01 \quad .1089 E-01 \quad .8331 E-02 \quad .5 C 13 E-02 \quad .2673 E-02 \quad .1233 E-02 \quad .7010 E-03 \quad .3149 E-03$

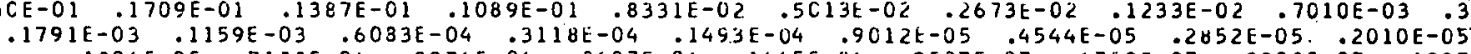

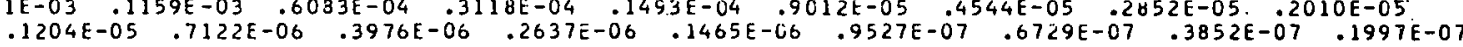


TABLE B-5. DEPOSITIUN FLUX.

SURFACE DEPLETILA MLDEL, VC/U =.001

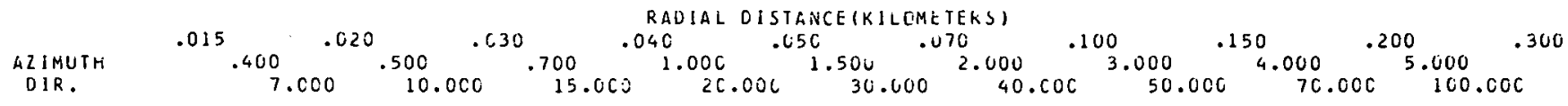

NNE .2400E-05 .1864E-G5 .1211E-U5 .8273E-06 .5379E-06 .3312E-06 .1711E-C6 .7818E-07 .4450E-07 .2015E-07

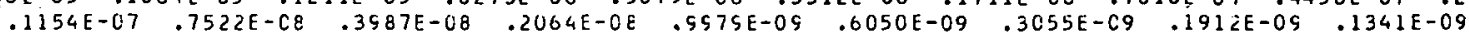

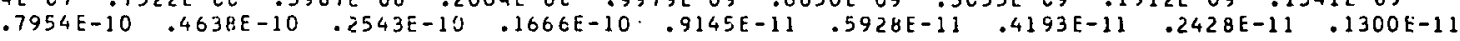

NE $\quad .4274 \mathrm{E}-05 \quad .3372 \mathrm{E}-05 \quad .2112 \mathrm{E}-05 \quad .139 \mathrm{CE}-05 \quad .9646 \mathrm{E}-06 \quad .5308 \mathrm{E}-06 \quad .2710 \mathrm{E}-060 \quad .1235 \mathrm{E}-06 \quad .7040 \mathrm{t}-07 \quad .3203 \mathrm{E}-07$

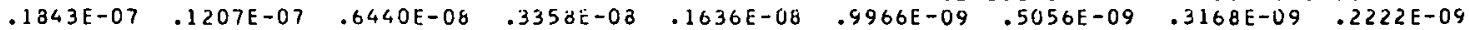
$.1315 \mathrm{E}-09.764 \mathrm{CE}-10 \cdot .4164 \mathrm{E}-1 \mathrm{C}$.271EE-1C .1484E-10 .5613E-11 .6005E-11.3963E-11 .2150E-11

ENE $.5646 E-05 \quad .4487 E-05 \quad .2841 E-05 \quad .1886 E-05 \quad .1316 E-05 \quad .7288 E-06 \quad .3735 E-06 \quad .1705 E-06 \quad .9730 E-07 \quad .4431 E-077$

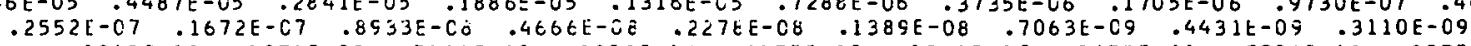

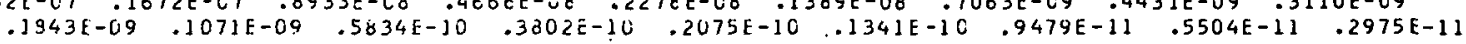

$\mathrm{E} \quad .5516 \mathrm{E}-05 \quad .4729 \mathrm{E}-\mathrm{C5} \quad .32 \mathrm{C2E}-05 \quad .2167 \mathrm{E}-05 \quad .1523 \mathrm{E}-05 \quad .8461 \mathrm{E}-06 \quad .4337 \mathrm{E}-\mathrm{C6} \quad .1978 \mathrm{E}-06 \quad .1127 \mathrm{E}-06 \quad .5127 \mathrm{E}-0 \mathrm{07}$ $.2949 \mathrm{E}-07 \quad .1930 \mathrm{E}-07 \quad .1030 \mathrm{E}-07 \quad .5377 \mathrm{E}-08 \quad .2626 \mathrm{E}-08 \quad .1604 \mathrm{E}-08 \quad .8166 \mathrm{E}-09 \quad .5158 \mathrm{E}-09 \quad .3635 \mathrm{E}-099$

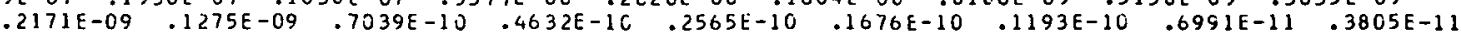

ESE .1334E-04 .1025E-04 .6065E-05 .3663E-05 .2635E-05. $1427 E-05 \quad .7242 E-C 6 \quad .3300 E-06 \quad .1888 E-06 \quad .8646 E-07$ $.5005 \mathrm{E}-07.3293 \mathrm{E}-07 \quad .1771 \mathrm{E}-07 \quad .9308 \mathrm{E}-08 \quad .4571 \mathrm{E}-06 \quad .2796 \mathrm{E}-08 \quad .1422 \mathrm{E}-08 \quad .8906 \mathrm{E}-099 \quad .6230 \mathrm{E}-099$

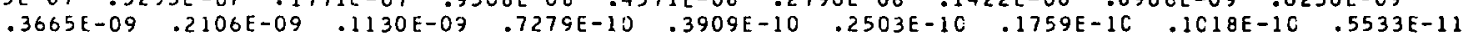

SE . $5569 E-05 \quad .7252 E-05 \quad .4351 E-05 \quad .2 E 12 \mathrm{E}-05 \quad .1935 E-C 5 \quad .1057 E-05 \quad .5376 E-06 \quad .2446 E-06 \quad .1394 E-06 \quad .6338 E-07$ $.3646 \mathrm{E}-07.2335 \mathrm{E}-07$.1271E-07 .6616E-08 $.3213 \mathrm{E}-08.1951 \mathrm{E}-08.0853 \mathrm{E}-09.0914 \mathrm{SE}-09.09297 \mathrm{E}-09$ $.2530 \mathrm{E}-09 \quad .1460 \mathrm{E}-09 \quad .7897 \mathrm{E}-10 \quad .5122 \mathrm{E}-10 \quad .278 \mathrm{CE}-10 \quad .1792 \mathrm{E}-1 \mathrm{C} \quad .1265 \mathrm{E}-10 \quad .7348 \mathrm{E}-11 . .3985 \mathrm{E}-11$

SSE .2405E-05 .1241E-05 .1272E-05 .9068E-06 .6598E-06 .3795E-06 .1978E-06 .9041E-07 .5128E-07 .2303E-07 $.1309 E-07 \quad .8477 E-08 \quad .4443 E-08 \quad .2272 E-08 \quad .1 C 84 E-08 \quad .6515 E-09 \quad .3262 E-09 \quad .2036 E-09 \quad .1428 E-09$

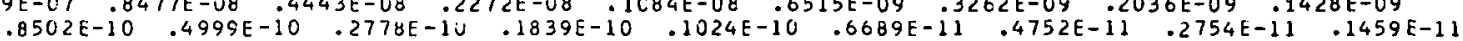

$S \quad .2505 E-05 \quad .174 E E-05 \quad .1072 E-05 \quad .7294 E-06 \quad .5198 E-06 \quad .2941 E-06 \quad .1523 E-06 \quad .6942 E-07 \quad .3937 E-07 . .1768 E-07$

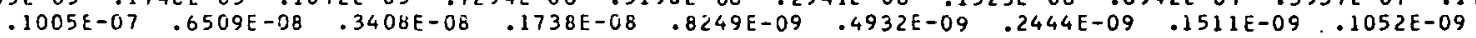

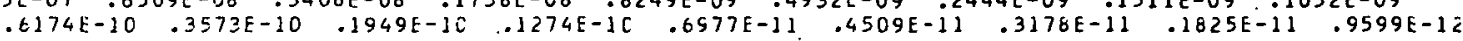

SSh .2695E-C5 .1814E-05 .1019E-C5 $.6592 E-06 \quad .4575 E-06 \quad .2530 E-06 \quad .1296 E-06 \quad .5894 E-07 \quad .3347 E-07 \quad .1508 E-07$ $.8602 \mathrm{E}-08 \quad .5583 \mathrm{E}-08 \quad .2534 \mathrm{E}-0 \mathrm{~d} \quad .1501 \mathrm{E}-0 \mathrm{O} \quad .7134 \mathrm{E}-09 \quad .4262 \mathrm{E}-09 \quad .21 \mathrm{C} 3 \mathrm{E}-\mathrm{C9} \quad .1292 \mathrm{E}-09 \quad .8928 \mathrm{E}-10$

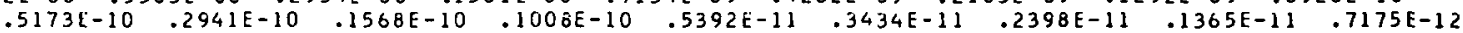

SW .167EE-0S .1119E-05 .6656E-06 .4515E-06 .3222E-06 .1829E-06 .9425E-C7 .4325E-07 .2451E-07 .1099E-07

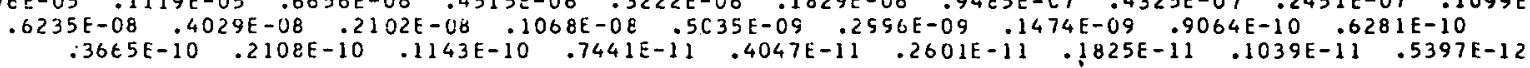

WSH .8099E-0E .5749E-06 .4CE3E-UE .3032E-06 .2269E-06 .1342E-06 .7094E-C7 .3256E-07 .1846E-07 .8257E-08

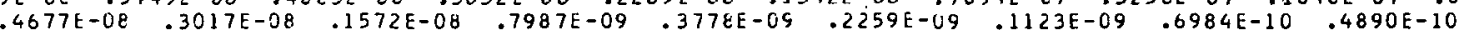

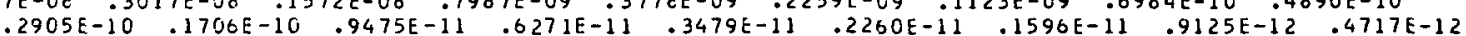

W. $.1023 \mathrm{E}-05 \quad .7226 \mathrm{E}-06 \quad .5012 \mathrm{E}-06 \quad .3703 \mathrm{E}-06 \quad .2758 \mathrm{E}-06 \quad .1624 \mathrm{E}-06 \quad .8568 \mathrm{E}-\mathrm{C} 7 \quad .3930 \mathrm{E}-07 \quad .2227 \mathrm{E}-07 \quad .9959 \mathrm{E}-08$ $.5640 E-C 8 \quad .3638 E-08 \quad .18 .95 E-08 \quad .9619 E-09 \quad .4546 E-09 \quad .2716 \mathrm{E}-09 \quad .1349 \mathrm{E}-09 \quad .8375 \mathrm{E}-10 \quad .5858 \mathrm{E}-10$

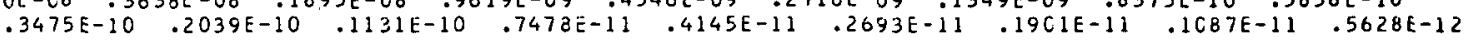

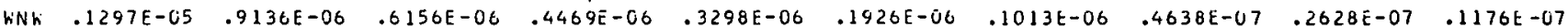

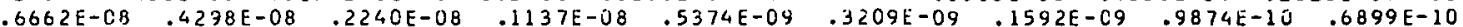

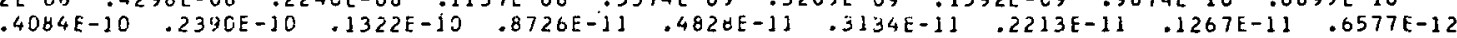

Nh .1565E-G5 .I175E-05 .8127E-0O .58GZE-GO .4335E-06 .2523E-C6 .1323E-C6 .0663E-07 .3439E-07 .1543E-U7

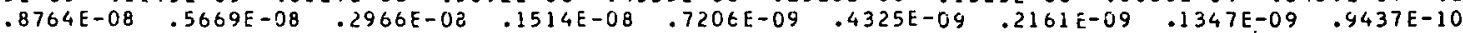

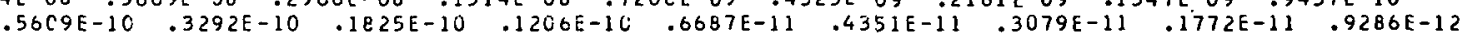

NNh $\quad .1400 E-05 \quad: 1047 E-05 \quad .6986 E-06 \quad .4932 E-06 \quad .3577 E-66 \quad .2055 E-06 \quad .1072 E-06 \quad .4904 E-07 \quad .2786 E-07 \quad .1254 E-07$

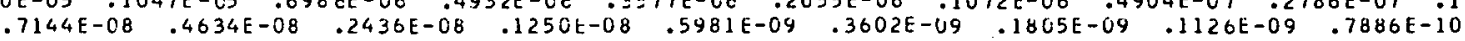

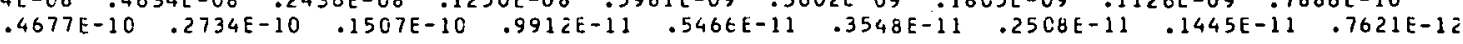

N $\quad .1347 E-05 \quad .1073 E-05 \quad .7642 E-06 \quad .5506 E-06 \quad 04024 E-66 \quad .2324 E-06 \quad .1214 E-06 \quad .5561 E-07 \quad .3159 E-07 \quad .1422 E-07$ $.8108 \mathrm{E}-08$.5262E-08 .277CE-C8 .1424E-0E .6E35E-0S .4129E-09.2C61E-C9.1304E-0S. . $168 \mathrm{E}-10$

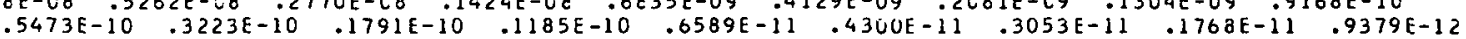

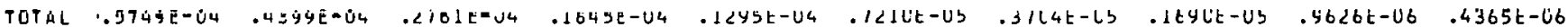

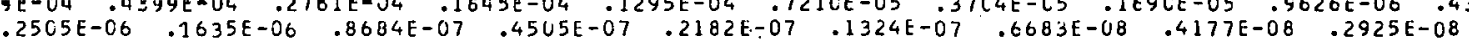

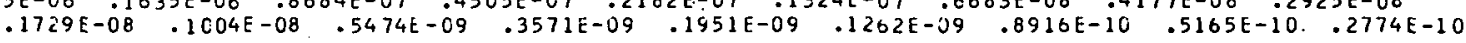


TABLE B-6. INITIAL. PLLME AIR CONCENTRATION.

SOURCE DEPLETIUN MODEL, VO/U $=.01 \mathrm{C}$

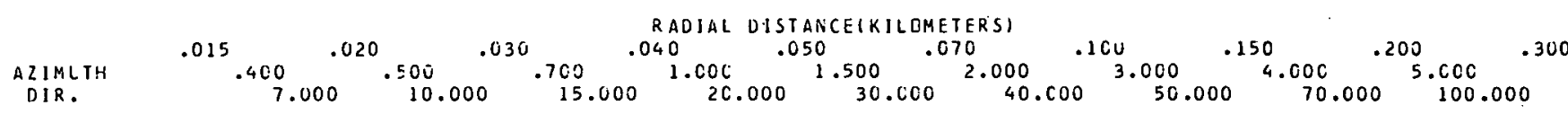

NNE $\quad .8473 E-03 \quad .7166 E-03 \quad .6561 E-03 \quad .5285 E-03 \quad .3989 E-03 \quad .2277 E-03 \quad .1127 E-C 3 \quad .4726 E-04 \quad .2500 E-04 \quad .1008 E-04$ $.5293 \mathrm{E}-05 \quad .3213 \mathrm{E}-05 \quad .1519 \mathrm{E}-05$.05 .6965-06 .2836E-06 .1547E-06 .6485E-C7 .3491E-07 .2139E-07

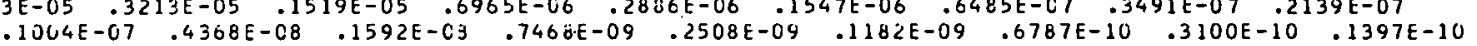

NE $.1175 E-02 \quad .9952 E-03 \quad .7957 E-03 \quad .5954 E-03 \quad .4346 E-C 3 \quad .2420 E-03 \quad .1189 E-03 \quad .5005 E-04 \quad .2666 E-04 \quad .1090 E-04$

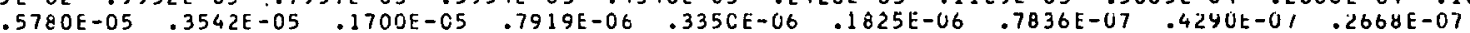
$\begin{array}{llllllll}.1287 \mathrm{E}-07 & .5793 \mathrm{E}-08 & .2209 \mathrm{E}-08 & .1070 \mathrm{E}-08 & .3688 \mathrm{E}-09 & .1723 \mathrm{E}-09 & .9653 \mathrm{E}-10 . & .4187 \mathrm{E}-10 \quad .1776 \mathrm{E}-\mathrm{i} 0\end{array}$

ENE .1532E-02 .1310E-02 .1056E-0Z .7951E-03 .5822E-03 .3251E-03 .1599E-03 .6733E-04 .3587E-04. .1466E-04

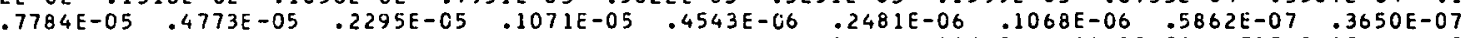
$\begin{array}{llllllll}.1764 \mathrm{E}-07 & .7961 \mathrm{E}-08 & .3049 \mathrm{E}-08 & .1483 \mathrm{E}-08 & .5151 \mathrm{E}-09 & .2412 \mathrm{E}-09 & .1347 \mathrm{E}-09 & .5752 \mathrm{E}-10 \quad .2367 \mathrm{E}-10\end{array}$

E .1641E-02 .15U8E-02 .1223E-02 .9018E-03 .6521E-03 .3601E-03 .1763E-03 .7423E-04 .3960E-04.1624E-04

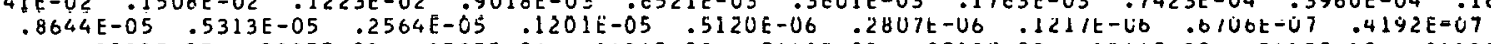

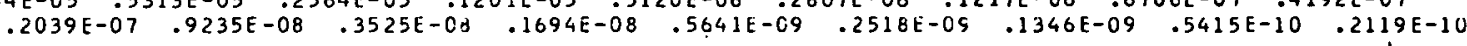

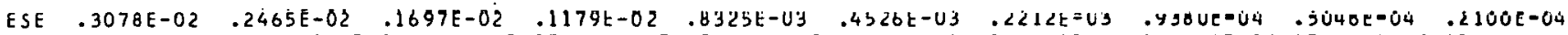
$.1131 \mathrm{E}-\mathrm{C} 4.7024 \mathrm{E}-05 \quad .3444 \mathrm{E}-05$. $1639 \mathrm{E}-05$. $712 \equiv \mathrm{E}-0 \mathrm{E}$.3960E-06 .1746E-06 .9740E-07 .6144E-07 $.3045 \mathrm{E}-07.1418 \mathrm{E}-07 \quad .5684 \mathrm{E}-08 \quad .2868 \mathrm{E}-08 \quad .1050 \mathrm{E}-08 \quad .5044 \mathrm{E}-09 \quad .2838 \mathrm{E}-09 \quad .1201 \mathrm{E}-09.4484 \mathrm{E}-10$

SF .2661E-0? .2083E-02 .1469E-02 .1042E-02 .7437E-03 .4675E-03 .1955E-03 .8433E-04 $\quad 4518 E-04 \quad .1866 E-04$

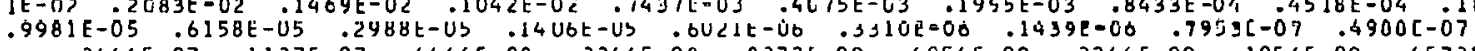

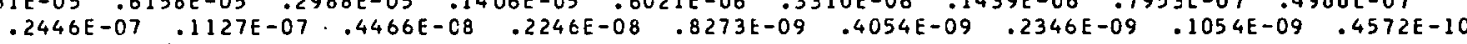

SSE .1205E-02 .9787E-03 .8656E-03 .6900E-03 .5187E-03 .2953E-03 $.1460 E-03 \quad .6125 E-04 \quad .3242 E-04 \quad .1308 E-04$ $.6865 \mathrm{E}-05 \quad .4167 \mathrm{E}-05 \quad .1968 \mathrm{E}-05 \quad .9007 \mathrm{E}-0 \mathrm{E} \quad .3722 \mathrm{E}-06 \quad .1990 \mathrm{E}-06 \quad .8306 \mathrm{E}-07 \quad .4457 \mathrm{E}-07 \quad .2726 \mathrm{E}-07$

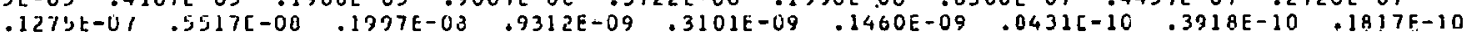

$S \quad 1449 E-02 \quad .1037 E-02 \quad .8035 E-03 \quad .6196 E-03 \quad .4610 E-03 \quad .2610 E-03 \quad .1291 E-03 \quad .5434 E-04 \quad .2886 E-04 \quad 01171 E-04$ $.6174 \mathrm{E}-05 \quad .3760 \mathrm{E}-05 \quad .1785 \mathrm{E}-05 \quad .82,04 \mathrm{E}-06 \quad .3404 \mathrm{E}-06 \quad .1825 \mathrm{E}-06 \quad .7634 \mathrm{E}-0 \mathrm{C} 7.4104 \mathrm{E}-07 \quad .2516 \mathrm{E}-07$

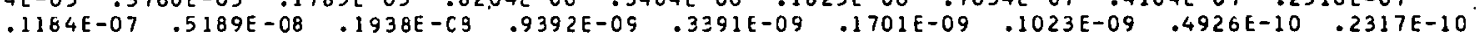

SSW .134CE-02 .9110E-03 .6499E-03 .4877E-03 $.3594 E-03 \quad \ldots 2023 E-03 \quad .10 C 0 E-03 \quad .4221 E-04 \quad .2248 E-04 \quad .9166 E-05$

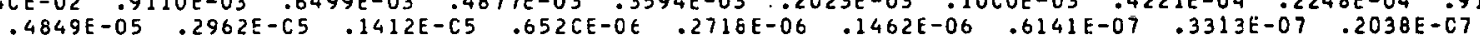

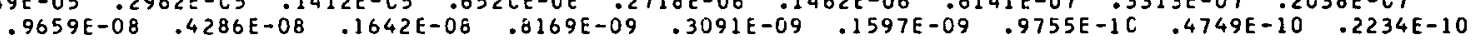

Sh .1C95E-02 .7546E-03 .5713E-03 .4405E-C3 .3283E-03 .11E62E-03 .9220E-C4 .3884E-04 .2063E-04 .8372E-05 $\begin{array}{lllllllll}.4412 \mathrm{E}-05 & .2686 \mathrm{E}-05 & .1274 \mathrm{E}-05 & .5850 \mathrm{E}-06 & .2423 \mathrm{E}-06 & .1296 \mathrm{E}-06 & .5402 \mathrm{E}-07 & .2897 \mathrm{E}-0 \mathrm{0} & .1773 \mathrm{E}-07\end{array}$

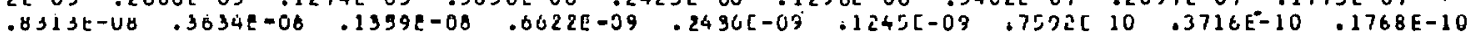

WSW $.698 C E-03 \quad .5259 E-03 \quad .4795 E-03 \quad .3953 E-03 \quad .3020 E-03 \quad .1741 E-03 \quad .6649 E-C 4 \quad .3628 E-04 \quad .1916 E-04 \quad .7699 E-05 \quad$

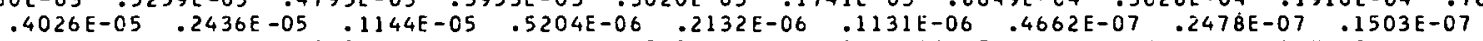

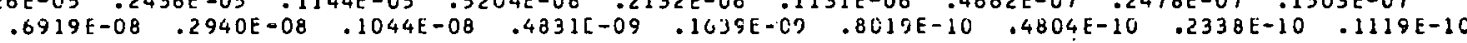

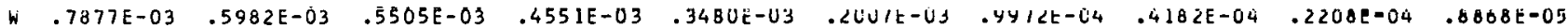
$.4635 \mathrm{E}-05 \quad .2803 \mathrm{E}-05$.1316E-05 .5985E-06 .2451E-06. .1300E-06 .5356E-07.2847E-07 .1726E-07

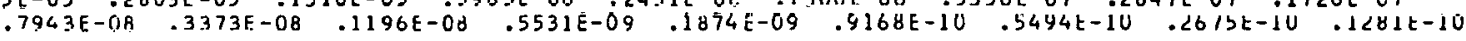

HNh $.8069 E-C 3 \quad .6218 E-03 \quad .5765 E-03 \quad .4768 E-03 \quad .3645 E-C Z \quad .2102 E-03 \quad .1044 E-03 \quad .4376 E-64 \quad .2311 E-04 \quad .9276 E-05$

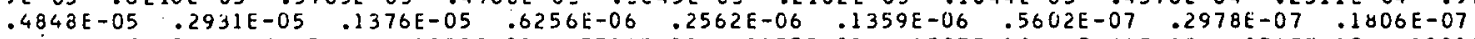
$\begin{array}{llllllll}.8315 \mathrm{E}-08 & .3533 \mathrm{E}-\mathrm{CB} & .1253 \mathrm{E}-08 & .5786 \mathrm{E}-09 & .1955 \mathrm{E}-09 & .9527 \mathrm{E}-10 & .5694 \mathrm{E}-1 \mathrm{C} & .2765 \mathrm{E}-10 \quad .1321 \mathrm{E}-10\end{array}$

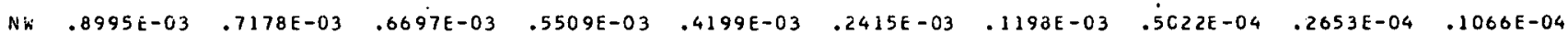
$.5575 E-05$.3374E-05 .1586E-05 .7226E-06 .2967E-06 .1578E-06 .6534E-007.3485E-07 .2119E-07

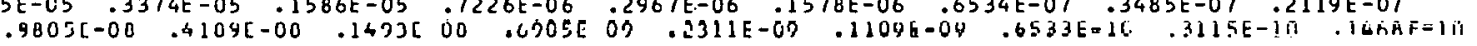

$N N{ }^{2} .7453 E-03 \quad .5956 E-03 \quad .5452 E-03 \quad .4446 E-03 \quad .3378 E-03 \quad .1938 E-03 \quad .9611 E-04 \quad .4031 E-04 \quad .2131 E-04 \quad .8577 E-05$

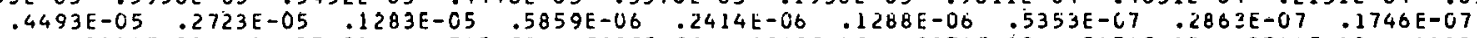

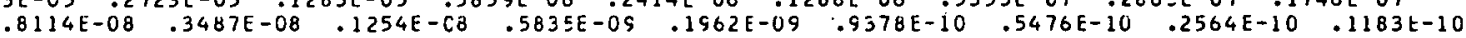

$N \quad .7024 E-03 \quad .5896 E-03 \quad .5526 E-03 \quad .4498 E-03 \quad .3409 E-03 \quad .1952 E-03 \quad .9666 E-64 \quad .4 C 52 E-04 \quad .2142 E-04 \quad .8619 E-05$

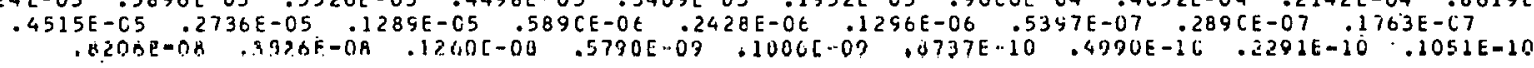

TOIAL .2066E-01 .1641E-01 .1316E-01 .1005E-01 .7424E-02 .4175E-02 .2059E-02 .0665E-03 .4608E-03 .1870E-03

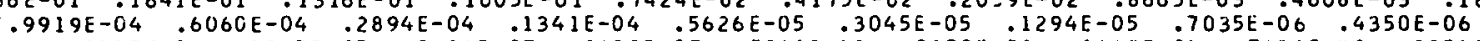

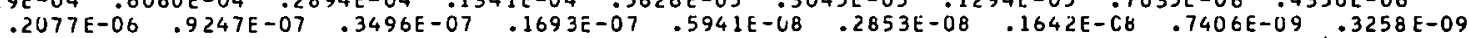


TABLË B-7. OEPDSITILIN. FLUX.

SUUKCE DEPLETIUN MODEL, VO/L = .01C

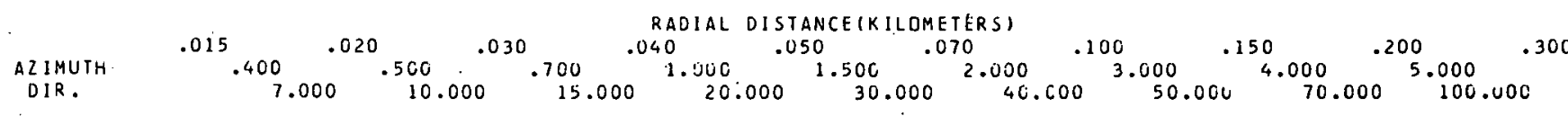

NNE $.2323 E-04 \quad .1780 E-04 \quad .1129 E-04 \quad .7499 E-05 \quad .5179 E-05 \quad .2768 E-05 \quad .1346 E-05 \quad .5729 E-06 \quad .3098 E-06 \quad .1301 E-066$

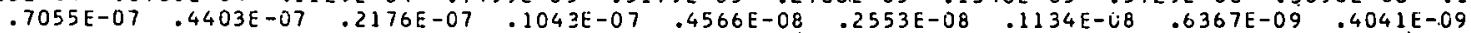

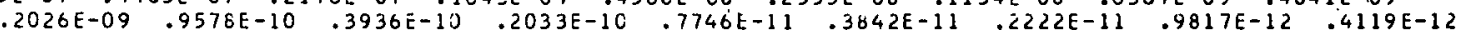

NE $\quad .4145 E-04 \quad .3220 E-04 \quad .1959 E-04 \quad .1252 E-04 \quad .8453 E-05 \quad .4433 E-05 \quad .2145 E-05 \quad .9170 E-06 \quad .4993 E-06 \quad .2124 E-C 6$ $.1163 \mathrm{E}-06 \quad .7321 \mathrm{E}-07 \quad .3666 \mathrm{E}-07 \quad .178 \mathrm{CE}-07 \quad .7916 \mathrm{E}-08 \quad .4476 \mathrm{E}-08 \quad .2017 \mathrm{E}-\mathrm{CO} \quad .1142 \mathrm{E}-088.7293 \mathrm{E}-09$

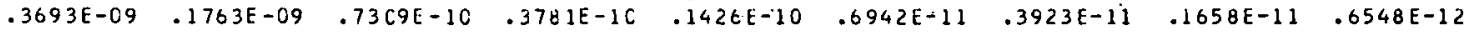

ENE $.5475 E-04 \quad .4284 E-04 \quad .2635 E-04 \quad .1699 E-04 \quad .1154 E-64 \quad .6 C 80 E-05 \quad .2947 E-C 5 \quad .1260 E-05 \quad .6852 E-06 \quad .2911 E-06$

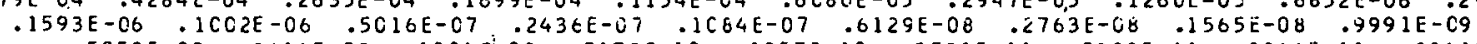

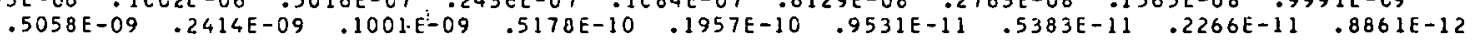

$E^{*} .5366 E-04 \quad .4535 E-04 \quad .2975 E-04 \quad .1952 E-04 \quad .1331 E-04 \quad .7019 E-05 \quad .3355 E-C 5 \quad .1445 E-05 \quad .7636 E-06 \quad .3311 E-06$ $.1805 E-06 \quad .1132 \mathrm{E}-06 \quad .5639 \mathrm{E}-07: .2725 \mathrm{E}-07.1207 \mathrm{E}-07$.67 .682E-08 .3059E-C8 .1728E-08.11201E-08

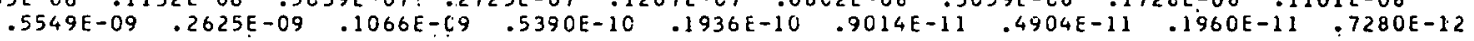

ESE $.1294 E-03 \quad .9769 E-04 \quad .5598 E-04 \quad .3464 E-04 \quad .2304 E-04 \quad .1195 E-04 \quad .5779 E-05 \quad .2487 E-05 \quad .1364 E-05 \quad .5877 E-06$

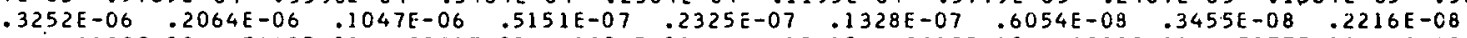

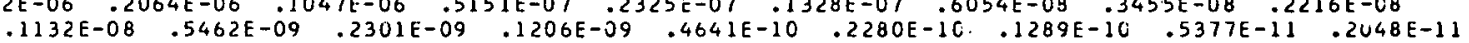

SE $.9266 E-04 \quad .6910 E-04 \quad .4029 E-04 \quad .2532 E-04 \quad .1698 E-04 \quad .8865 E-05 \quad .4288 E-C 5 \quad .1837 E-05 \quad .1602 E-05 \quad .4278 E-06$ $.2349 \mathrm{E}-06$.1481E-06 .7431E-07 .3614E-07 .1610E-07 .9112E-08 .4111E-08 .2332E-08 .1491E-08

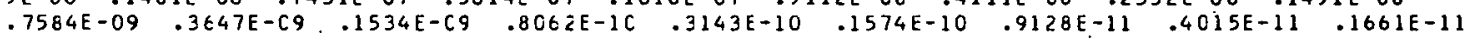

SSE .2320E-04 .1762E-04 .1195E-04 .8292E-C5 .5351E-05..3177E-05 .1550E-C5 .6554E-0E .3515E-06 .1454E-06 $.7782 \mathrm{E}-07.4802 \mathrm{E}-07$.2328E-C7 .1093E-07 .4E61E-08 .2555E-08 .11COE-C8 .6091E-05 .3816E-C9

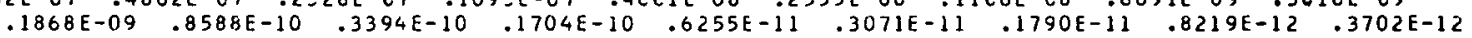

$S \quad: 2412 E-04 \quad .1665 E-04 \quad .1004 E-04 \quad .6675 E-05 \quad .4632 E-05 \quad .2440 E-05 \quad .1215 E-C 5 \quad .5167 E-04 \quad .2789 E-06 \quad .1165 E-06$

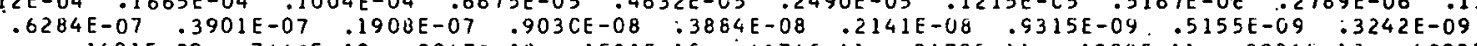

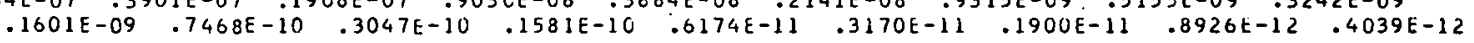

SSW $.2595 E-04 \quad .1723 E-04 \quad .9468 E-05 \quad .6008 E-05 \quad .4077 E-05 \quad .2157 E-05 \quad .1050 E-05 \quad .4499 E-06 \quad .2448 E-06 \quad .1037 E-06$

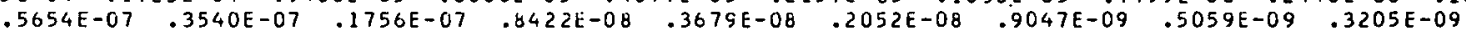

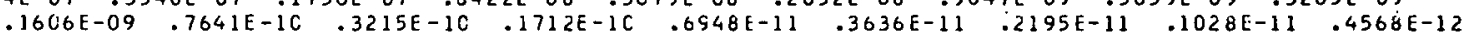

SW. $.1611 E-04 \quad .1065 E-U 4 \quad .6243 E-05 \quad .4148 E-05 \quad .2386 E-05 \quad .1557 E-05 \quad 0.7611 E-C 6 \quad .3241 E-06 \quad .1749 E-06 \quad .7303 E-07$

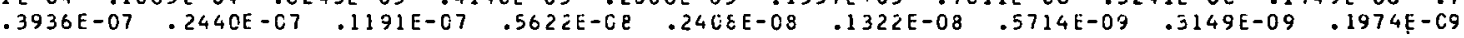

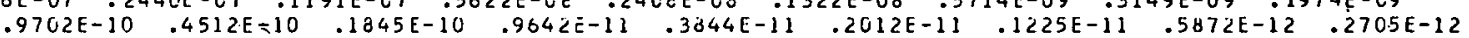

WiSh .778EE-05 .5496E-05 .3848E-05 .28C3E-C5 . 2C 32E-C5 .112SE-05 .55E3E-L6 .2343E-0E .1250E-06 .5115E-07

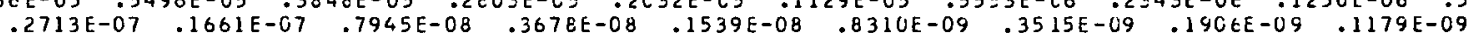

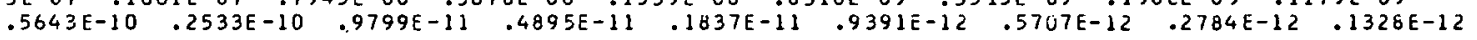

W. $.9830 E-05 \quad .6901 E-05 \quad .474$ CE-05 $.3419 E-05 \quad .2469 E-05 \quad .1367 E-05 \quad .6717 E-60 \quad .2836 E-06 \quad .1514 E-06 \quad .6203 E-07$ $.3293 \mathrm{E}-07 \quad .2018 \mathrm{E}-07 \quad .9664 \mathrm{E}-08 \quad .4478 \mathrm{E}-08.08 .1877 \mathrm{E}-08 \quad .1014 \mathrm{E}-08 \quad .4298 \mathrm{E}-09 \quad .2334 \mathrm{E}-09.1446 \mathrm{E}-09$

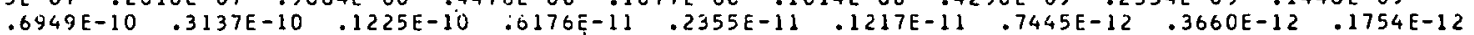

WNW .1247E-04 .8717E-05 .5808E-05 .4117E-05 $.2949 E-05 \quad .1623 E-05 \quad .7903 E-06 \quad .3365 E-06 \quad .1800 E-06 \quad .7400 E-07$

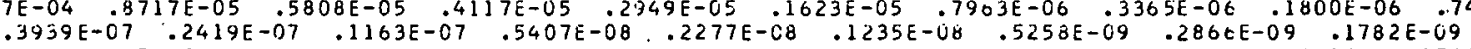

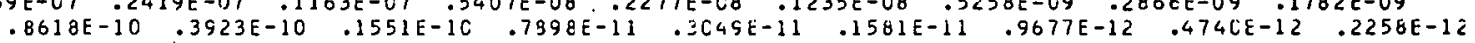

$\mathrm{NH} .1527 \mathrm{E}-04 \quad .1123 \mathrm{E}-04 \quad .7652 \mathrm{E}-05 \cdot .5407 E-05 \quad .3358 \mathrm{E}-05 \quad .2116 \mathrm{E}-05 \quad .1036 \mathrm{E}-05 \quad .4379 \mathrm{E}-06 \quad .2344 \mathrm{E}-06 \quad .9658 \mathrm{E}-07$ $.5153 \mathrm{E}-07.3171 \mathrm{E}-07$.1531E-C7 .715EE-CE .3C 3EE-08 .1657E-08.7128E-09.3912E-09.2444E-C9

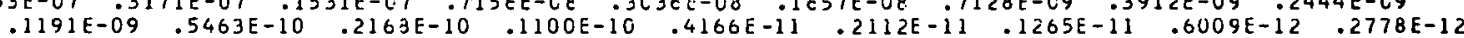

NNG .1351E-04 .9996E-05 .655CE-05 .45CEE-05 .2173E-C5 .1723E-05 .8417E-C6 .3568E-0E .1918E-06 .7965E-07

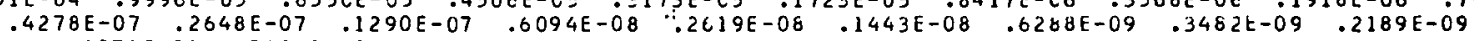
$.1079 \mathrm{E}-09.5008 \mathrm{E}-10$. $2016 \mathrm{E}-10$. $1030 \mathrm{E}-1 \mathrm{C}$.3909E-11 .1959E-11. .1153E-11.5283E-12.2333E-12

$N \quad .1302 E-04 \quad .1028 E-04 \quad .7180 E-05 \quad .5027 E-05 \quad .3560 E-05 \quad .1938 E-05 \quad .9466 E-C 6 \quad .04 C 03 E-06 \quad .2147 E-06 \quad .8883 E-07$

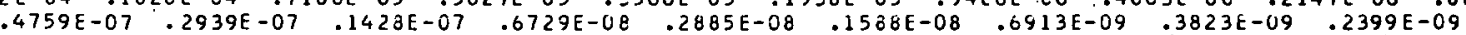
$.1178 \mathrm{E}-09.5425 \mathrm{E}-10 \quad .2142 \mathrm{E}-10$.1071E-10 .3875E-11 .1867E-11 .1066E-11 $.4714 \mathrm{E}-12 \quad .2027 \mathrm{E}-12$

TOTAL .5565E-03 $.4198 E-03 \quad .2568 E-U 3 \quad .1669 E-03 \quad .1140 E-03 \quad .6040 E-04 \quad .2933 E-04 \quad .1251 E-04 \quad .6792 E-05 \quad .2871 E-05$ $.1565 E-05 \quad .9805 E-06 \quad .4875 E-06 \quad .2350 E-06 \quad .1036 E-06 \quad .5819 E-07 \quad .2599 E-07 \quad .1464 E-07 \quad .9309 E-08$

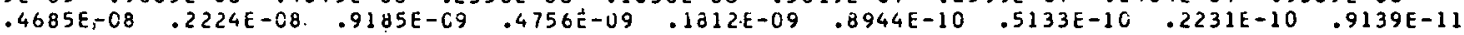


tABLE B-8. INITIAL PLUME AIR CCACEITRATICA.

SOURCE DEPLETIUN MDDEL, VU/U $=.001$

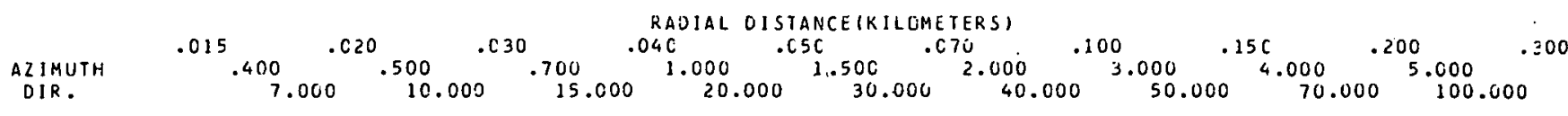

NNE $\quad .8769 E-03 \quad .7440 E-03 \quad .6869 E-03 \quad .5684 E-03 \quad .4443 E-03 \quad .2724 E-03 \quad .1477 E-03 \quad .6954 E-04 \quad .4007 E-04 \quad .1830 E-04$ $.1051 \mathrm{E}-04 \quad .6852 \mathrm{E}-05 \quad .3627 \mathrm{E}-05 \quad .1876 \mathrm{E}-05 \quad .9065 \mathrm{E}-06 \quad .5508 \mathrm{E}-06 \quad .2806 \mathrm{E}-06 \quad .1775 \mathrm{E}-06 \quad .1257 \mathrm{E}-06$

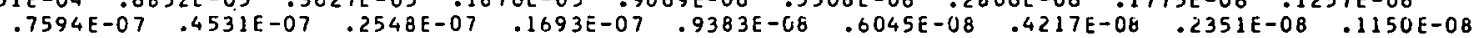

NE $.1213 E-02 \quad .1034 E-02 \quad .8398 E-03 \quad .6462 E-03 \quad .4879 E-03 \quad .2904 E-03 \quad .1552 E-03 \quad .7259 E-04 \quad .4177 E-04 \quad .1909 E-04$

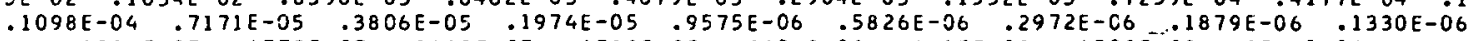

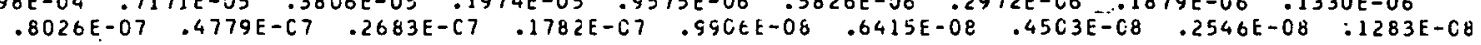

ENE .1578E-02 .136CE-02 .1116E-02 .8634E-03 .6539E-03 .39U4E-03 .2091E-03 .9793E-04 .5642E-04 .2582E-04 $.1487 E-04$. $9724 E-05$.5171E-05 .2689E-05 .13U6E-05 .797UE-06 .4074E-C6 .2579E-06 .1826E-06 $\begin{array}{lllllllll}.1102 \mathrm{E}-06 & .6553 \mathrm{E}-07 & .3672 \mathrm{E}-07 & 07436 \mathrm{E}-07 & .1350 \mathrm{E}-07 & .8728 \mathrm{E}-08 & .0118 \mathrm{E}-08 & .3454 \mathrm{E}-088 & .1738 \mathrm{E}-08\end{array}$

- $.16 C C E-02 \quad .1561 E-02 \quad 01292 E-02 \quad .9825 E-03 \quad .7354 E-03 \quad .4341 E-03 \quad \cdot 23 C 9 E-C 3 \quad .1 C 78 E-03 \quad .6206 E-04 \quad .2840 E-04$ $.1636 E-C 4 \quad .1 C 71 E-04 \quad .5698 E-C 5 \quad .2967 E-05 \quad .1445 E-C 5 \quad .8825 E-06 \quad .1523 E-06 \quad .2868 E-06 \quad .2035 E-C 6$

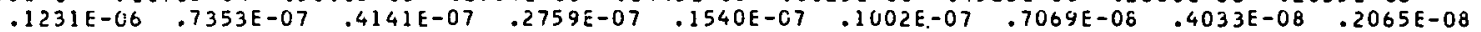

ESF .3168E-02 .2569E-02 .18CSE-02 .1293E-02 .9415E-C3 .5436E-03 .2863E-C3 .1332E-03 .767CE-04 .3518E-04

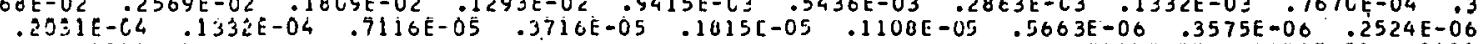

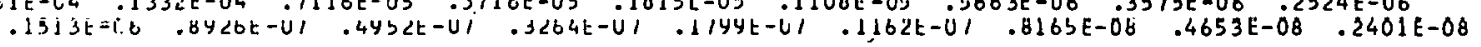

SF .2745[-C2 .2172E-02 .1561E-02 .1137E-02 $\quad .8371 E-03 \quad .4878 E-03 \quad .2519 E-03 \quad .1200 E-03 \quad .6899 E-04 \quad .3151 E-04$ $.1812 \mathrm{E}-04 \quad .1184 \mathrm{E}-04 \quad .6287 \mathrm{E}-05 \quad .3260 \mathrm{E}-05 \quad .1579 \mathrm{E}-05 \quad .9591 \mathrm{E}-06 \quad .4874 \mathrm{E}-06 \quad .3069 \mathrm{E}-06 \quad .2165 \mathrm{E}-06$ $.1299 \mathrm{E}-06 \quad .7680 \mathrm{E}-07 \quad .4279 \mathrm{E}-\mathrm{C} 7 \quad .2830 \mathrm{E}-07 \quad .1566 \mathrm{E}-07 \quad .1012 \mathrm{E}-07 \quad .7109 \mathrm{E}-0 \mathrm{0} \quad .4 \mathrm{C} 34 \mathrm{E}-08 \quad .2054 \mathrm{E}-\mathrm{C} 8$

SSE .1251E-02 .1018E-02 .9063E-03 .7417E-03 $.577 Z E-03 \quad .3526 E-03 \quad .1908 E-03 \quad .8967 E-04 \quad .5162 E-04 \quad .2353 E-04$

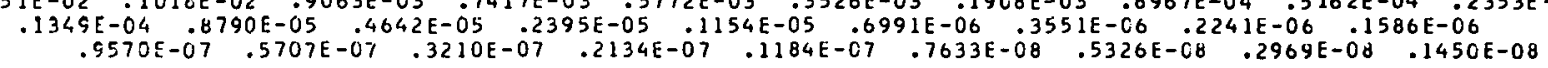

r :15097-02 .10245-02 .8437E-03 $.6654 \mathrm{E}-03 \quad .5111 \mathrm{E}-03 \quad .3094 \mathrm{E}-03 \quad .1667 \mathrm{E}-03 \quad .7818 \mathrm{E}-04 \quad .4495 \mathrm{E}-04 \quad .2046 \mathrm{E}-04$

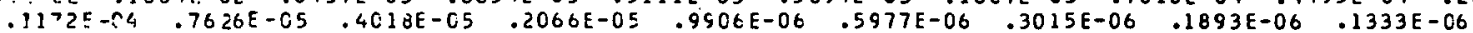

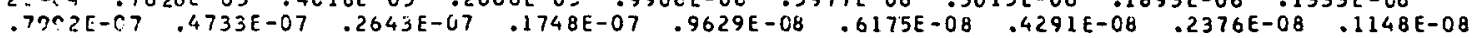

CSH .12:5r-02 .9548E-03 .6847E-03 .5244E-03 .3982E-03 .2389E-03 .1282E-C3 :6C00E-04 .3448E-04 .1568E-04 $.8 ? 76 \mathrm{E}-\mathrm{i} 5$. $5838 \mathrm{E}-05$.3672E-05 .1577E-05 .7541E-06 .4538E-06 .2278E-06 .1425E-06 .1000E-06

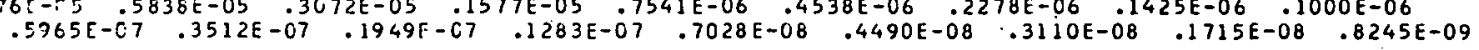

SU .1!41I-^2 .7398E-03 .5995E-03 .4722E-03 .3631E-03 .2201E-03 .11E7E-03 .5565E-04 .3200E-.04 .1456E-04 .2323E-CE .5416E-05 .285UE-05 .1463E-05 .6999E-06 .4215E-06 .2120E-06 .1328E-06 .9344E-0

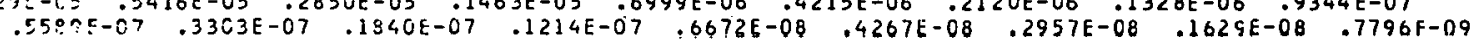

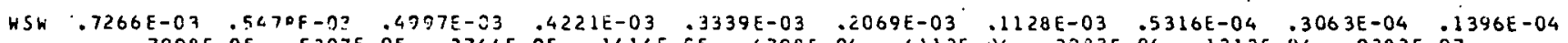
$.7998 \mathrm{E}-0.5$.5207F-n5 .274tE- 05 .1414E-05 .6798E-06 .4112E-UE .2083E-06 .1313E-06 .9282E-07

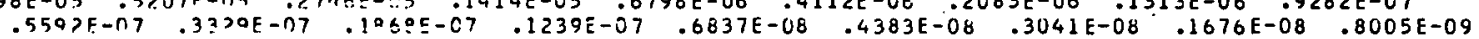

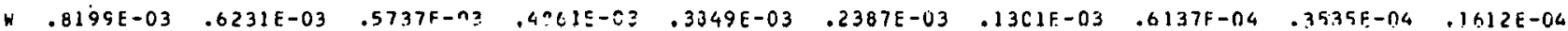
$.4235 \mathrm{E}-05$.6012E-05 .3171F-05 .1F32E-05 .7854E-06 .4752E-06 .2404E-06 .1518E-06 .1073E-06

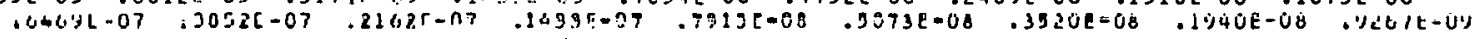

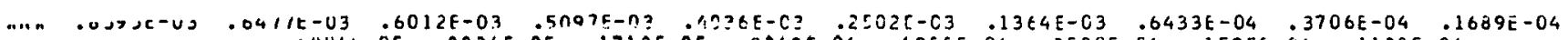

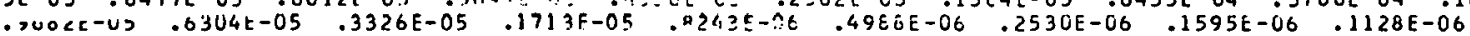

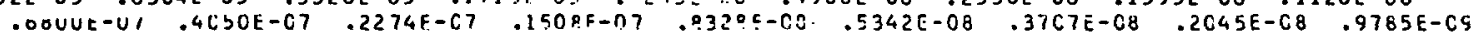

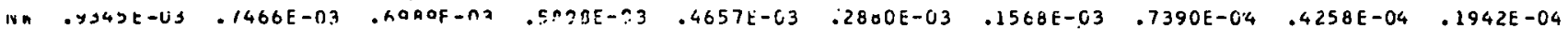

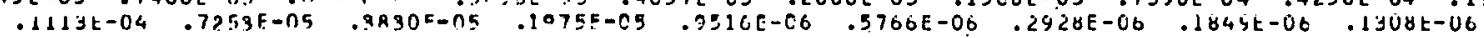

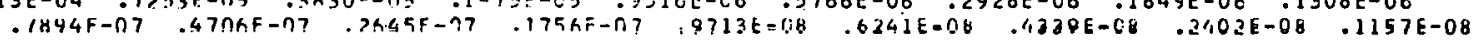

NNW .1737F-n3 .3104F-n3 .563.6E-03 .4766E-03 .3750E-03 $.2312 E-03 \quad .1257 E-03 \quad .5924 E-04 \quad .3413 E-04.04557 E-04$ . $9924 \mathrm{E}-\mathrm{CS} \quad .5^{\circ} 22 \mathrm{E}-05 \quad .3076 \mathrm{E}-05 \quad .1588 \mathrm{E}-05 \quad .7658 \mathrm{E}-06 \quad .464 \angle \mathrm{E}-06 \quad .2359 \mathrm{E}-06 \quad .1489 \mathrm{E}-06 \quad .1054 \mathrm{E}-06$

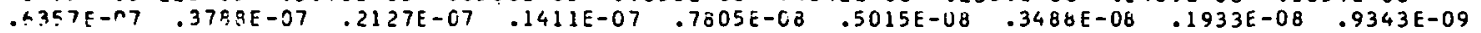

$n .1609 t-U S$.61]AF-03 .5771F-23 .4226E-03 .2791E-C3 .2332E-03 .1267E-03 .5965E-04 .3436E-04 .1568E-04

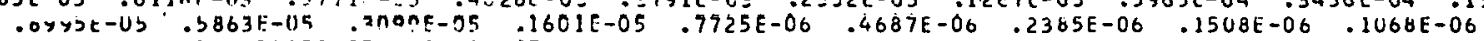

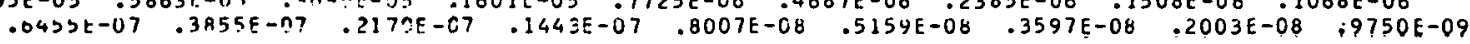

IUIAL . L139E-01 .17RRF-01 .1396F-C1 .1006E-01 .0292E-C2 .4968E-C2 .26E0E-C2 .1256E-C2. .7232E-03 .3302E-03

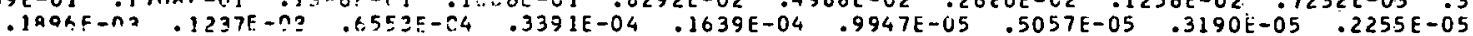

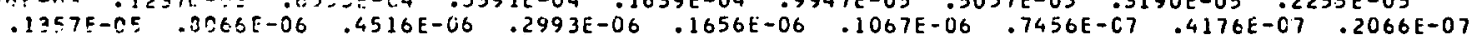


TABLE B-9. DEPOSITIUN FLUX.

SCURCE CEPLETICA NCCEL, VCIU = .COI

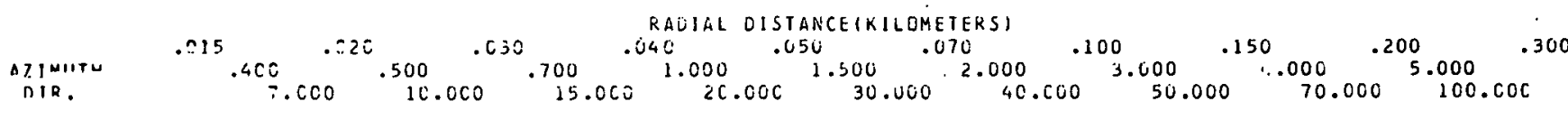

NNF .2305F-05 .1940E-25 .12CEE-C5 . .2261E-06 .5875E-06 .3319E-06 .1727E-06 .7989E-07 .4590E-07 .2102E-07

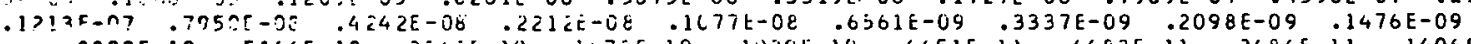

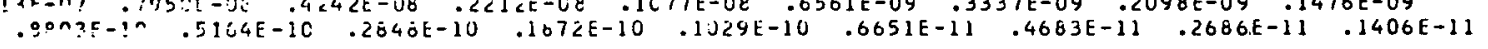

NF .4265F-n5 .32RPF-nE .21675-05 .136EE-05 .9650E-CE .5332E-06 .2744E-06 .1263E-0E .7261E-07 .3336E-07

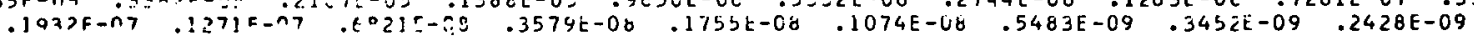

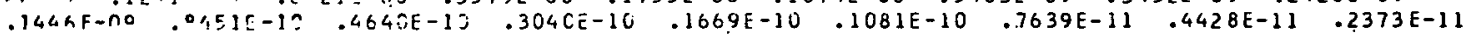

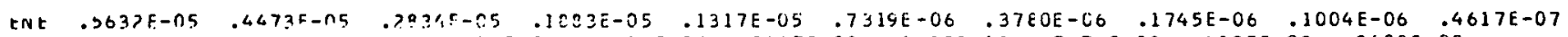

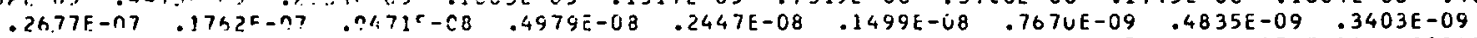

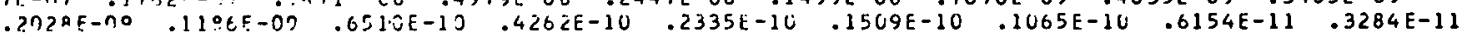

$+.55 n 4 F-n 5 \quad .4715 E-05 \quad .3192 E-05 \quad .2161 E-05.05 .1521 E-05 \quad .8486 E-06 \quad .4388 E-06 \quad .2025 E-06 \quad 01164 E-06 \quad .5350 E-07$

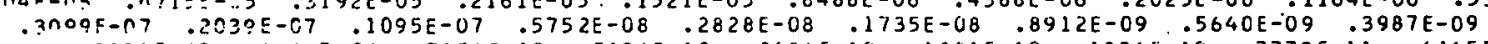

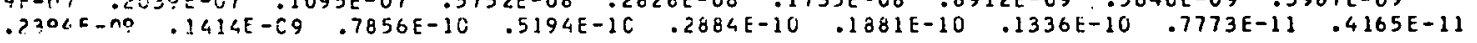

ESE .1331E-04 .10?7F-n\& .6051E-35 .3661E-05 .264UE-05 .1437E-05 .7346E-06 .3379E-06 .1946E-06 .8985E-07 $.5229 F-n 7.7451 E-07.10675-C 7.3871 E-C E$.4877E-08 .25S5E-08 .1533E-C8 .4645E-09 .6768E-C9

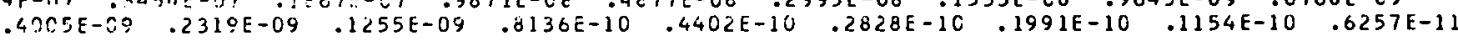

SF .0647E-nE .7232E-E5 .4342E-J5 .2810E-05 .1930E-05 .1063E-05 .5446E-C6 .2502E-06 .1436E-06 .6592E-07

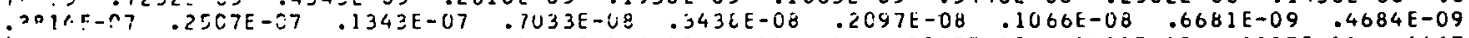

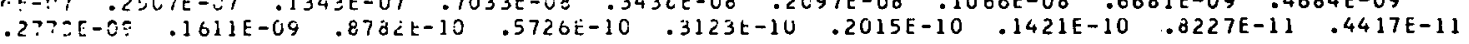

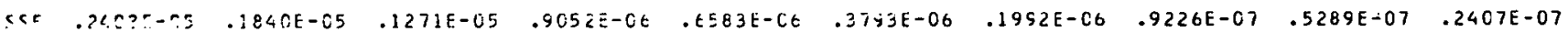

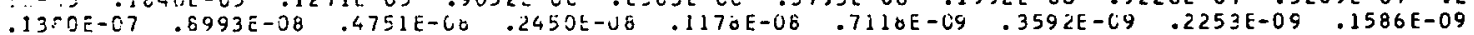

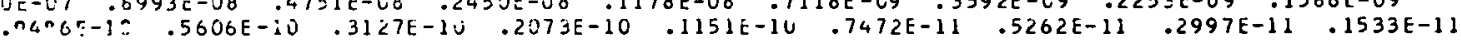

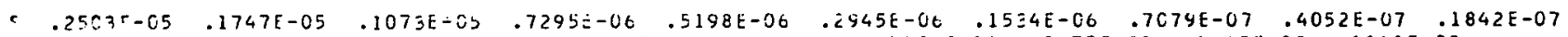
$.1055 E-07.6072 E-08 \quad .3624 E-28$.1862E-08 .8509E-09 .5354E-09 .2675E-09 .1663E-09.1161E-09

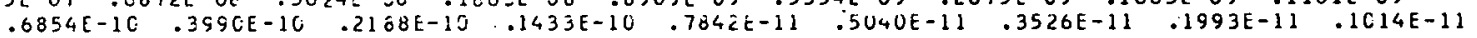

SSW .2691E-05 .1812E-05 .1020E-05 .6603E-06 .4586E-06 .2541E-06 .1309E-06 .06011 E-07 .3440E-07 .1566E-07

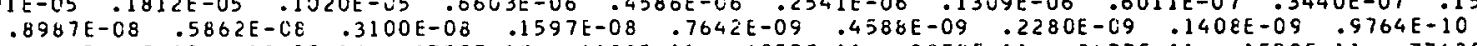

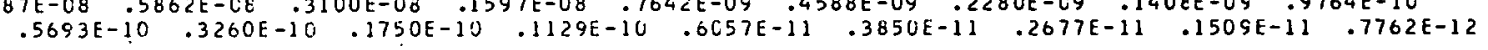

SW .1674E-05 .1119E-05 $.6666 E-06 \quad .4520 E-06 \quad .3224 E-06 \quad .1631 E-06 \quad .9548 E-C 7 \quad .4405 E-07 \quad .2520 E-07 \quad .1143 E-07$

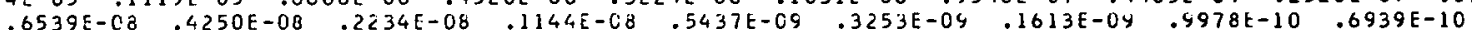

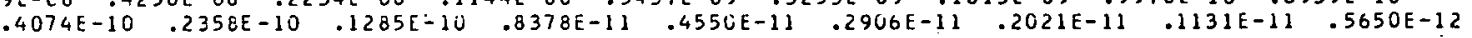

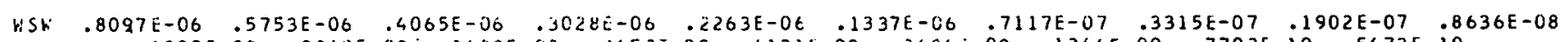

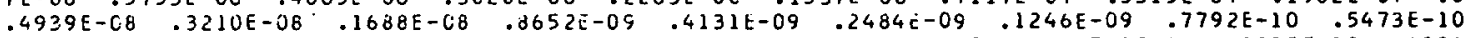

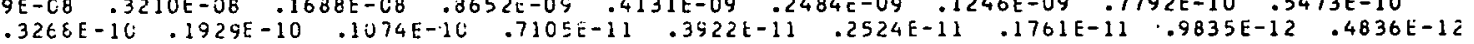

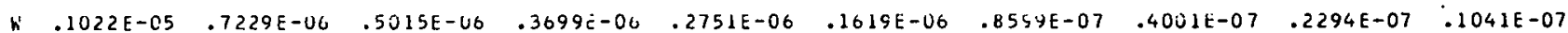

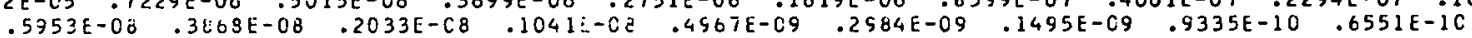

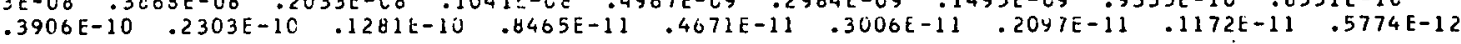

WNA .129EE-C5 .9138E-06 . E1E1E-06 .4465E-0E .3291E-06 .1423E-06 .1011E-C6 .4724E-07 .2707E-07 .1229E-C7

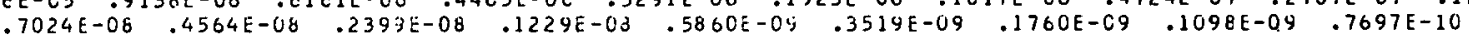

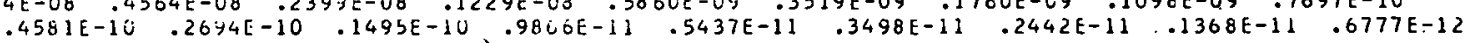

Nir. .1563E-05 .1174E-05 .8125E-06 .5883E-06 .4325E-06 .2514E-06 .1331E-CO $.6181 E-07 \quad .3545 E-07 \quad .1613 E-07$

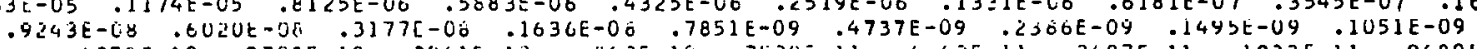

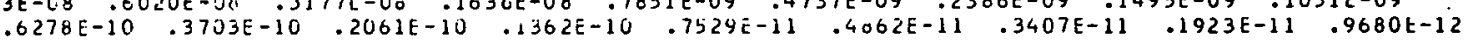

NNW .1398E-05 .1046E-05 .69E1E-06 .4925E-06 .3571E-OC .2C54E-06 .1079E-C6 .5C03E-07 .2871E-07 .1309E-07 $.7523 E-U E$. $4911 E-08$.2602E-U8 .1346E-08 .6490E-09 .3926E-09 .1984E-09 .1244E-09 .8740E-10

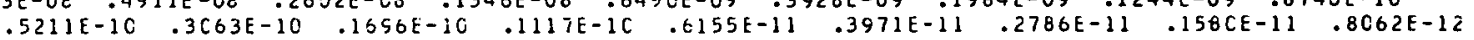

$N \quad .1345 E-05 \quad .1072 E-05 \quad .7631 E-06 \quad .5493 E-00 \quad .4013 E-06 \quad .2321 E-06 \quad 01222 E-06 \quad .5676 E-U 7 \quad .3259 E-07 \quad .1488 E-07$ $.8552 \mathrm{E}-\mathrm{C} .8 \quad .5586 \mathrm{E}-0 \mathrm{E} \quad .2964 \mathrm{E}-08$. $.1536 \mathrm{E}-08$.7434E-04 .4513E-09 .2292E-C9 .1443E-0G .1C18E-09

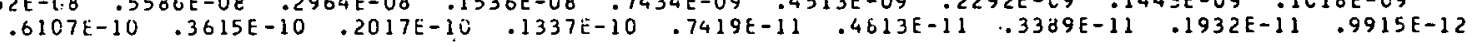

TETAL .5737E-04 .4385E-C4. .275EE-04 .1843E-04 .1295E-L4 $.7234 E-05 \quad .3744 E-05 \quad .1728 E-05 \quad .9923 E-06 \quad .4548 E-06$ $.2628 \mathrm{E}-\mathrm{C} 6 \quad .1724 \mathrm{E}-06 \quad .9216 \mathrm{E}-07 \quad .4813 \mathrm{E}-07 \quad .2347 \mathrm{E}-07 \quad .1430 \mathrm{C}-07 \quad .727 \angle \mathrm{E}-00 \quad .4567 \mathrm{E}-\mathrm{CB} \quad .3208 \mathrm{E}-\mathrm{CB}$

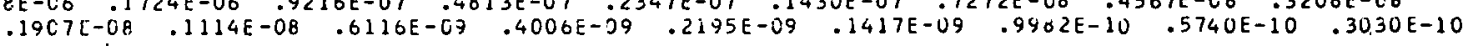



the Source Depletion and Surface Depletion Models

The calculations used to substantiate the conclusions of this report utilized the surface depletion model, equation (10). A less realistic, but also computationally less complex, method is provided by the source depletion model described by Van der Hoven (1968).

The source depletion model accounts for deposition by reducing the source strength as a function of downwind distance, 1.e.,

$$
C(x, y, z)=\frac{\dot{Q}(x)}{u} D(x, y, z)
$$

Conservation of the contaminant requires that

$$
\begin{aligned}
\frac{d \dot{Q}}{d x} & =-\int_{-\infty}^{\infty} v_{d} C\left(x, y, z_{d}\right) d y \\
& =-v_{d} \dot{Q}(x) D\left(x, z_{d}\right)
\end{aligned}
$$

where $D\left(x, z_{d}\right)$ is the cross-wind-integrated value of $D\left(x, y, z_{d}\right)$, given by $\pi x / 8$ times equation (2). Hence

$$
\dot{Q}(x)=\dot{Q}_{0} \exp \left\{-\frac{v_{d}}{u} \int_{-\infty}^{\infty} \dot{D}\left(\xi, z_{d}\right) \cdot d \xi\right\} .
$$

Although the source depletion model correctly determines the deposition flux in terms of the air concentration near the surface $\left(z=z_{d}\right)$, the material loss is instantaneously distributed throughout the vertical extent of the plume, retaining its Gaussian shape. This is not a sertous error when the deposition is small; but for strong deposition the surface depletion model is needed to correctly predict the altered vertical distribution of contaminant, with the loss due to deposition concentrated near the 
surface. As a consequence of its artificially enhanced air concentration at $z=z_{d}$, the source depletion model consistently overpredicts the deposition loss. Horst (1974b) has shown that for Individual micrometeorological situations the model predictions begin to diverge significantly for $v_{d} / \mathrm{u}=10^{-3}$

Figure C-1 shows the climatologically and polar-averaged comparison of the two models for $\mathrm{v}_{\mathrm{d}} / \mathrm{u}=10^{-3}$ and $10^{-2}$. The quantity plotted is the ratio, as predicted by both models, of the airborne contaminant for a depositing substance to that for a non-depositing contaminant. The results are very similar to those presented by Horst (1974b). The differences between the predictions increase with $v_{d} / u$, being only about $15 \%$ to $20 \%$ at $v_{d} / u=10^{-3}$. The surface depletion model predicts a smaller air concentration near the surface because the deposition loss is concentrated near the surface rather than being distributed throughout the plume. At greater distances this is balanced by the greater deposition loss of the source depletion model, which eventually reduces its predicted air concentration below that of the surface depletion model. 


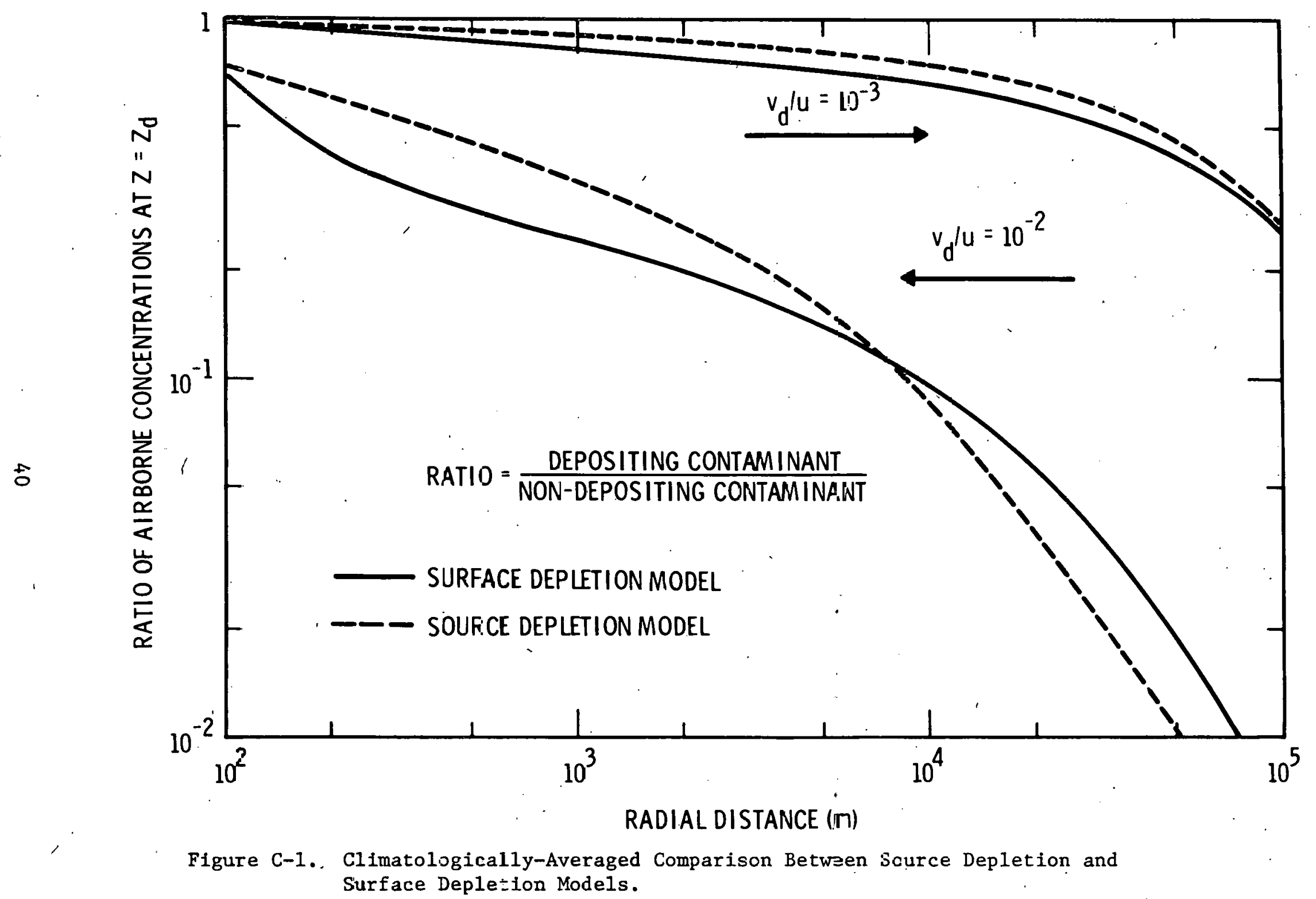


The following tables show the cllmatologically-averaged resuspended air concentration as calculated with (13) for a constant resuspension rate and for $t \rightarrow \infty$. The resuspended air concentrations have been normalized with the initial source strength $\dot{Q}$ and hence have dimensions of $\mathrm{sec} / \mathrm{m}^{3}$. Tables $D-1$ and $D-2$ correspond to the deposition fluxes for $v_{d} / u=10^{-2}$ (Table $B-3$ ) and $10^{-3}$ (Table $B-5$ ) respectively. As indicated in the main text, calculations were made for overlapping ranges of the radial distance from the original source by varying the cartesian grid interval DIX. The results are labeled with the grid interval used and are displayed as a function of radial distance and azimuthal direction, NNE through $N$, i.e.,

$\begin{array}{lllllllll}\text { NNE } & \text { NE } & \text { ENE } & \text { E } & \text { ESE } & \text { SE } & \text { SSE } & \text { S } & \\ \text { SSW } & \text { SW } & \text { WSW } & \text { W } & \text { WNW } & \text { NW } & \text { NNW } & \text { N } & \text {. }\end{array}$


Tajle D-1. Climatologically-Averaged Resuspended Air Concentration Distribution for $v_{d} / u=10^{-2}$.

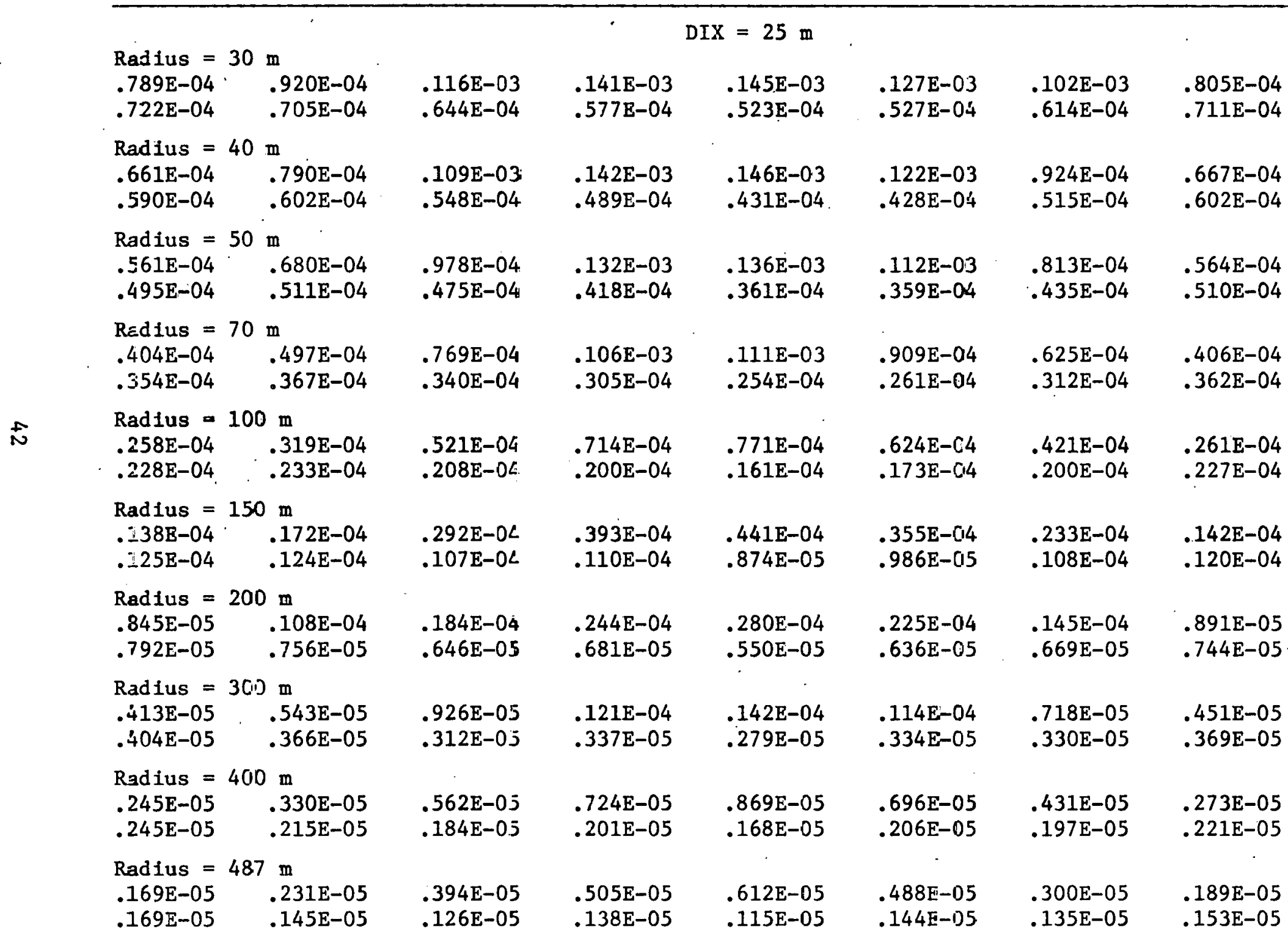


Table D-1 (Continued). Climatologically-Averaged Resuspended Air Concentration Distribution for $v_{d} / u=10^{-2}$.

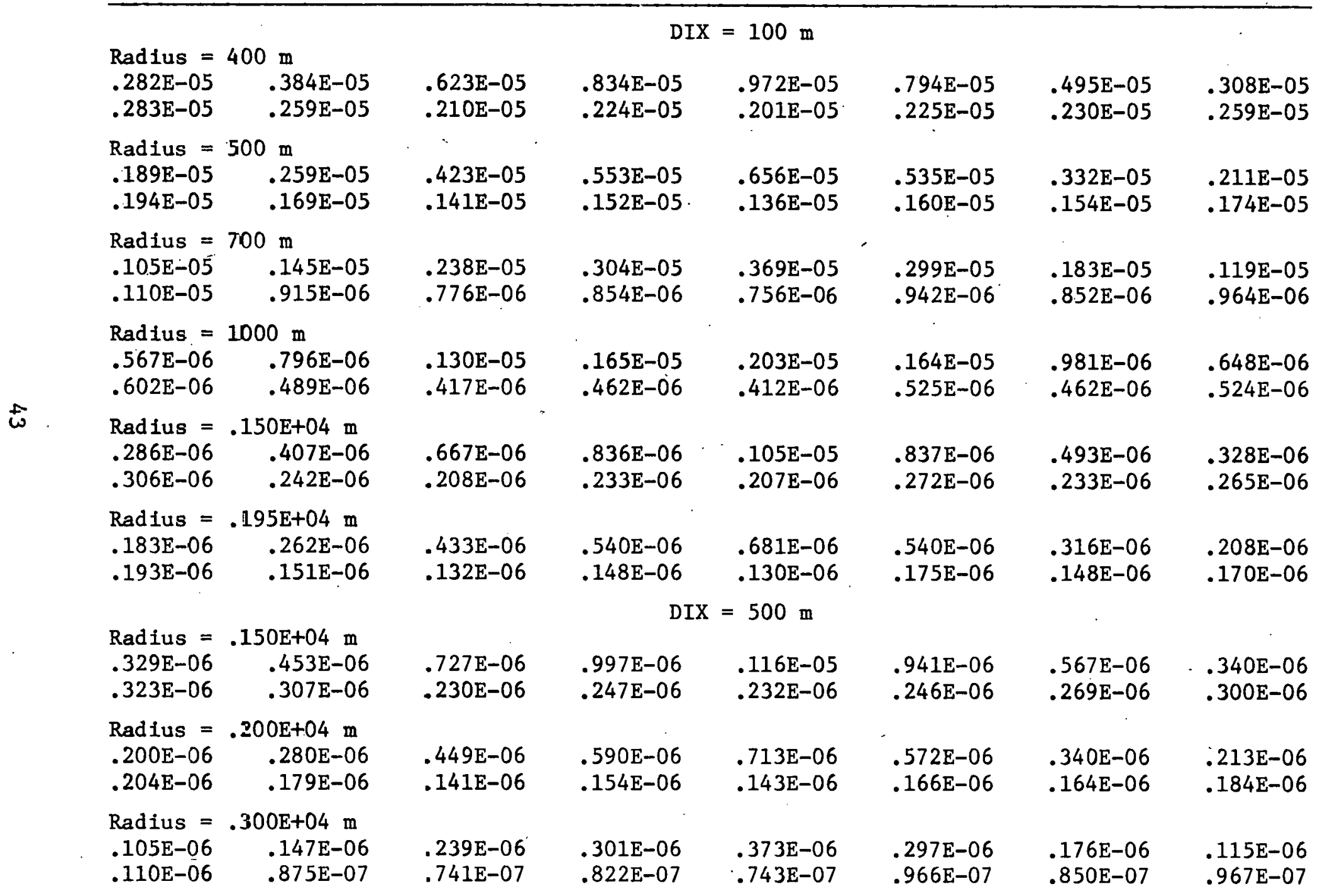


Table D-1 (Continued). Climatologically-Averaged Resuspended Air Eoncentration Distribution for $v_{d} / u=10^{-2}$.

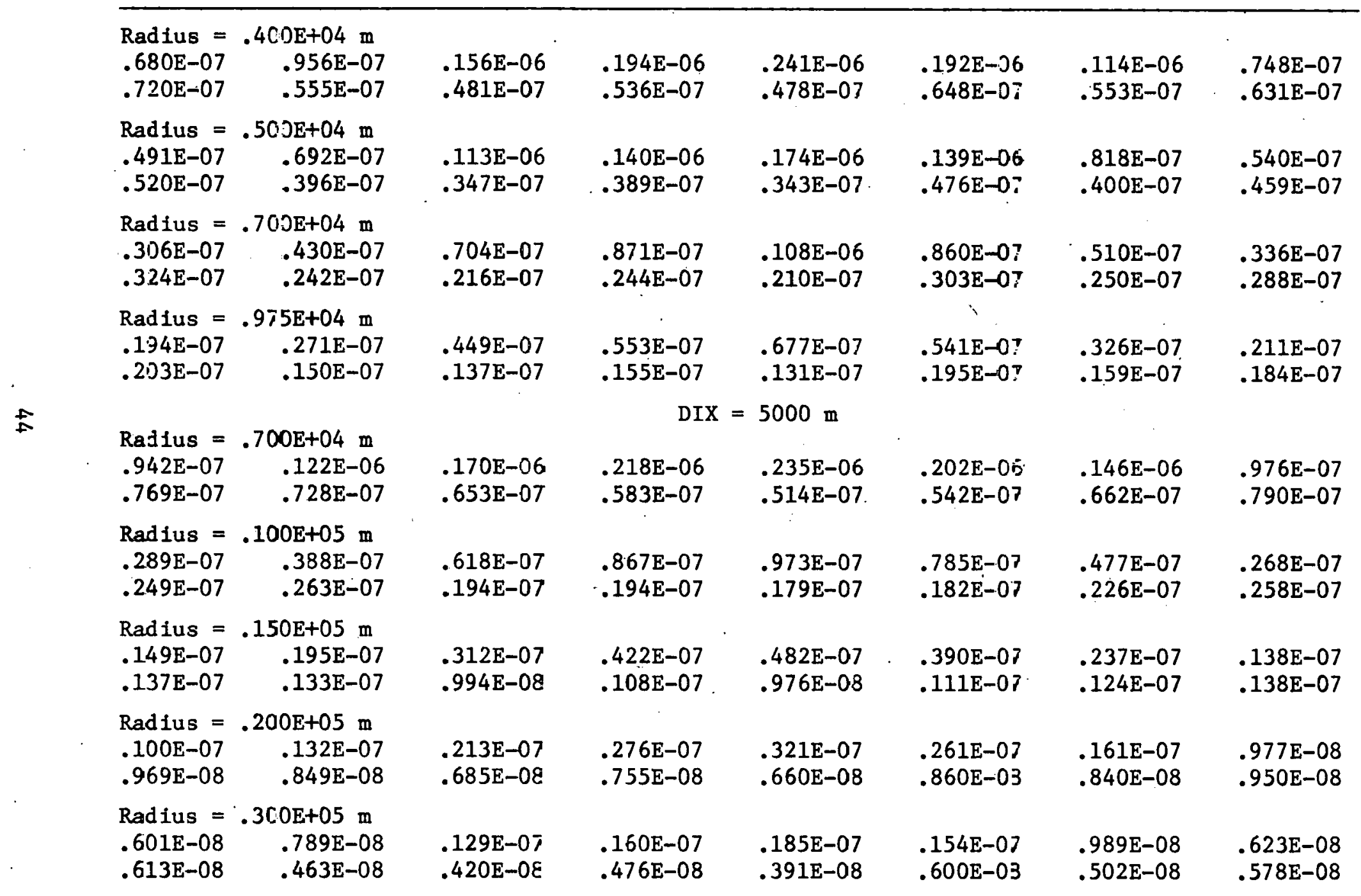


Table D-1 (Continued). Climatologically-Averaged Resuspended Air Concentration Distribution for $v_{d} / u=10^{-2}$.

\begin{tabular}{|c|c|c|c|c|c|c|c|}
\hline $\begin{array}{l}\text { Radius = } \\
.427 \mathrm{E}-08 \\
.443 \mathrm{E}-08\end{array}$ & $\begin{array}{r}.400 \mathrm{E}+05 \mathrm{~m} \\
.554 \mathrm{E}-08 \\
.319 \mathrm{E}-08\end{array}$ & $\begin{array}{l}.918 E-08 \\
.301 E-08\end{array}$ & $\begin{array}{l}.113 \mathrm{E}-07 \\
.346 \mathrm{E}-08\end{array}$ & $\begin{array}{l}.128 \mathrm{E}-07 \\
.275 \mathrm{E}-08\end{array}$ & $\begin{array}{l}.108 \mathrm{E}-07 \\
.449 \mathrm{E}-08\end{array}$ & $\begin{array}{l}.713 E-08 \\
.358 E-08\end{array}$ & $\begin{array}{l}.451 E-08 \\
.415 E-08\end{array}$ \\
\hline $\begin{array}{l}\text { Radius }= \\
.329 E-08 \\
.343 E-08\end{array}$ & $\begin{array}{r}.500 \mathrm{E}+05 \mathrm{~m} \\
.425 \mathrm{E}-08 \\
.245 \mathrm{E}-08\end{array}$ & $\begin{array}{r}.706 \mathrm{E}-08 \\
.233 \mathrm{E}-08\end{array}$ & $\begin{array}{l}.867 \mathrm{E}-08 \\
.270 \mathrm{E}-08\end{array}$ & $\begin{array}{l}.968 E-08 \\
.211 E-08\end{array}$ & $\begin{array}{l}.829 E-08 \\
.354 E-08\end{array}$ & $\begin{array}{l}.555 \mathrm{E}-08 \\
.278 \mathrm{E}-08\end{array}$ & $\begin{array}{l}.351 E-08 \\
.324 E-08\end{array}$ \\
\hline $\begin{array}{l}\text { Radius = } \\
.225 E-08 \\
.237 E-08\end{array}$ & $\begin{array}{r}.700 \mathrm{E}+05 \mathrm{~m} \\
.287 \mathrm{E}-08 \\
.166 \mathrm{E}-08\end{array}$ & $\begin{array}{l}.482 \mathrm{E}-08 \\
.160 \mathrm{E}-08\end{array}$ & $\begin{array}{l}.590 \mathrm{E}-08 \\
.188 \mathrm{E}-08\end{array}$ & $\begin{array}{l}.646 \mathrm{E}-08 \\
.143 \mathrm{E}-08\end{array}$ & $\begin{array}{l}.562 \mathrm{E}-08 \\
.249 \mathrm{E}-08\end{array}$ & $\begin{array}{l}.386 \mathrm{E}-08 \\
.192 \mathrm{E}-08\end{array}$ & $\begin{array}{r}.242 \mathrm{E}-08 \\
.224 \mathrm{E}-08\end{array}$ \\
\hline $\begin{array}{l}\text { Radius }= \\
.157 \mathrm{E}-08 \\
.167 \mathrm{E}-08\end{array}$ & $\begin{array}{r}.975 \mathrm{E}+05 \mathrm{~m} \\
.198 \mathrm{E}-08 \\
.115 \mathrm{E}-08\end{array}$ & $\begin{array}{l}.336 \mathrm{E}-08 \\
.112 \mathrm{E}-08\end{array}$ & $\begin{array}{l}.409 E-08 \\
.132 E-08\end{array}$ & $\begin{array}{l}.440 \mathrm{E}-08 \\
.100 \mathrm{E}-08\end{array}$ & $\begin{array}{l}.388 \mathrm{E}-08 \\
.177 \mathrm{E}-08\end{array}$ & $\begin{array}{l}.275 \mathrm{E}-08 \\
.135 \mathrm{E}-08\end{array}$ & $\begin{array}{l}.171 \mathrm{E}-08 \\
.158 \mathrm{E}-08\end{array}$ \\
\hline
\end{tabular}


Tajle D-2. C1imatologically-Averaged Resuspended Air Concentration Distribution for $v_{d} / u=10^{-3}$.

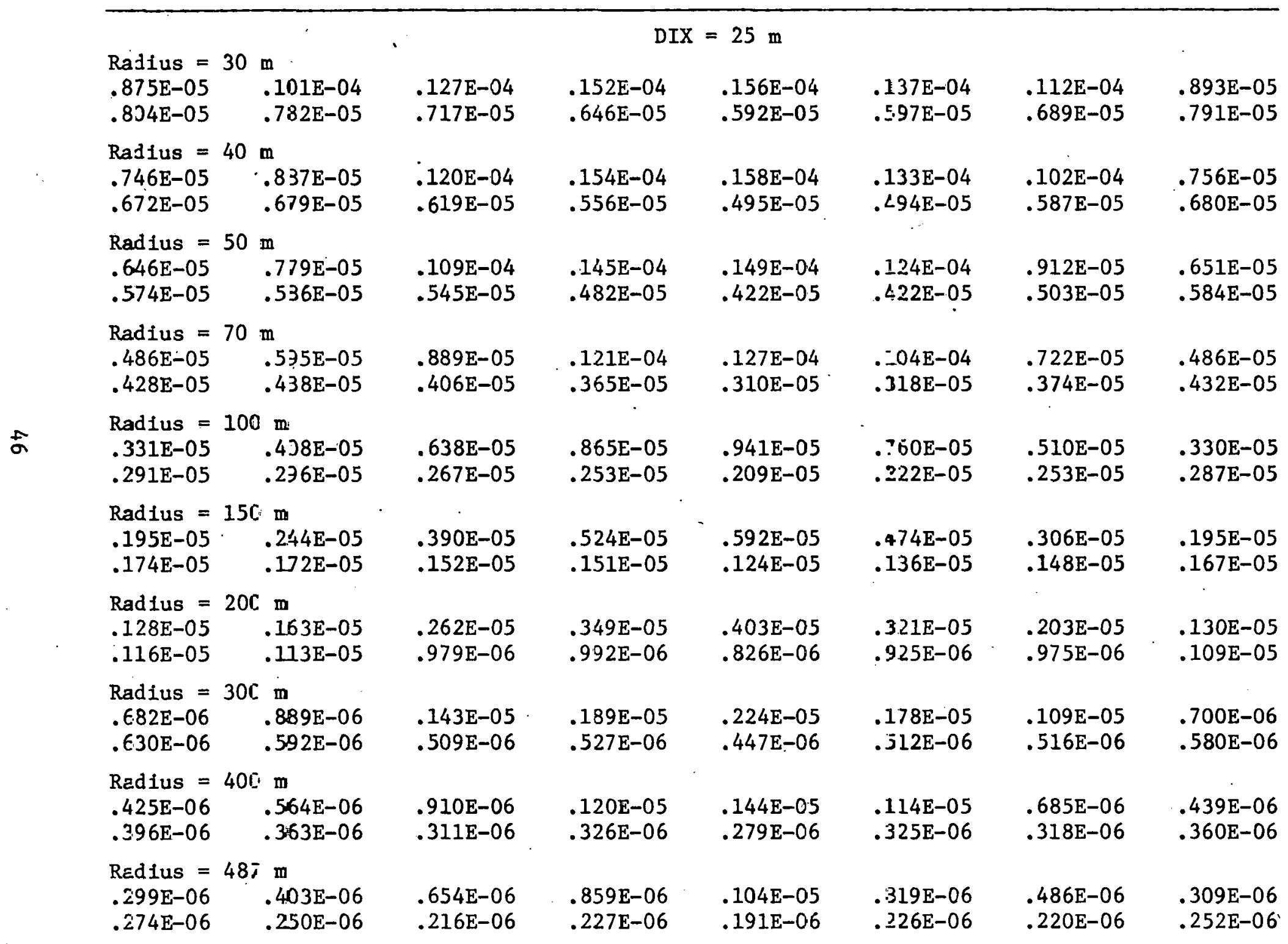


Table D-2 (Continued). Climatologically-Averaged Resuspended Air Concentration Distribution for $v_{d} / u=10^{-3}$.

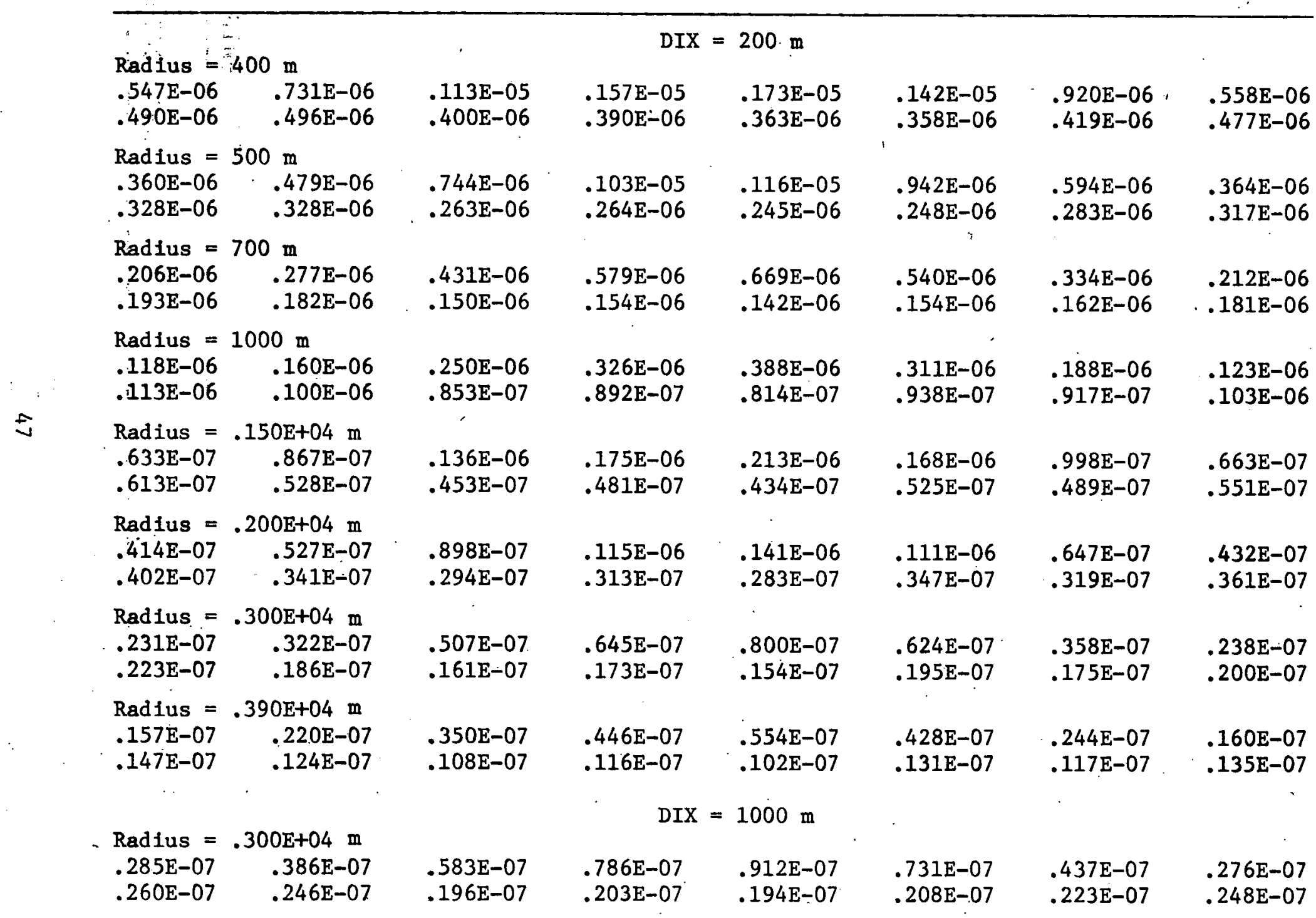


Table D-2 (Continued). Climatologically-Averaged Resuspended Air Ccncertration Distribution for $v_{d} / u=10^{-3}$.

\begin{tabular}{|c|c|c|c|c|c|c|c|}
\hline $\begin{array}{l}\text { Radius }= \\
.191 \mathrm{E}-07 \\
.178 \mathrm{E}-07\end{array}$ & $\begin{array}{r}.40 .0 \mathrm{E}+04 \mathrm{~m} \\
.260 \mathrm{E}-07 \\
.160 \mathrm{E}-07\end{array}$ & $\begin{array}{l}.393 \mathrm{E}-07 \\
.132 \mathrm{E}-07\end{array}$ & $\begin{array}{l}.513 \mathrm{E}-07 \\
.138 \mathrm{E}-07\end{array}$ & $\begin{array}{r}.616 \mathrm{E}-07 \\
.130 \mathrm{E}-07\end{array}$ & $\begin{array}{l}.487 \mathrm{E}-37 \\
.150 \mathrm{E}-37\end{array}$ & $\begin{array}{l}.287 \mathrm{E}-07 \\
.148 \mathrm{E}-07\end{array}$ & $\begin{array}{l}.187 \mathrm{E}-07 \\
.167 \mathrm{E}-07\end{array}$ \\
\hline $\begin{array}{l}\text { Radius }= \\
.144 \mathrm{E}-07 \\
.135 \mathrm{E}-07\end{array}$ & $\begin{array}{r}.50 D \mathrm{E}+04 \mathrm{~m} \\
.194 \mathrm{E}-07 \\
.116 \mathrm{E}-07\end{array}$ & $\begin{array}{l}.295 \mathrm{E}-07 \\
.988 \mathrm{E}-08\end{array}$ & $\begin{array}{l}.379 \mathrm{E}-07 \\
.104 \mathrm{E}-07\end{array}$ & $\begin{array}{r}.458 \mathrm{E}-07 \\
.966 \mathrm{E}-08\end{array}$ & $\begin{array}{l}.38 .1 \mathrm{E}-37 \\
.177 \mathrm{E}-37\end{array}$ & $\begin{array}{l}.213 \mathrm{E}-07 \\
.111 \mathrm{E}-07\end{array}$ & $\begin{array}{l}.141 \mathrm{E}-07 \\
.125 \mathrm{E}-07\end{array}$ \\
\hline $\begin{array}{l}\text { Radius }= \\
.955 \mathrm{E}-08 \\
.893 \mathrm{E}-08\end{array}$ & $\begin{array}{r}.70 \mathrm{DE}+04 \mathrm{~m} \\
.128 \mathrm{E}-07 \\
.749 \mathrm{E}-08\end{array}$ & $\begin{array}{l}.195 \mathrm{E}-07 \\
.655 \mathrm{E}-08\end{array}$ & $\begin{array}{l}.248 \mathrm{E}-07 \\
.697 \mathrm{E}-08\end{array}$ & $\begin{array}{r}.301 \mathrm{E}-07 \\
.629 \mathrm{E}-08\end{array}$ & $\begin{array}{l}.256 \mathrm{E}-07 \\
.803 \mathrm{E}-08\end{array}$ & $\begin{array}{l}.139 \mathrm{E}-07 \\
.727 \mathrm{E}-08\end{array}$ & $\begin{array}{l}.935 \mathrm{E}-08 \\
.828 \mathrm{E}-08\end{array}$ \\
\hline $\begin{array}{l}\text { Radius = } \\
.633 E-08 \\
.585 E-08\end{array}$ & $\begin{array}{r}.103 \mathrm{E}+05 \mathrm{~m} \\
.844 \mathrm{E}-08 \\
.489 \mathrm{E}-08\end{array}$ & $\begin{array}{l}.129 \mathrm{E}-07 \\
.432 \mathrm{E}-08\end{array}$ & $\begin{array}{l}.163 E-07 \\
.460 \mathrm{E}-08\end{array}$ & $\begin{array}{l}.197 \mathrm{E}-07 \\
.408 \mathrm{E}-08\end{array}$ & $\begin{array}{l}.155 \mathrm{E}-07 \\
.535 \mathrm{E}-08\end{array}$ & $\begin{array}{r}.914 \mathrm{E}-08 \\
.479 \mathrm{E}-08\end{array}$ & $\begin{array}{l}.612 \mathrm{E}-08 \\
.549 \mathrm{E}-08\end{array}$ \\
\hline $\begin{array}{l}\text { Radius }= \\
.403 \mathrm{E}-08 \\
.355 \mathrm{E}-08\end{array}$ & $\begin{array}{r}.153 \mathrm{E}+05 \mathrm{~m} \\
.534 \mathrm{E}-08 \\
.305 \mathrm{E}-08\end{array}$ & $\begin{array}{l}.820 \mathrm{E}-08 \\
.273 \mathrm{E}-08\end{array}$ & $\begin{array}{l}.104 \mathrm{E}-07 \\
.292 \mathrm{E}-08\end{array}$ & $\begin{array}{r}.124 \mathrm{E}-07 \\
.251 \mathrm{E}-08\end{array}$ & $\begin{array}{l}. c 81 \mathrm{E}-08 \\
. \quad \Xi 40 \mathrm{E}-08\end{array}$ & $\begin{array}{l}.582 \mathrm{E}-08 \\
.301 \mathrm{E}-08\end{array}$ & $\begin{array}{l}.384 \mathrm{E}-08 \\
.349 \mathrm{E}-08\end{array}$ \\
\hline $\begin{array}{l}\text { Radius }= \\
.301 E-08 \\
.266 \mathrm{E}-08\end{array}$ & $\begin{array}{r}.195 \mathrm{E}+05 \mathrm{~m} \\
.395 \mathrm{E}-08 \\
.223 \mathrm{E}-08\end{array}$ & $\begin{array}{l}.615 \mathrm{~B}-08 \\
.202 \mathrm{~B}-08\end{array}$ & $\begin{array}{l}.782 E-08 \\
.216 E-08\end{array}$ & $\begin{array}{l}.925 \mathrm{E}-08 \\
.180 \mathrm{E}-08\end{array}$ & $\begin{array}{l}.730 \mathrm{E}-03 \\
.250 \mathrm{E}-03\end{array}$ & $\begin{array}{r}.436 \mathrm{E}-08 \\
.221 \mathrm{E}-08\end{array}$ & $\begin{array}{l}.281 E-08 \\
.258 E-08\end{array}$ \\
\hline $\begin{array}{l}\text { Radius }= \\
.548 \mathrm{E}-08 \\
.468 \mathrm{E}-08\end{array}$ & $\begin{array}{r}.150 \mathrm{E}+05 \mathrm{~m} \\
.710 \mathrm{E}-08 \\
.449 \mathrm{E}-08\end{array}$ & $\begin{array}{l}.104 E-07 \\
.373 E-08\end{array}$ & $\begin{array}{r}\text { DIX } \\
.137 \mathrm{E}-07 \\
.381 \mathrm{E}-08\end{array}$ & $\begin{array}{l}5000 \mathrm{~m} \\
.155 \mathrm{E}-07 \\
.362 \mathrm{E}-08\end{array}$ & $\begin{array}{l}.125 \mathrm{E}-07 \\
.399 \mathrm{E}-0 \mathrm{~B}\end{array}$ & $\begin{array}{l}.769 E-08 \\
.430 E-08\end{array}$ & $\begin{array}{l}.496 \mathrm{E}-08 \\
.479 \mathrm{E}-08\end{array}$ \\
\hline $\begin{array}{l}\text { Radius = } \\
.404 \mathrm{E}-08 \\
.350 \mathrm{E}-08\end{array}$ & $\begin{array}{r}.200 \mathrm{C}+05 \mathrm{~m} \\
.520 \mathrm{E}-08 \\
.321 \mathrm{E}-08\end{array}$ & $\begin{array}{c}.762 E-08 \\
.277 E-08\end{array}$ & $\begin{array}{l}.980 \mathrm{E}-08 \\
.286 \mathrm{E}-08\end{array}$ & $\begin{array}{l}.113 \mathrm{E}-07 \\
.263 \mathrm{E}-08\end{array}$ & $\begin{array}{l}.91) 4 \mathrm{E}-08 \\
.314 \mathrm{E}-08\end{array}$ & $\begin{array}{l}.558 \mathrm{E}-08 \\
.315 \mathrm{E}-08\end{array}$ & $\begin{array}{l}.368 \mathrm{E}-08 \\
.354 \mathrm{E}-08\end{array}$ \\
\hline $\begin{array}{l}\text { Radius }= \\
.271 E-08 \\
.235 E-08\end{array}$ & $\begin{array}{r}.300 \mathrm{E}+05 \mathrm{~m} \\
.342 \mathrm{E}-08 \\
.205 \mathrm{E}-08\end{array}$ & $\begin{array}{l}.507 \mathrm{E}-08 \\
.186 \mathrm{E}-08\end{array}$ & $\begin{array}{l}.640 \mathrm{E}-08 \\
.195 \mathrm{E}-08\end{array}$ & $\begin{array}{l}.731 \mathrm{E}-08 \\
.171 \mathrm{E}-08\end{array}$ & $\begin{array}{l}.570 E-088 \\
.222 E-0.8\end{array}$ & $\begin{array}{l}.371 E-08 \\
.208 E-08\end{array}$ & $\begin{array}{l}.248 \mathrm{E}-08 \\
.237 \mathrm{E}-08\end{array}$ \\
\hline
\end{tabular}


Table D-2 (Continued). CClimatologically-Averaged Resuspended Air Concentration Distribution for $v_{d} / u=10^{-3}$

\begin{tabular}{|c|c|c|c|c|c|c|c|}
\hline $\begin{array}{l}\text { Radius }= \\
.206 \mathrm{E}-08 \\
.178 \mathrm{E}-08\end{array}$ & $\begin{array}{r}.400 \mathrm{E}+05 \mathrm{~m} \\
.257 \mathrm{E}-08 \\
.154 \mathrm{E}-08\end{array}$ & $\begin{array}{l}.384 \mathrm{E}-08 \\
.141 \mathrm{E}-08\end{array}$ & $\begin{array}{l}.483 \mathrm{E}-08 \\
.148 \mathrm{E}-08\end{array}$ & $\begin{array}{l}.546 \mathrm{E}-08 \\
.126 \mathrm{E}-08\end{array}$ & $\begin{array}{l}.443 \mathrm{E}-08 \\
.170 \mathrm{E}-08\end{array}$ & $\begin{array}{l}.282 \mathrm{E}-08 \\
.157 \mathrm{E}-08\end{array}$ & $\begin{array}{l}.187 \mathrm{E}-08 \\
.179 \mathrm{E}-08\end{array}$ \\
\hline $\begin{array}{l}\text { Radius }= \\
.166 \mathrm{E}-08 \\
.142 \mathrm{E}-08\end{array}$ & $\begin{array}{r}.500 \mathrm{E}+05 \mathrm{~m} \\
.206 \mathrm{E}-08 \\
.124 \mathrm{E}-08\end{array}$ & $\begin{array}{l}.309 \mathrm{E}-08 \\
.114 \mathrm{E}-08\end{array}$ & $\begin{array}{l}.390 \mathrm{E}-08 \\
.120 \mathrm{E}-08\end{array}$ & $\begin{array}{l}.438 \mathrm{E}-08 \\
.997 \mathrm{E}-09\end{array}$ & $\begin{array}{l}.357 \mathrm{E}-08 \\
.137 \mathrm{E}-08\end{array}$ & $\begin{array}{l}.228 E-08 \\
.126 E-08\end{array}$ & $\begin{array}{l}.150 \mathrm{E}-08 \\
.145 \mathrm{E}-08\end{array}$ \\
\hline $\begin{array}{l}\text { Radius = } \\
.120 \mathrm{E}-08 \\
.102 \mathrm{E}-08\end{array}$ & $\begin{array}{r}.700 \mathrm{E}+05 \mathrm{~m} \\
.148 \mathrm{E}-08 \\
.888 \mathrm{E}-09\end{array}$ & $\begin{array}{l}.225 \mathrm{E}-08 \\
.818 \mathrm{E}-09\end{array}$ & $\begin{array}{l}.285 E-08 \\
.867 E-09\end{array}$ & $\begin{array}{l}.316 \mathrm{E}-08 \\
.695 \mathrm{E}-09\end{array}$ & $\begin{array}{l}.259 \mathrm{E}-08 \\
.989 \mathrm{E}-09\end{array}$ & $\begin{array}{l}.166 \mathrm{E}-08 \\
.900 \mathrm{E}-09\end{array}$ & $\begin{array}{l}.107 \mathrm{E}-08 \\
.104 \mathrm{E}-08\end{array}$ \\
\hline $\begin{array}{l}\text { Radius }= \\
.887 \mathrm{E}-09 \\
.740 \mathrm{E}-09\end{array}$ & $\begin{array}{r}.975 \mathrm{E}+05 \mathrm{~m} \\
.108 \mathrm{E}-08 \\
.646 \mathrm{E}-09\end{array}$ & $\begin{array}{l}.167 \mathrm{E}-08 \\
.594 \mathrm{E}-09\end{array}$ & $\begin{array}{l}.211 E-08 \\
.634 E-09\end{array}$ & $\begin{array}{l}.231 E-08 \\
.491 E-09\end{array}$ & $\begin{array}{l}.190 \mathrm{E}-08 \\
.719 \mathrm{E}-09\end{array}$ & $\begin{array}{l}.124 \mathrm{E}-08 \\
.652 \mathrm{E}-09\end{array}$ & $\begin{array}{l}.780 \mathrm{E}-09 \\
.761 \mathrm{E}-09\end{array}$ \\
\hline
\end{tabular}

$E$ 
$C_{r}$ is correctly calculated as

$$
\mathrm{C}_{\mathrm{r}}(\mathrm{x}, \mathrm{y}, z)=\int_{0}^{\mathrm{x}} \int_{-\infty}^{\infty}\left[\Lambda \bar{G}(\xi, \eta)-v_{d}^{\prime} \mathrm{C}_{r}\left(\xi, \eta, z_{d}\right)\right] \frac{D}{u}(x-\xi, y-\eta, z) d \eta d \xi \quad \cdot \quad(E-1)
$$

where $v_{d}^{\prime}$ characterizes the redeposition of the resuspended material. The climatologically-averaged value of $G$ has been found in (12) to be

$$
\bar{G}=\bar{G}_{d}+\bar{G}_{r}=\left(\overline{v_{d} C_{d}}+\overline{v_{d}^{\prime} C_{r}}\right)\left(1-e^{-\bar{\Lambda} t}\right) / \bar{\Lambda}
$$

However, the results presented thus far have neglected the effect of redeposition on the resuspended air concentration. By setting $v_{d}^{\prime}$ equal to zero in $(E-1)$ and $(E-2)$ we obtain $\vec{G}_{d}$, the surface contamination due to deposition from the direct plume only, and $C_{r}^{\prime}$, the air concentration due to resuspension from $\bar{G}_{d}$. Substituting $(E-2)$ into $(E-1)$ then gives (13), the equation used to calculate $C_{r}^{\prime}$.

As discussed previously, redeposition from $C_{r}^{\prime}$ will form another source of resuspendable material which will in turn contribute to $C_{r}$. This additional surface contamination is

$$
\bar{G}_{r}^{1}={\overline{v_{d}^{T}}}_{r}^{1} / \bar{\Lambda}
$$

where $C_{r}^{1}$ is the depleted value of $C_{r}^{\prime}$,

$$
\mathrm{C}_{\mathrm{r}}^{1}=\int_{0}^{\mathrm{x}} \int_{-\infty}^{\infty}\left[\Lambda \overline{\mathrm{v}_{\mathrm{d}} \mathrm{C}_{\mathrm{d}}} / \bar{\Lambda}-\mathrm{v}_{\mathrm{d}}^{\prime} \mathrm{C}_{\mathrm{r}}^{1}\right] \frac{\mathrm{D}}{\mathrm{u}} \cdot \mathrm{dn} \mathrm{d} \xi
$$

and the growth factor $\left(1-e^{-\bar{\Lambda} t}\right)$ has been set equal to one. The resuspension from $\bar{G}_{r}^{1}$, including further redeposition, will then be 


$$
c_{r}^{2}=\int_{0}^{x} \int_{-\infty}^{\infty}\left[\Lambda \bar{v}_{d}^{T} C_{r}^{1} / \bar{\Lambda}-v_{d}^{\prime} C_{r}^{2}\right] \frac{D}{u} d \eta d \xi,
$$

and this too will contribute additional surface contamination

$$
\bar{G}_{\mathbf{r}}^{2}={\overline{v_{d}^{T}}}_{r}^{2} / \bar{\Lambda}
$$

Thus both $\bar{G}_{r}$ and $\bar{C}_{r}$ may be calculated by means of an infinite series

$$
\begin{aligned}
& \overline{\mathrm{G}}_{\mathrm{r}}=\sum_{\mathrm{N}=1}^{\infty} \overline{\mathrm{v}}_{\mathrm{d}}^{\mathrm{C}}{ }_{\mathrm{r}}^{\mathrm{N}} / \bar{\Lambda} \\
& \overline{\mathrm{c}}_{\mathrm{r}}=\sum_{\mathrm{N}=1}^{\infty} \overline{\mathrm{c}}_{\mathrm{r}}^{\mathrm{N}}
\end{aligned}
$$

where

$$
C_{r}^{N}=\int_{0}^{x} \int_{-\infty}^{\infty}\left[\Lambda{\overline{v_{d}}}_{r}^{N-1} / \bar{\Lambda}-v_{d}^{\prime} C_{r}^{N}\right] \frac{D}{u} d \eta d \xi
$$

$\mathrm{C}_{\mathrm{r}}^{\mathrm{N}}$ is the difference of the $\mathrm{N}-1$ resuspension cycle $\mathrm{R}^{\mathrm{N}-1}$ and the $\mathrm{Nth}$ deposition cycle $\mathrm{DP}^{\mathrm{N}}$. Hence

$$
\overline{\mathrm{C}}_{\mathrm{r}}=\overline{\mathrm{R}}^{0}-\overline{\mathrm{DP}}^{1}+\overline{\mathrm{R}}^{1}-\overline{\mathrm{DP}}^{2}+\overline{\mathrm{R}}^{2}-\overline{\mathrm{DP}}^{3}+\ldots
$$

where $\overline{\mathrm{R}}^{0}=\overline{\mathrm{C}}_{\mathrm{r}}^{\prime}$. It should be apparent from $(\mathrm{E}-9)$ that $\overline{\mathrm{DP}}^{\mathrm{N}}<\overline{\mathrm{R}}^{\mathrm{N}-1}$. If also $\overline{\mathrm{R}}^{\mathrm{N}}<\overline{\mathrm{DP}}^{\mathrm{N}}$, then it may easily be shown from(E-10) that $\overline{\mathrm{C}}_{r}<\overline{\mathrm{C}}_{r}^{\prime}$ and the net effect of redeposition is a reduction of $\bar{C}_{r}$. This needs to be investigated by the computation of $(\mathrm{E}-4)$ and higher-order terms. 
Another approach has been taken to estimate the effect of redeposition. In this approach the diffusion function $D$ has been approximated by.

$$
D\left(x-\xi, y-\eta, z_{d}\right)=\phi_{0} \delta(x-\xi) \delta(y-n)
$$

for the calculation of deposition from the initial plume and by

$$
D\left(x-\xi, y-n, z_{d}\right)=\phi_{\mathbf{r}} \delta(x-\xi) \delta(y-n)
$$

for the calculation of resuspension and redeposition. Here $\delta(x-\xi)$ and $\delta(y-n)$ are Dirac delta functions. This implies that the deposition loss depends only on the local air concentration and that the resuspended air concentration depends only on the local ground concentration. With this approximation ( 7 ) may be easily solved to get

$$
c_{d}=c_{0} /\left(1+\frac{v_{d}}{u} \phi_{0}\right)
$$

and

$$
C_{r}=\frac{\Lambda G}{n} \frac{巾_{r}}{\left(1+\frac{v_{d}^{\prime}}{u} \phi_{r}\right)}
$$

Substituting into (5) and solving gives then

$$
r=\frac{v_{d} C_{o}}{\left(1+\frac{v_{d}}{u} \phi_{o}\right)}\left(1-e^{-\Lambda^{\prime} \tau}\right)
$$

where $\Lambda^{\prime}=\Lambda /\left(1+\frac{v_{d}^{\prime}}{u} \phi_{r}\right)$. Substituting back into $(E-14)$,. 


$$
c_{r}=\frac{v_{d}}{u} \frac{\phi_{r} C_{0}}{\left(1+\frac{v_{d}}{u} \phi_{0}\right)}\left(1-e^{-\Lambda^{\prime} t}\right)
$$

Thus the only effect of redeposition in this solution is to reduce the resuspension rate by the factor $\left(1+\frac{v_{d}^{\prime}}{u_{d}} \phi_{r}\right)^{-1}$. This leads to an increase In the surface contamination, but a reduction of the resulting air concentration due to the slower approach of $G$ to its equilibrium value. Further, the maximum exposure to resuspension is unaffected since it is independent of the magnitude of the resuspension rate.

In conclusion, both of these approaches hint that the net effect of redeposition is a reduction of the resuspended air concentration. However the first of these depends on the determination that $\overline{\mathrm{R}}^{\mathrm{N}}<\overline{\mathrm{DP}}^{\mathrm{N}}$ and, circularly, that is very similar to the conclusion expressed by (18) and (19) which has only been substantiated without redeposition. That conclusion may be summarized by the assertion that the exposure due to resuspension is less than the loss of exposure due to prior deposition. 
No. of

Copies

Off-Site

1 ERDA Chicago Patent Group 9800 South Cass Avenue Argonne, IL 60439

A. A. Churm

4 ERDA Division of Blomedical and Environmental Research Washington, DC 20545

D. H. Slade

R. W. Beadle

D. S. Ballantine

N. F. Barr

2 ERDA Division of Nuclear Fuel Cycle and Production Washington, DC 20545

F. P. Baranowski

W. K. Eister

2 NRC Division of Research Washington, DC 20555

J. J. Davis

H. Landon

1. Norfolk State College

Amello J. Amato Mathematics Department 2401 Corprew Avenue Norfolk, Virginia 23504

200 ERDA Technical Information Center
No. of

Copies

$\underline{\text { On-Site }}$

3 ERDA Richland Operations office

R. B. Goranson

N. T. Karaglanes

70 Battelle-Northwest

T. J. Bander

J. W. Bartlett

N. E. Carter

W. E. Davis

R. L. Drake

.T. F. Droppo

C. E. Elderkin

.J. M. Hales

T. W. Horst (35)

L. V. Kimmel

J. L. McEl roy

J. Mishima

E. S. Murphy

R. E. Nightingale

M. M. Orgill

P. Pelto

A. M. Platt

J. V. Rámsdell

K. J. Schnelder

L. C. Schwendiman

G. A. SehmeI

D. B. Shiplex

C. L. Eimpoon

W. G. N. S1inn

T. H. Smith

J. K. Soldat

J. M. Taylor

E. C. Watson

L. L. Wendell

L. D. Williams

W. K. Winegardner

R. K. Woodruff

Technical Information Files (3)

Technical Publications (1) 
No. of

Copies

\section{On-Site}

3 Atlantic Richfield Hanford Company

R. E. Isaacson

D. J. Brown

L. E. Bruns 